\title{
ENERGY FOR DESALINATION: A STATE-OF-THE-ART REVIEW
}

Haya Nassrullah $^{\mathrm{a}}$, Shaheen Fatima Anis ${ }^{\mathrm{a}}$, Raed Hashaikeh ${ }^{\mathrm{a}^{*}}$, Nidal Hilal ${ }^{\mathrm{a}, b^{*}}$

${ }^{a}$ NYUAD Water Research Center, Engineering Division, New York University Abu Dhabi, P.O. Box 129188, Abu Dhabi, United Arab Emirates

${ }^{\mathrm{b}}$ Centre for Water Advanced Technologies and Environmental Research (CWATER), College of Engineering, Swansea University, Fabian Way, Swansea SA1 8EN, United Kingdom

*Corresponding authors

E-mail address: R. Hashaikeh: raed.hashaikeh@nyu.edu, N. Hilal: $\underline{\text { n.hilal@ } @ \text { swansea.ac.uk }}$ 


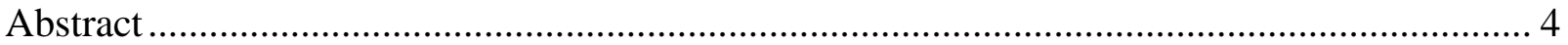

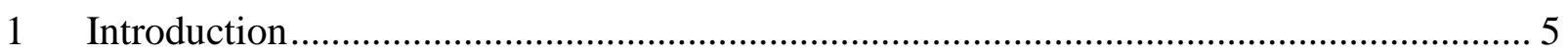

2 Thermodynamic limit of desalination technologies.............................................. 10

3 Energy efficiency of thermal desalination technologies ............................................ 16

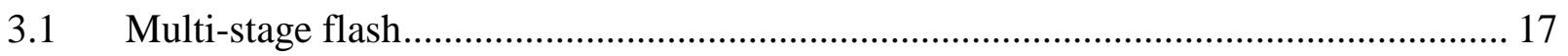

3.2 Multi-effect distillation ............................................................................ 24

4 Energy efficiency evolvement of reverse osmosis desalination .................................. 28

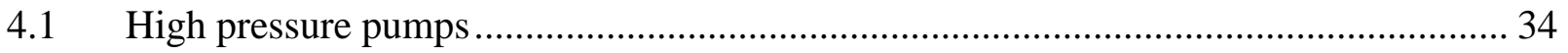

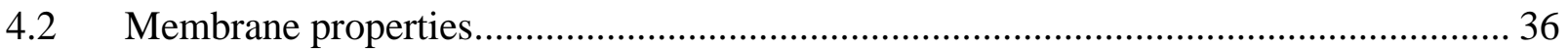

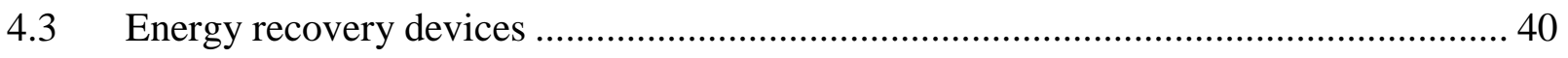

5 Energy requirements of emerging desalination technologies ................................... 50

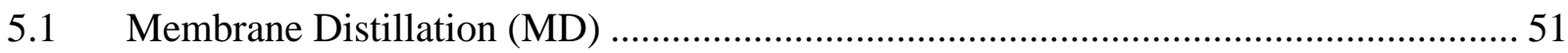

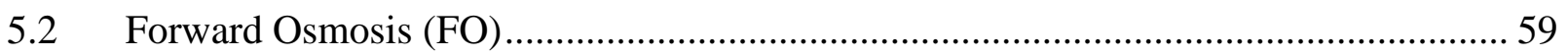

$6 \quad$ Hybrid desalination technologies: a solution for improved energy efficacy? ................. 65

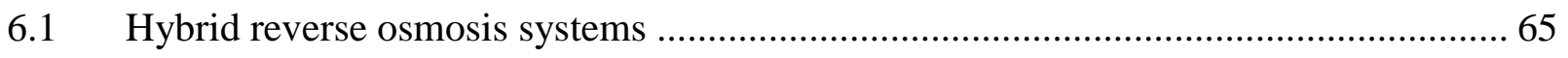

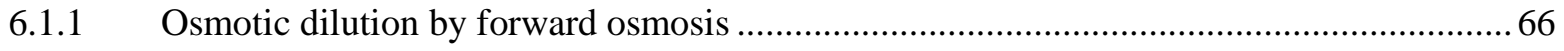

6.1.2 Energy recovery from brine by pressure retarded osmosis .............................................. 70

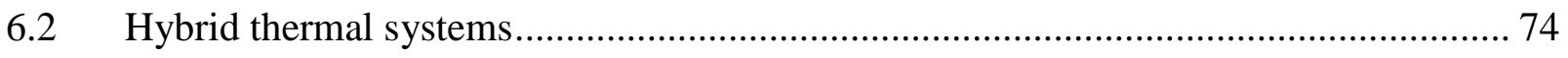

6.2.1 Pretreatment by nanofiltration and forward osmosis ................................................ 74

6.2.2 Multi-effect distillation-adsorption desalination......................................................... 77 


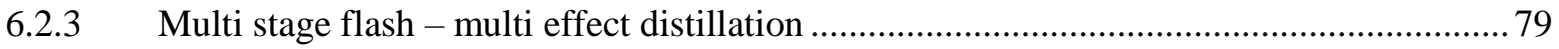

$6.3 \quad$ Hybrid Reverse osmosis-thermal processes .......................................................... 81

7 Energy considerations in renewable energy driven desalination processes: Is renewable

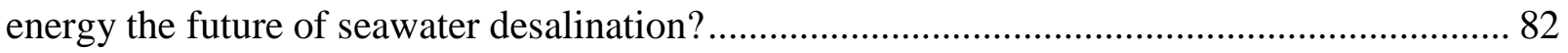

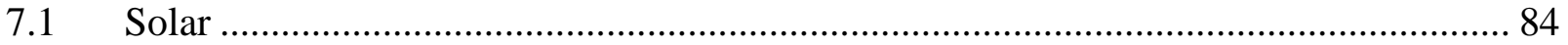

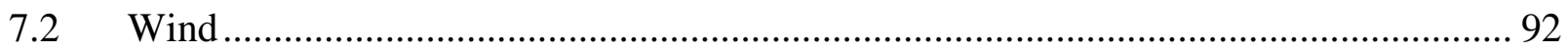

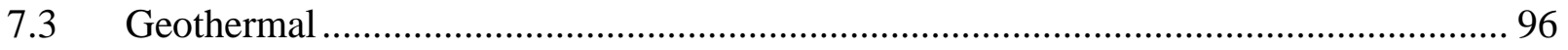

7.4 Current status, challenges involved and possible future road map ........................... 102

8 The quest for innovative systems and novel materials for reduced energy demands...... 105

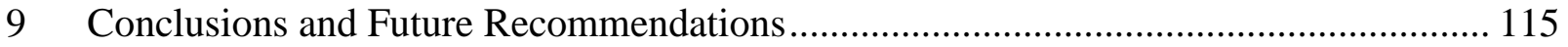

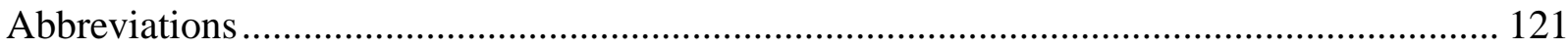

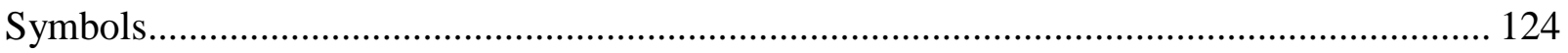

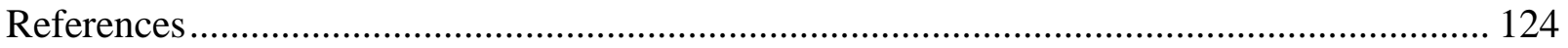




\begin{abstract}
The utilization of seawater for drinking purposes is limited by the high specific energy consumption (SEC) $\left(\mathrm{kW}-\mathrm{h} / \mathrm{m}^{3}\right)$ of present desalination technologies; both thermal and membranebased. This is in turn exasperated by high water production costs, adding up to the water scarcity around the globe. Most technologies are already working near their thermodynamic limit, whilst posing challenges in further SEC reductions. Understanding the current energy status and energy breakdowns of leading desalination technologies will further help in realizing limitations and boundaries imposed while working for improved system performances. This paper comprehensively reviews the energy requirements and potential research areas for reduced SEC of various thermal, membrane-based and emerging desalination technologies. For thermal desalination processes, which consume a large chunk of energy for heating, renewable energy sources can be a viable option for bringing down the energy requirements. Hence, this review also focuses on the potential of desalination-renewable energy integrations. The review extends beyond conventional energy reduction possibilities to utilizing novel, advanced membranes and innovative techniques for energy offsets. The future of desalination for optimized energy requirements is projected to include ultra-high permeability membranes, fouling resistant membranes, hybrid systems, and renewable-energy driven desalination.
\end{abstract}

Keywords: desalination energy; SEC; reverse osmosis; hybrid; renewable energy; novel membranes; energy recovery 


\section{Introduction}

Desalination has become one of the world's most crucial water treatment solutions to meet the increased water demand caused by rapid population growth, economic expansion, and agricultural developments [1]. According to the International Desalination Association (IDA), in 2018, the total capacity of all operating desalination plants in the world was 92.5 million $\mathrm{m}^{3} / \mathrm{d}$ [2]. Since July 2018, around 400 desalination projects were contracted worldwide. The capacity of the desalination projects contracted in the first half of 2019 was approximately 4 million $\mathrm{m}^{3} / \mathrm{d}$, which is equivalent to the total of both the years of 2015 and 2016 [3]. Four independent projects in the Middle East made up 60\% of this capacity which are Taweelah and Umm al Quwain (1.6 million $\left.\mathrm{m}^{3} / \mathrm{d}\right)$ in the United Arab Emirates, and Shuqaiq 3 and Rabigh $3\left(980,000 \mathrm{~m}^{3} / \mathrm{d}\right)$ in the Saudi Arabia [3]. These high desalination capacities are necessary as their fresh water resources are not enough to meet their growing water needs [4].

Although desalination has been considered a critical source for fresh water worldwide, one of the main challenges to extend it is its high cost [5]. According to the Global Water Intelligence (GWI) DesalData, a total of $\$ 93,700$ million is expected to be spent on desalination projects in the coming four years [6]. Approximately, \$51,600 million is dedicated only for operating expenditures. As shown in Fig. 1, operating costs are divided into four main services which are energy, labor, replacements, and chemicals $[6,7]$. Almost $50 \%$ of the operating expenditures will be spent on thermal and electrical energies. This high cost of energy for desalination is not surprising given that in 2014 , desalination was classified as the most energy-intensive water treatment process which consumes 75.2 TWh of energy per year [8]. 


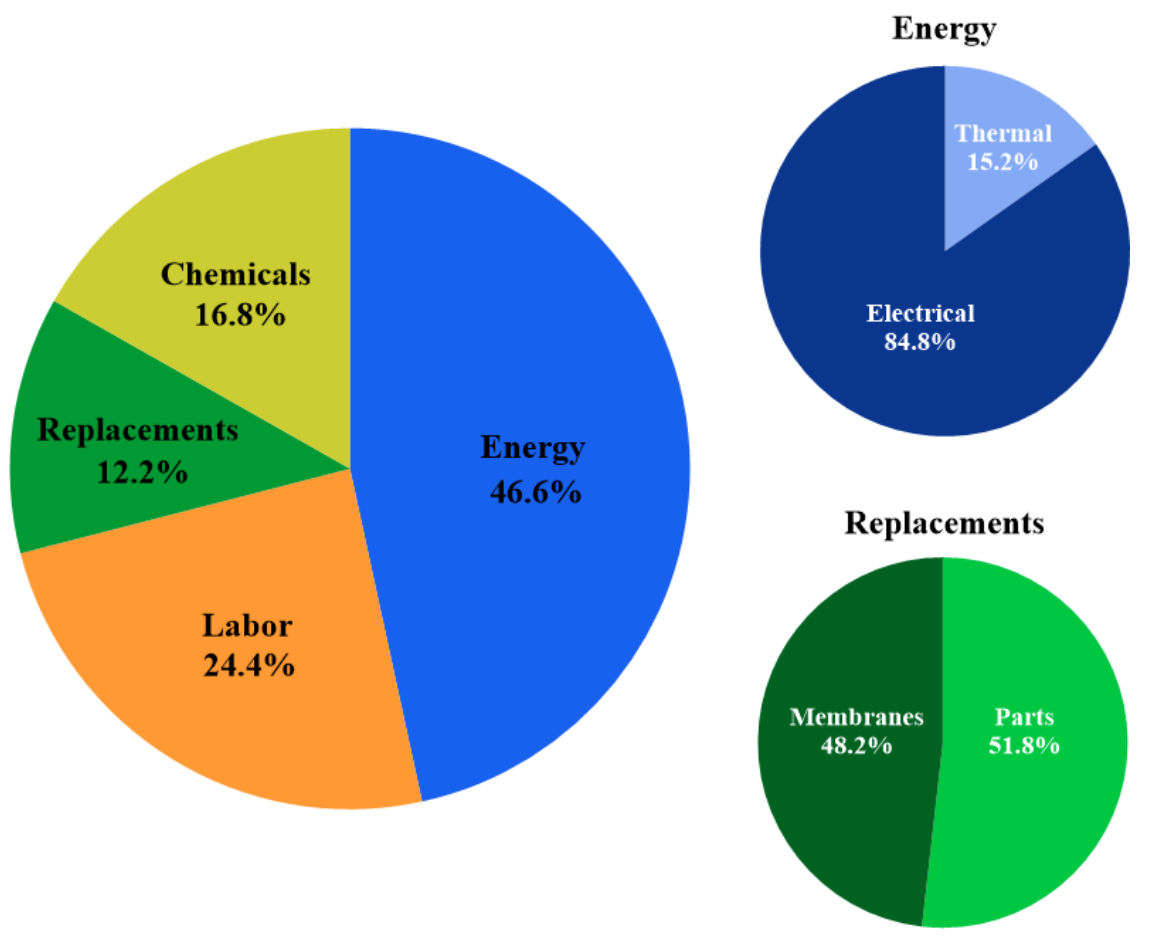

Fig. 1. Desalination operating expenditure by service. Reproduced from Ref. [9].

The amount of energy required for a desalination process is dependent on the quality of feed water, level of water treatment, treatment technology used by the facility, and plant capacity $[7,9,10]$.

Table 1 shows the various energies needed to obtain $1 \mathrm{~m}^{3}$ of drinking water when water is treated from different sources. Compared to the other water resources, desalination of seawater (SW) is the most energy intensive. Even though energy costs are lower for groundwater and surface water treatment, the supply from these source is not enough to meet the increasing demand for fresh water. Therefore, desalination of SW seems to be the world's most suitable solution for water scarcity regardless of the energy costs associated with it. As shown in Fig. 2, amongst all the different water types, the amount of SW consumed in new desalination plants has been the highest over the last years. In fact, in 2019, the amount of SW consumption for newly contracted desalination plants was almost double the amount used by plants built in 2018 . This continuous 
increase in the consumption leads to higher energy demands and rising costs. Research and development on the current desalination technologies could be one way to lower Specific energy consumptions (SEC) and achieve higher efficiency [11].

Table 1. Required energy for producing $1 \mathrm{~m}^{3}$ of drinking water from different water sources. Reproduced from Ref. [12, 13].

\begin{tabular}{|c|c|}
\hline Water source & Energy $\left(\mathbf{k W h} / \mathbf{m}^{\mathbf{3}}\right)$ \\
\hline Surface water (lake or river) & 0.37 \\
\hline Groundwater & 0.48 \\
\hline Wastewater treatment & $0.62-0.87$ \\
\hline Wastewater reuse & $1.0-2.5$ \\
\hline Seawater & $2.58-8.5$ \\
\hline
\end{tabular}

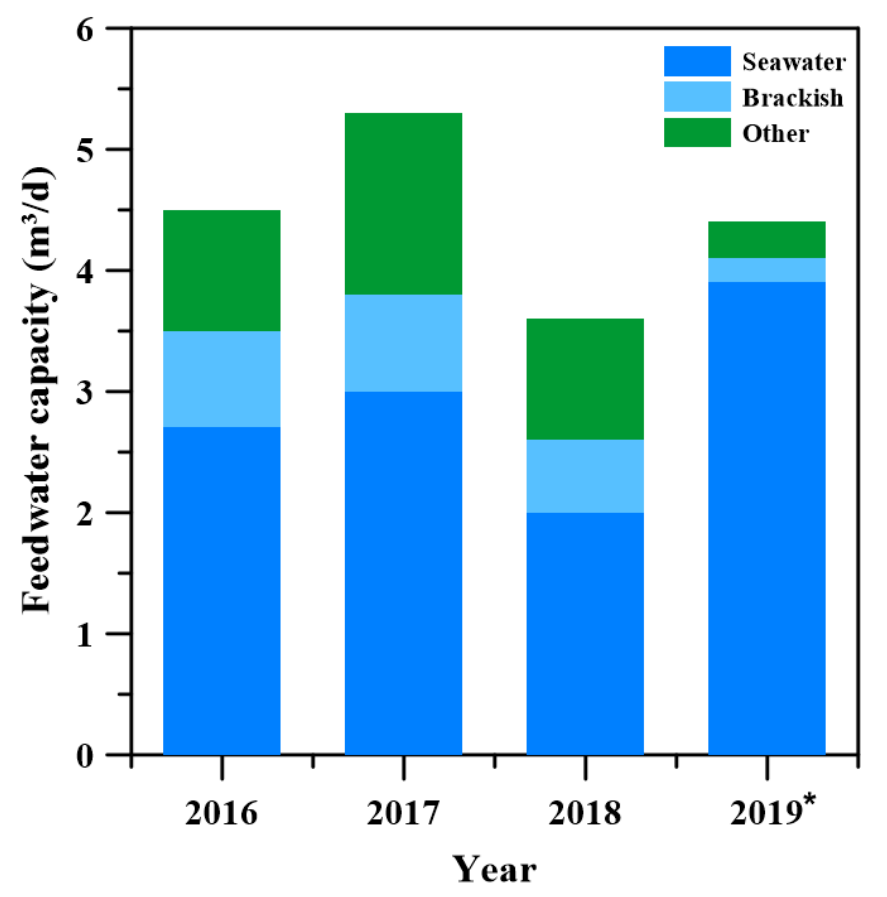

Fig. 2. Contracted desalination capacity by feed water type $2016-2019, * 1^{\text {st }}$ half only. Reproduced from Ref. [3]. 
Desalination technologies consist of thermal and membrane separation processes. Thermal desalination technologies are multi effect distillation (MED), multistage flash distillation (MSF), and vapor compression (VC) which can be either mechanical (MVC) or thermal (TVC). There are several membrane-based desalination processes but the most common technologies are reverse osmosis (RO) and electrodialysis (ED). All thermal desalination processes except MVC, require two forms of energy: (1) low temperature heat, which is essential to raise the temperature of the saline feed and (2) electricity, which is used to drive the pumps [9]. On the other hand, only electrical energy is required to operate RO and ED but in different forms. For example, in RO, electricity is used for pumping while in ED, it is used to supply a direct current between electrodes to achieve separation of ions by ionic membranes [14].

Water and energy are inseparable sources which interchangeably affect each other (Fig. 3). Producing fresh water by desalination requires energy which is conventionally supplied from fossil fuels [15]. Similarly, water is required in the extraction and refining of fossil fuels [16]. These processes as well as burning fossil fuels to produce energy for desalination have severe harmful impacts on the environment due to the greenhouse gases (GHG) emissions. By 2050, the worldwide emission from desalination processes is expected to reach 0.4 billion tons of $\mathrm{CO}_{2}$ equivalents per year [17]. Therefore, the growing demand for clean water will not only cause a depletion of fossil fuels but also significant damage to our environment [18]. Relying on fossil fuels as the main energy source for desalination also affects the process economics due to the rapid changes in the cost of fossil fuels [19]. Thus using renewable energy sources for desalination is essential to provide a suitable supply of clean water to meet our future needs and reduce the harmful effects on the environment $[7,16]$. 


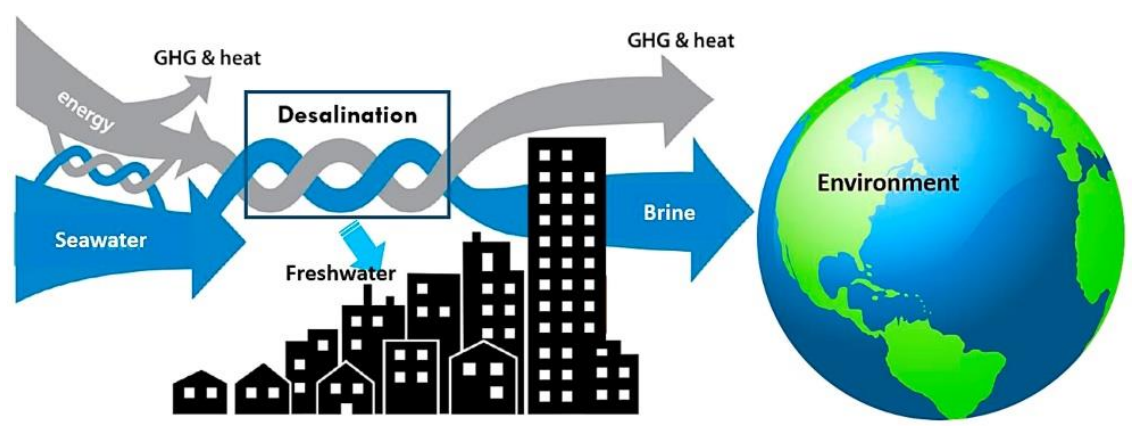

Fig. 3. Desalination in the energy-water-environment nexus [16]. Copyright @ 2016, Elsevier.

Compared to RO, thermal desalination technologies require higher energy demands and maintenance costs which make them less attractive [20]. Recently, more interest is directed towards RO as it has potentially lower SEC and there are continuous research developments in this technology [21]. However, in some parts of the world such as the Gulf, thermal desalination technologies are still prominent. Reasons for this constitute the plentiful supply of oil for energy, frequent occurrences of algae bloom, and the operational limitations of RO for the treatment of high SW feed salinities and turbidity [20, 22]. Nevertheless, the interest in RO based desalination has increased over the years in the Gulf region due to the substantial advances in the technology. Both thermal and membrane-based processes are a key for supplying fresh water and thus, reducing their energy demands through research advancements is equally important for both.

There are other low-energy emerging desalination technologies that are still in the research and development stage and have not been scaled up for commercialization. These technologies include membrane distillation (MD), forward osmosis (FO), capacitive deionization (CDI), Pressure retarded osmosis (PRO) and adsorption desalination (AD). Research interest in these technologies have risen recently to develop alternative desalination processes with lower energy demands [7, 14]. In addition, hybridization of different desalination technologies can be an effective approach 
to minimize energy requirements and overcome the operational limitations in the conventional treatment methods. [7, 23].

This paper aims to provide a comprehensive review on energy requirements for prominent thermal and membrane-based desalination technologies. While majority of the previously published research articles and reviews [14, 24-30] focus on a single technology, this review cumulatively presents its readers the current and future prospects of energy consumption for both conventional and membrane desalination technologies. Moreover, hybrid desalination systems for optimized energy consumptions have been reviewed, focusing more on the energy potential of those hybrids which are in their research phase. This will provide researchers and scientists with a further insight on how existing technologies can be integrated with each other for efficient energy utilization. Several reviews have been published in the past [31-38] discussing renewable energy sources for desalination, however only a few [39, 40] focus on its energy requirements and subsequent comparisons with existing conventional energy sources. Thus, this paper also assesses the possibility of using solar, wind and other alternate energy sources and their current challenges and future prospects in terms of energy consumptions and associated viability. Lastly, the question on investing time and research in novel membranes and innovative technologies is addressed, if further energy reductions are possible in the light of advanced materials and state-of-the-art processes.

\section{Thermodynamic limit of desalination technologies}

In efforts to reduce the energy demands, it is important to realize the theoretical minimum energy required for desalination processes. High water costs remain as one of the major barriers in extending the desalination technology, which in turn is influenced by the energy consumed by the 
conventional and membrane desalination processes, accounting almost 50-60\% of the total costs $[14,20,41]$. As researchers, we need to realize the theoretical minimum energy required for separating fresh water from SW, in order to push our efforts for reducing the desalination energy demands.

Thermodynamics places a lower bound on the energy required for desalination processes [24]. At present, we are operating close to the thermodynamic limit of thermal and membrane desalination processes. Hence, reducing the energy for such processes is becoming more challenging. An ideal desalination system is identified as the one which requires least operating resources which can be recovered from its product (reversible thermodynamics). However, ideal systems are not practically possible, hence, an increase in operating resources occurs rendering the system irreversible. The second law of thermodynamics plays a yet critical role in defining the operating resources and establishing a significant relationship between the operating and the making resources.

Generally, calculating the energy required $\left(\mathrm{kW}-\mathrm{h} / \mathrm{m}^{3}\right)$ to separate fresh water from salt water can be used for the calculation of the minimum energy required for any desalination process, where the feed, product and brine are at ambient temperature and pressures:

$$
\text { Energy required }=\text { RTlna }_{\mathrm{W}} \quad \text { Equation } 1
$$

Where $\mathrm{T}$ is the absolute temperature $(\mathrm{K}), \mathrm{R}$ is a constant $(8.314 \mathrm{~J} / \mathrm{mol} \cdot \mathrm{K})$ and $\mathrm{a}_{\mathrm{W}}$ is the activity of the contents in water. Thus, the energy required depends upon the salt concentration in the SW, and is entirely process independent [42]. Equation 1 can be used if the involved activities of the species are known, which most of the times is uncertain and difficult to evaluate. Thus, at this stage, suitable assumptions need to be introduced. Ideal liquid solutions, recovery ratios $\approx 0$, mole 
fraction substitutions instead of activities and zero salt concentrations are some of the many assumptions that may be introduced. These assumptions help in obtaining a simplified equation for the minimum theoretical energy. The energy of separation is equal to the free energy of mixing [43]:

$$
-\mathrm{d}\left(\Delta \mathrm{G}_{\text {mix }}\right)=\pi \mathrm{V}_{\mathrm{m}} \mathrm{dn}_{\mathrm{W}} \quad \text { Equation } 2
$$

Where $\Delta \mathrm{G}_{\mathrm{mix}}(\mathrm{J} / \mathrm{mol})$ is the free energy of mixing, $\pi(\mathrm{Pa})$ is the feed water osmotic pressure, $\mathrm{V}_{\mathrm{m}}$ $\left(\mathrm{m}^{3} / \mathrm{mol}\right)$ is the molar volume of water and $\mathrm{n}_{\mathrm{W}}(\mathrm{mol})$ is the number of moles of water. From Equation 2, it can be seen that the energy for salt separation from water is equal to but opposite in sign to $\Delta \mathrm{G}_{\text {mix }}$. This relation between $\Delta \mathrm{G}_{\text {mix }}$ and $\pi$ is highly recognized in calculating the theoretical minimum energy required for desalting in an RO process, where the applied pressure must overcome the osmotic pressure of the SW for driving an infinitesimally small volume of water through a semipermeable membrane. In desalination, water recovery $(\%)$ is an important term which defines the percentage of SW converted into fresh water. This term is generally quantified as the total energy consumed by the desalination process, and can be obtained by integrating Equation 2. Though Equations 1 and 2 represent specific energy requirements independent of the desalination technology, specific energy for desalination may also be classified as technology dependent. This will in turn depend upon the efficiency of that particular technology, and hence any losses incurred during the process. For example, in RO, this energy will depend upon the efficiency of the feed pump, membrane modules and energy recovery devices (ERDs) (Section 4). A minimum energy of $1.06 \mathrm{~kW}-\mathrm{h} / \mathrm{m}^{3}$ is required to desalt $35,000 \mathrm{ppm}$ salt water, with a typical recovery of 50\% [24]. However, with all the pump constraints and system losses, desalination plants do not operate on a reversible thermodynamic process, and hence the actual energy required is much larger than this. Fig. 4a shows the minimum thermodynamic barrier posed at different feed 
concentrations as a function of various water recoveries [24]. Most SWRO plants operate in the recovery range from $45-55 \%$.

In case of thermal desalination, the technology-dependent energy will be a function of the energy source and thermal losses in the system. Table 2 highlights the progression in energy reduction for both thermal and membrane desalination technologies over the past decades. Fig. 4b highlights the dramatic decrease in energy consumption for SWRO alone during the past 40 years. The horizontal dashed line corresponds to the theoretical minimum energy which is required to desalt 35,000 ppm salt water at a 50\% recovery. However, the value does not take into account the energy input during the intake, pretreatment, post treatment and brine disposal stages. Again, this decrease is attributed to the various technological improvements and the advanced membrane materials. Thus, along with high efficiency pumps, advancement in novel membrane materials is also important to condense the existing gap between the thermodynamic limit and the current SEC. Because high efficiency energy pumps and energy recovery devices are accountable for further efficiency gains, we need to incorporate these in the system level energy consumption. Figure $4 \mathrm{c}$ illustrates the cumulative energy sources in an RO desalination system which accounts for the efficiency losses in the pump and the energy recovery devices, together with other frictional losses in the system. The work done during $\mathrm{RO}\left(\mathrm{W}_{\mathrm{RO}}\right)$ for salt separation can be written as:

$$
\mathrm{W}_{\mathrm{RO}}=\mathrm{E}_{\mathrm{flow}}+\mathrm{E}_{\text {module }}+\mathrm{E}_{\text {system }} \quad \text { Equation } 3
$$

Where $E_{\text {flow }}\left(\mathrm{kW}-\mathrm{h} / \mathrm{m}^{3}\right)$ represents the energy required to generate flow in a finite area of a membrane, $\mathrm{E}_{\text {module }}\left(\mathrm{kW}-\mathrm{h} / \mathrm{m}^{3}\right)$ represents the energy losses from the membrane module and $\mathrm{E}_{\text {system }}\left(\mathrm{kW}-\mathrm{h} / \mathrm{m}^{3}\right)$ represents all the losses in the system through pumps and ERDs. The $\mathrm{E}_{\text {module }}$ accounts for all the losses which can be as a function of channel hydrodynamics and geometry, 
and feed spacer and permeate spacer geometry. Though this paper focuses more on SWRO, it is worth mentioning here that brackish water (BW) RO [44], which also forms a significant contribution for fresh water production differs in its feed concentration and operating recoveries. Fig. 4d shows the thermodynamic minimum energy of separation for a typical BWRO plant as a function of water recovery. For example, for a feed concentration of $800 \mathrm{ppm}$, at a recovery of $85 \%$, the specific energy consumption is $0.038 \mathrm{~kW}-\mathrm{h} / \mathrm{m}^{3}$.

Table 2. Evolution in specific energy reduction for thermal and RO technologies in Spain. Adapted from [14].

\begin{tabular}{|c|c|c|}
\hline Year & Desalination technology & $\mathbf{k W}-\mathbf{h} / \mathbf{m}^{3}$ \\
\hline 1970 & MSF & 22 \\
\hline 1980 & MSF & 18 \\
\hline 1985 & $\mathrm{VC}$ & 15 \\
\hline 1988 & $\mathrm{VC}$ & 13 \\
\hline 1990 & RO & 8.5 \\
\hline 1994 & RO & 6.2 \\
\hline 1996 & RO & 5.3 \\
\hline 1998 & RO & 4,8 \\
\hline 1999 & RO & 4.5 \\
\hline 2000 & RO & 4.0 \\
\hline 2001 & RO & 3.7 \\
\hline 2002 & RO & 3.5 \\
\hline 2005 & RO & 3.0 \\
\hline 2009 & RO & $\mathrm{RO}<3.0$ \\
\hline
\end{tabular}


a)

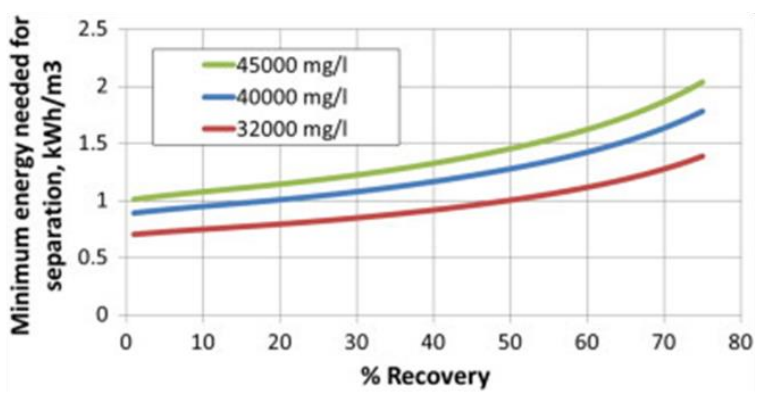

c)

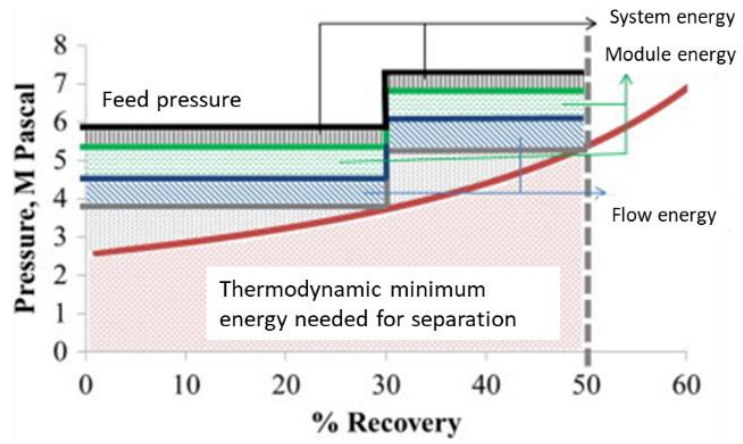

b)

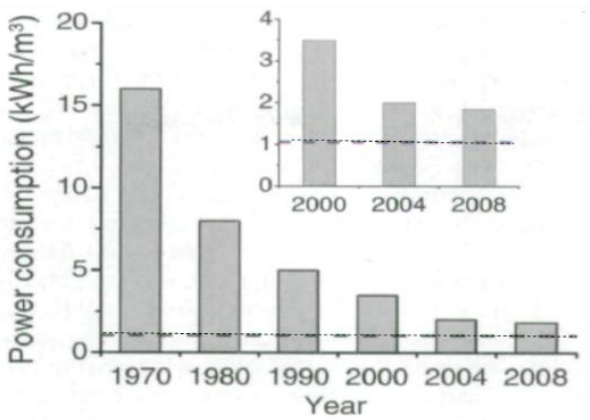

d)

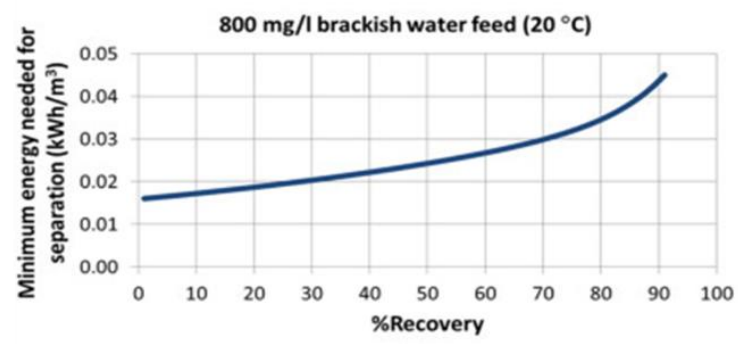

Fig. 4. (a) Thermodynamic minimum energy of separation varying with feed water concentrations and $\%$ recovery [24], (b) The change in power consumption for SWRO plants over the past decades (The dashed

line corresponds to the theoretical minimum energy for desalting 35,000 ppm saline water at a $50 \%$

recovery) [45], (c) Schematic illustration of all the energy input in a typical RO system [24] (d)

Thermodynamic minimum energy of separation for a BWRO plant as a function of \% recovery [24]

Thermodynamically speaking, desalination technologies maybe categorized as one where there is no change in phase such as in RO, ED and CDI, while the others includes change of the liquid phase to separate water such as in MED, MSF and MD. This section defined the thermodynamic energy barrier which cannot be reduced and hence poses a limit on the minimum energy required for desalination. In order to reduce the energy of the current technologies, several factors might be considered. This paper, comprehensively reviews these factors including system and membrane modifications, module configurations, and operating parameters. Several unit operations need to be optimized for minimal losses. However, it has to be kept in mind that several of those losses, such as those occurring from frictional and modules cannot be optimized significantly any further due to their already high efficiencies [46, 47]. High pressure pumps (HPPs) are the major energy 
consumers in RO plants, and at most times, selection among the best available pump is the only choice which can be made for an optimum working point. Energies from these contribute to almost $75 \%$ of the total specific energy, whilst the remaining comes from the membrane [48]. Thus, membranes with high permeability and selectivity are desirable for SWRO which are discussed in greater detail in Sections 4 and 8. Membranes form the core of any RO plant, and thus, research in this area is critical for reduction of further SECs. Recently, hybridization trends are also increasing, whereby more than one technology is incorporated for improved system performances. These include several combinations such as MED-AD [22, 49] ,RO-MSF [50, 51], NF-MSF [52] and MSF-MED [53, 54]. The synergy between membrane and thermal processes reduces the burden on energy demands with improved fresh water qualities (Section 6).

\section{Energy efficiency of thermal desalination technologies}

The most common and commercially implemented thermal desalination technologies are MSF and MED. In these processes, fresh water is produced by the evaporation of saline feed water followed by condensation. These processes mainly differ by the operating temperature and pressure at which the saline feed water is boiled to form vapor. Historically, thermal technologies have been widely adopted by countries in the Middle East due to the availability of low cost energy and high salinity of SW feed in the region $[19,55]$. Despite being significantly important technologies for water desalination, their considerable energy consumption results in high operating costs which make them less attractive than RO. Therefore, it is essential to understand the energy requirements of these mature processes and learn about the possible ways to achieve higher energy efficiency. In simple words, the desalination process becomes more energy efficient when it consumes less energy to produce the same amount of fresh water. 


\subsection{Multi-stage flash}

Approximately, $11 \%$ of the desalination plants in the world use the MSF technology [56]. Several design configurations have been developed for MSF but the most popular are once through (OT) and brine recirculation (BR) [57]. Historically, MSF-OT was the first MSF plant configuration. However, due to its lower operating cost and less corrosion problems at large capacities, MSF-BR became more dominating [58]. Nowadays, the situation has completely changed. With the advances in corrosion protection techniques and availability of cost effective antiscalants, the number of MSF-OT plants is expected to rise [59]. The MSF-OT process consists of two main sections which are the brine heater (heat input) and flashing stages (heat recovery). Initially, saline feed water flows through a series of heat exchanger tubes where it is preheated prior to entering the brine heater. In the brine heater, feed water is heated using thermal energy from low-pressure bleed steam (1-3 bars) until it reaches a temperature of $90-110{ }^{\circ} \mathrm{C}$, which is called the top brine temperature (TBT) [7, 9, 60-62]. Then, heated saline water enters the first stage where the ambient pressure is lower than the pressure in the brine heater. This decrease in pressure causes flashing of the saline water. The flashing vapor condense on the heat exchanger tubes where it loses latent heat of condensation to the saline feed water flowing inside the tubes. Distillate water is collected on a tray while the remaining saline water enters the next stage which has lower pressure and the same process is repeated until the brine reaches the final stage where is it discharged $[19,63]$. Increasing the number of flashing stages can increase the internal energy recovery [55]. In a typical MSF unit size from 50,000 to $70,000 \mathrm{~m}^{3} / \mathrm{d}$, the number of stages is 18 to $25[9,19]$. One drawback of MSF-OT is the absence of a control system on the temperature of the inlet SW which varies from winter to summer [64]. The increase in the feed water temperature causes a reduction in total temperature difference (TTD), the difference between TBT and inlet saline feed water temperature, 
which in return lowers the fresh water production of the plant [60]. Better control over feed temperature is achieved through MSF-BR. In this configuration, stages are divided into two sections: heat recovery and heat rejection. Heat recovery section is the same as MSF-OT flashing stages where latent energy of condensation is recovered but in the case of MSF-BR, the inlet is brine recycled from the last stage of the heat rejection section. In this section, cooling SW and feed SW absorb the latent energy of formed vapors and after that, cooling SW is rejected back to the sea [65]. Brine recycle reduces the volume of intake SW and the steam required for evaporation $[55]$.

In a typical MSF process, with capacities ranging between 50,000 and $70,000 \mathrm{~m}^{3} / \mathrm{d}$, the amount of thermal energy required is between 190 and $282 \mathrm{MJ} / \mathrm{m}^{3}$ which is equivalent to 15.8 and $23.5 \mathrm{~kW}$ $\mathrm{h} / \mathrm{m}^{3}$ based on heat conversion efficiency of $30 \%$ [7, 9]. MSF also consumes electrical energy for pumping which is in the range of 2.5 to $5 \mathrm{~kW}-\mathrm{h} / \mathrm{m}^{3}[7,9]$. Therefore, total equivalent energy consumed by a typical MSF unit is between 18.3 and $28.5 \mathrm{~kW}-\mathrm{h} / \mathrm{m}^{3}$ [7, 9]. Representing energy consumption in terms of electrical energy requirement $\left(\mathrm{kW}-\mathrm{h} / \mathrm{m}^{3}\right)$ is useful for comparing thermal with membrane processes as presented in section 4. Understanding the sources of energy consumption in MSF and factors that affect it is a key for developing solutions to enhance the process efficiency and lower the energy requirements. The amount of energy consumed in MSF depends on many factors: temperature difference between the heat source and heat sink, salinity of feed water in the flashing stages, process configuration, construction material, number of stages, and type of heat-exchanger devices [9]. Another significant factor which affects energy consumption in MSF is scaling or fouling. At high temperature, different types of salts like magnesium hydroxide, calcium carbonate, and non-alkaline scales form deposits [66]. These deposits plug the heat exchanges leading to reduced heat transfer rate and lower heat transfer 
efficiency. Besides that, scaling can increase SEC and operating costs [67]. Our discussion in this section focuses on how changing the process conditions or configuration can affect the energy efficiency of the process.

One of the most important operating parameters in MSF is TBT which is the temperature of saline feed water right before it enters the flashing stages. Increasing TBT increases the flash range which in return results in higher production rate and better performance [7, 55]. Hanshik et al. [60] studied the effect of increasing TBT on the performance of an existing MSF-OT plant. The results were obtained using theoretical calculations and assuming ideal conditions. As shown in Table 3, as TBT increases, the amount of thermal energy required in the brine heater becomes higher. This is because the temperature difference between TBT and outlet temperature of cool feed water in the heat exchanger tubes leaving the first stage becomes higher. On the other hand, rising TBT does not significantly affect the total consumption of electrical energy. Pumping requirements of SW supply pump remain the same as the flowrate of inlet feed water is kept constant. Also, the increase in power of condensate pump is approximately cancelled out by the decrease in the power of brine rejection pump. Even though increasing TBT leads to an increase in the total energy consumption, energy required to produce one-unit mass of fresh water is reduced due to the increase in fresh water production. Higher fresh water production is caused by the rise in temperature difference between the evaporators which is calculated based on TTD. The results from this study suggest that fresh water productivity and energy efficiency can be improved by TBT elevation. Increasing the TBT is one way to make an existing MSF process more energy efficient with minimum cost. However, this is not an ultimate solution for energy efficiency as it is limited by serious scaling and fouling [7]. 
Table 3. Effect of TBT variation on the operating characteristics of MSF. Adapted from [60].

\begin{tabular}{|c|c|c|c|c|}
\hline & $\mathrm{TBT}=90^{\circ} \mathrm{C}$ & $\mathrm{TBT}=100{ }^{\circ} \mathrm{C}$ & $\mathrm{TBT}=110{ }^{\circ} \mathrm{C}$ & $\mathrm{TBT}=120^{\circ} \mathrm{C}$ \\
\hline $\begin{array}{c}\text { Temperature difference } \\
\text { between the evaporators }\left({ }^{\circ} \mathrm{C}\right)\end{array}$ & 2.5 & 3 & 3.5 & 4 \\
\hline $\begin{array}{l}\text { Production of fresh water } \\
\qquad(\mathrm{kg} / \mathrm{h})\end{array}$ & 6169 & 7607 & 9042 & 10475 \\
\hline $\begin{array}{l}\text { Temperature of cooling } \mathrm{SW} \\
\text { from the first stage }\left({ }^{\circ} \mathrm{C}\right)\end{array}$ & 76.02 & 85.01 & 93.86 & 102.56 \\
\hline $\begin{array}{c}\text { Heating energy for brine } \\
\text { heater (MW) }\end{array}$ & 1592.5 & 1708.6 & 1842.1 & 1992.9 \\
\hline $\begin{array}{c}\text { Power of SW supply pump } \\
(\mathbf{k W})\end{array}$ & 1636.8 & 1636.8 & 1636.8 & 1636.8 \\
\hline $\begin{array}{l}\text { Power of condensate pump } \\
\qquad(\mathbf{k W})\end{array}$ & 471.4 & 581.3 & 690.9 & 800.4 \\
\hline $\begin{array}{c}\text { Power of brine rejection } \\
\text { pump }(\mathbf{k W})\end{array}$ & 731.3 & 720.1 & 708.9 & 697.8 \\
\hline $\begin{array}{l}\text { Total energy for fresh water } \\
\qquad(\mathbf{k W})\end{array}$ & 1595.4 & 1711.5 & 1845.1 & 1966 \\
\hline $\begin{array}{l}\text { Required energy to produce } \\
\text { a unit mass of fresh water } \\
\text { (MW/kg) }\end{array}$ & 0.259 & 0.225 & 0.204 & 0.191 \\
\hline
\end{tabular}

Alternatively, the energy efficiency of MSF process can be improved by applying few changes to the process configuration. For instance, Choi [68] studied the effect of brine re-utilization on specific thermal energy consumption of an existing MSF-OT process. In brine re-utilization, part of the brine in the upstream stages is extracted, heated to TBT and injected in the downstream stages. This modification can be done by installing additional piping and heat exchangers to an operating MSF plant at present. The study covered different strategies to utilize brine. It is 
important to note that the results were obtained theoretically. The study showed that brine reutilization led to a $1.9-3.35 \%$ decrease in specific thermal energy consumption and a $1.18-2.10 \%$ increase in fresh water production. The comparison between the MSF process with and without brine re-utilization did not include electrical energy consumption. This is because increased power of fresh water pump is cancelled out by the decreased power of the brine rejection pump. Therefore, changes in electrical energy consumption are negligible. In a similar study, Hamahmy et al. [69] investigated an akin modification of MSF-OT. In this novel configuration named brine extraction, part of the cooling brine is extracted from the upstream stages and directly reinjected into the flashing chambers in the downstream stages (Fig 5). This process modification requires additional piping only as the extracted brine is not heated prior to the reinjection. The study was conducted using a computer model of 16.2 MIGD MSF process with and without brine extraction. Single point and multiple points extractions were studied. The results showed that the former is favored due to its relative simplicity and improved performance. The optimum extraction ratio was found to be $9 \%$ which led to $3.47 \%$ reduction in electrical energy consumption which in return caused a decrease by $3.9 \%$ in the total cost. The reduction in energy consumption is desired especially when solar power is used. This is because the cost of energy is significantly higher with solar compared to conventional energy sources. 


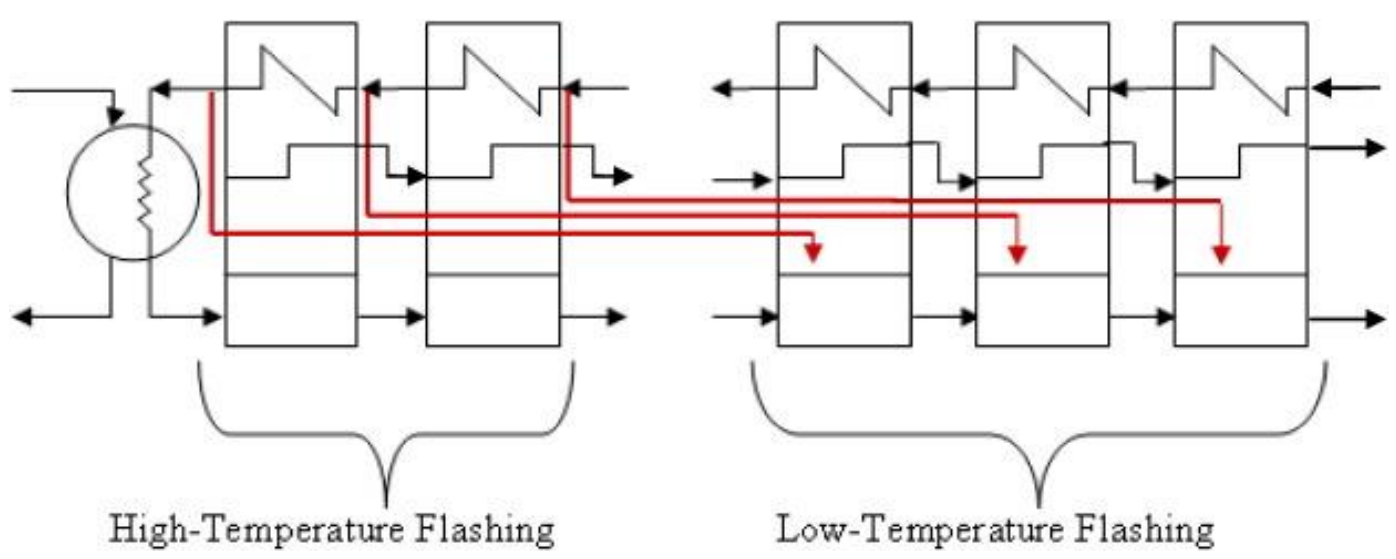

Fig 5. Brine extraction in MSF [69]. Copyright (C 2016, Elsevier.

Besides process configuration, the arrangement of the heat exchanger tubes can greatly affect the energy consumption in MSF. For instance, using long tube arrangement rather than cross-flow can help in saving the power of the SW supply pump by decreasing the pressure drop inside the heat exchanger tubes. The majority of commercial MSF plants use cross-flow configuration [70]. Despite the energy reductions in long tube arrangement, its implementation in commercial plants is limited. This is because in this arrangement the tubes penetrate all the stages straightly which increases the possibility of leakage trouble [60]. Also, a tube length of several hundred meters is required in the long tube arrangement. Currently, the long tube configuration is still in the research phase and have not been used in commercial processes [60].

The first law of thermodynamics provides a good estimate for the quantity of energy required for desalination [71-73]. However, there is a considerable difference between the theoretical energy estimated by the first law and the practical requirements. This difference is owing to the irreversible losses in real processes [74]. A more realistic estimation for energy requirements can be obtained by using a tool that considers both the quantity and quality of energy. Exergy analysis is gaining more acceptance as a powerful tool for evaluating the performance of thermal systems 
[75]. However, the determination of exergy is complex as it requires knowledge of the thermodynamic properties of the working fluid. Hence, the number of studies that use exergy analysis is limited. Exergy analysis provides a better understanding of the energy losses in desalination by determining the sites of irreversible losses in a process [74]. Exergy is the maximum useful work obtained when a system is moved from its initial state to equilibrium with the environmental (dead) state [74]. Al-Weshahi et al. [75], performed a detailed exergy analysis on a $3800 \mathrm{~m}^{3} / \mathrm{h}$ MSF-BR unit. Contribution of each component to the total exergy consumption in the process is presented in Fig. 6. Exergy destruction $\left(E_{d}\right)$ is defined as the difference between the input and output exergy of the component. The highest percentage of exergy destruction was found to be in the heat recovery and rejection stages $(65 \%)$. The detailed exergy destruction in each component of the MSF process provides useful information for future enhancement of the process. For example, the authors calculated the change in the process exergy efficiency when the distillate was extracted from flashing stage 8 to utilize its energy in another thermal process. They found that the exergy efficiency of the process increased from 5.8\% (without distillate recovery) to $14 \%$ (with distillate recover). 


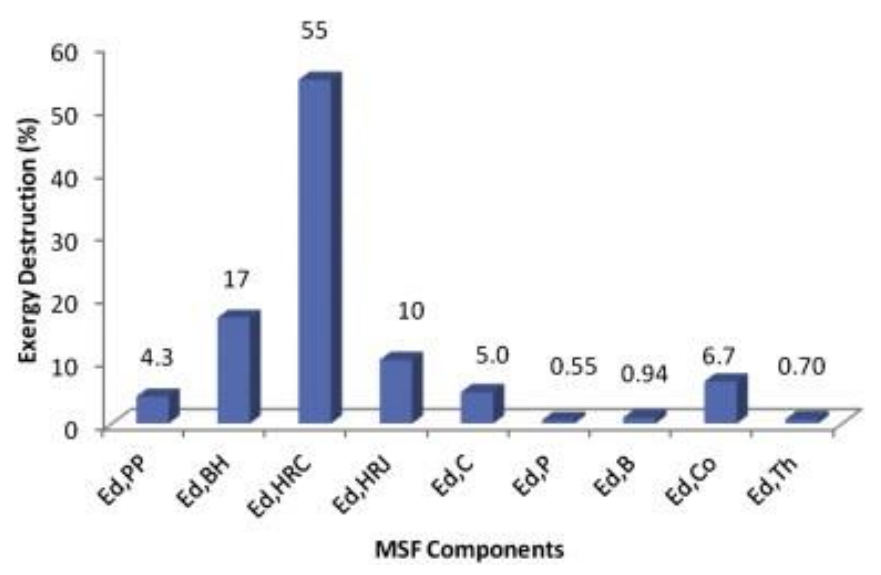

Fig. 6. Percentage of energy destruction in different MSF components [75]. $(\mathrm{PP}=$ pumps, $\mathrm{BH}=\mathrm{brine}$ heater, $\mathrm{HRC}=$ heat recovery, $\mathrm{HRJ}=$ heat rejection, $\mathrm{C}=$ cooling disposal, $\mathrm{P}=$ product disposal, $\mathrm{B}=\mathrm{brine}$ disposal, $\mathrm{Co}=$ condensate disposal, $\mathrm{Th}=$ throttling). Copyright $(C)$ 2013, Elsevier.

MSF is a mature technology that has been used for desalination since the 1960s [76]. Studies on enhancing the energy efficiency of the process focus on optimizing the operating conditions or modifying the process configuration. However, these improvements were mainly studied using computer models or theoretical calculations which are not enough to judge their real impact on the process energy. Taking into consideration the irreversible thermodynamic loses, the effect of these improvements on process efficiency might not be significant. Hybridization of MSF with other desalination technologies might be very effective in increasing the energy efficiency of the process. In 2004, Awerbuch and Sommariva [77] issued a patent in which they showed that the MSF process operated at its highest performance with a TBT higher than $120{ }^{\circ} \mathrm{C}$ when coupled with nanofiltration (NF). Section 6 provides details on prominent hybrid systems for reduced desalination SEC.

\subsection{Multi-effect distillation}

MED is one of the oldest desalination technologies [76]. In its early stages of development, MED suffered from significant scaling problems. In the 1960s, MSF was introduced and replaced MED 
because the former had less severe scaling issues [76]. However, the thermal energy requirements in MED are lower than MSF [78, 79]. This is because MSF requires large amounts of hightemperature steam to boil water at TBT close to $100^{\circ} \mathrm{C}$, whereas in MED water is boiled at a lower temperature $\left(70-90{ }^{\circ} \mathrm{C}\right)$ as the pressure is lower than the atmospheric pressure $[9,19,55,80,81]$. To produce the same volume of water, boiling at a lower temperature allows MED to use less and lower quality steam relative to MSF [55]. MED consists mainly of a condenser and multiple effects. Initially, saline feed water enters the condenser tubes where it gets preheated. Then, usually heated feed water is fed to the multiple effects in equal proportions. In each effect, saline feed water is sprayed on the outer surface of evaporator tubes. In the first effect, water sprayed on the evaporator tubes vaporizes as it absorbs heat from low-pressure steam inside the tubes. Steam condenses as it loses its energy to the saline water. Vapor formed from the evaporation of feed water is used as an energy source in the successive effects. Vapors from the last effect are used to preheat saline feed water in the condenser. As a result, these vapors condense to yield fresh water [19]. In MED, external steam is only supplied in the first stage while in the remaining stages the energy removed by cooling is used as an energy source for heating in the following effect [63]. This is accomplished by reducing the pressure in each successive stage [55]. The number of effects determine the amount of fresh water produced in the process which increases as the number of effects increases. However, it is limited by the minimum temperature difference between the consecutive effects as well as the total temperature range in the process [57]. Increasing the number of effects can also enhance the internal energy recovery [63]. The number of effects in MED is usually between 2 and $21[9,63,81]$.

Similar to MSF, MED requires two forms of energy which are thermal and electrical. Typical MED plants with capacity from 5000 to $50,000 \mathrm{~m}^{3} / \mathrm{d}$ use 145 to $230 \mathrm{MJ} / \mathrm{m}^{3}$ of thermal energy [7, 
9]. This is equivalent to 12.2 to $19.1 \mathrm{~kW}-\mathrm{h} / \mathrm{m}^{3}$ of electrical energy at heat conversion efficiency of $30 \%$ [7, 9]. Besides that, MED uses 2 to $2.5 \mathrm{~kW}-\mathrm{h} / \mathrm{m}^{3}$ of electrical energy for pumps [7, 9]. Therefore, the total SEC in a typical MED process ranges from 14.2 to $21.6 \mathrm{~kW}-\mathrm{h} / \mathrm{m}^{3}$. The SEC in MED is affected by the same factors which affect MSF. The performance of MED in terms of SEC changes depending on the flow arrangement of the feed and vapor. Feed water is supplied to the effects in MED in three different arrangements: forward feed, backward feed, and parallel feed [82]. The main difference between these arrangements is in the flow direction of brine and vapors. In the forward feed scheme, all the feed is heated in the first effect and vapor from the first effect is used to heat the following effects. In this case, the feed and vapor flow in the same direction. On the other hand, in the backward feed scheme, feed and vapor flow in opposite directions. Saline feed water enters from the low temperature end and the vapor flows from the high temperature end. This way, high salinity water is exposed to the high temperature end. Because the brine flows from high pressure to low pressure, this arrangement requires additional pumping between the stages. Also, the system is susceptible to severe scaling. Al-Mutaz and Wazeer [83] conducted a parametric study on the different arrangements of MED using mathematical models. They studied the effect of different parameters on the performance of MED. The results showed that as the number of effects increases, the specific heat transfer area increases. The same trend was observed in all schemes. This is because at a constant total temperature range in the process, increasing the number of effects reduces the temperature drop per effect. Thus, more area is required to maintain the water production at a specific level. Due to the drop in temperature difference across the effects and increase in specific heat transfer area, specific heat consumption decreases (Fig. 7a) and the gain output ratio (GOR) increases (Fig. 7b). GOR is a term extensively used to describe the efficiency of a distillation process. It is defined by the energy required to convert $1 \mathrm{~kg}$ of water 
into water vapor (latent heat) $[55,63,84]$. The authors also studied the impact of temperature drop across the effects on GOR and energy in a process with 8 effects. Their results showed that increasing the temperature drop across the effect leads to increased specific heat consumption and lower GOR. Among the different arrangements, parallel feed gives the best performance which is why it is the most common one. One major drawback in MED process design is the need for large specific heat transfer areas compared to MSF [81]. Morin [85] showed that MED needs about double the heat transfer area required in MSF. Also, MED plants which operate at higher TBT require less heat transfer area. This is because the low TBT gives a small heat transfer coefficient which increases the needed heat transfer area.
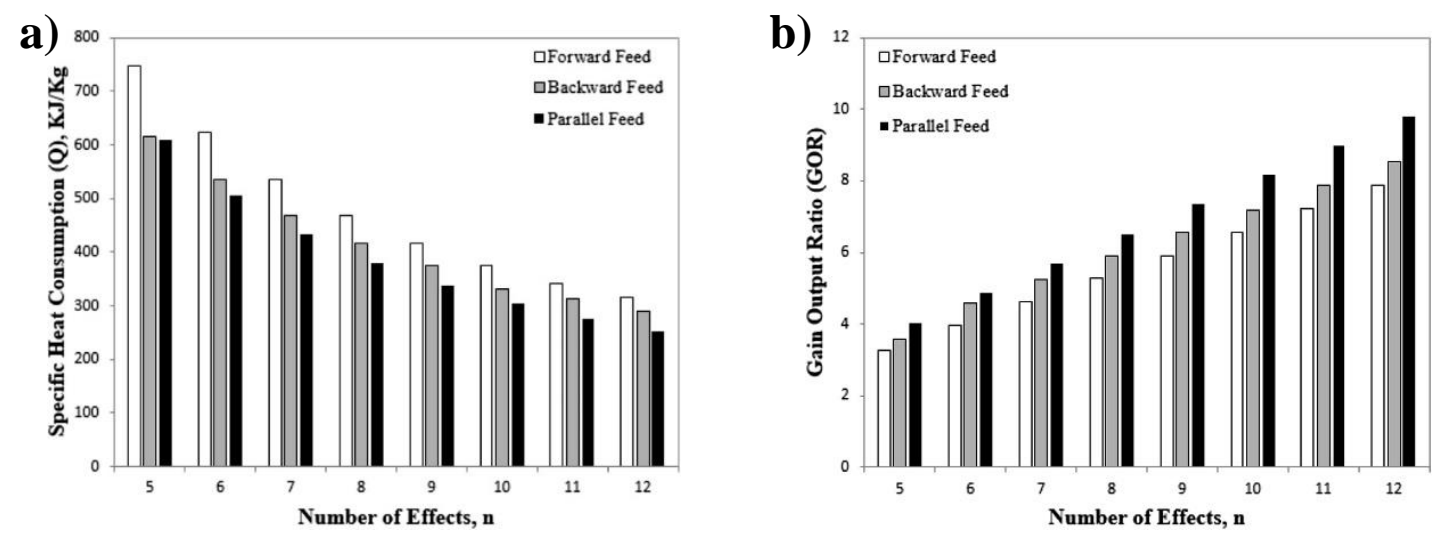

Fig. 7 Effect of number of effects on (a) specific heat consumption and (b) GOR [83]. Copyright @ 2014, Elsevier.

So far the most abundant thermal technology in the world is MSF, even though it requires more energy and has higher brine temperature and capital cost than MED. The interest in MED desalination technology has been rapidly increasing in countries close to the Arabian sea and the Persian gulf [4]. This is because in these regions solar energy is abundant and coupling MED with 
a solar power plant is promising $[7,86]$. Also, MED can be used with low temperature sources such as geothermal energy and waste heat as it can operate at low temperature [87]. Coupling MED with TVC or MVC increases the process capacity. Currently, the capacity of commercial MEDTVC plants ranges from 70,000 to 80,000 ton/d and the capacity of commercial MED-MVC plants is below 10,000 ton/d [88, 89]. Integrating TVC with MED can also lead to reduced thermal energy consumption by utilizing part of the vapor coming from the last effect [90].

MED is gaining more attention not only due to its recent technological developments but also because life of most MSF plants in the Middle East is ending [76]. Some researchers believe that there is still more room for further development in MSF and MSF will continue to grow in the future $[19,91,92]$. Studies by other researchers show that the number of MED plants will become more than MSF while the installed capacity of MSF will remain the highest $[1,56,93]$. We believe that more attention should be given to MED because of its low energy requirements compared to MSF.

\section{Energy efficiency evolvement of reverse osmosis desalination}

Recently, thermal desalination technologies have been replaced with membrane-based processes in many parts of the world due to their lower energy requirements (Table 4) [94]. The common membrane-based processes which are used in desalination plants nowadays are RO and ED. Other membrane processes like FO and MD are still emerging and have not yet passed the pilot plant stage [14]. Membrane processes account for $68 \%$ of the online desalination capacity [15]. RO alone comprises about $65 \%$ of the global constructed capacity [15]. This is because it requires the least amount of SEC among all the common desalination technologies (Table 4). As mentioned 
before in section 1, RO and ED require electrical energy only, unlike thermal processes which use both thermal and electrical energies. In ED, ionic species are separated from aqueous solution by applying a current across a series of ion exchange membranes (IEMs) [95]. The cost of ED is mostly affected by the concentration of salt in feed water $[95,96]$. Therefore, the process is more feasible for desalting BW. The global desalination capacity of ED is only $3 \%$ as scaling up the process is limited by the high cost of IEMs compared to RO membranes [15, 97]. Thus, we decided to focus more on RO as it is the leading technology for SW desalination nowadays [98].

Table 4. Comparison between thermal and membrane-based processes. Reproduced from [7, 9, 16, 81, 93, 99-101].

\begin{tabular}{|c|c|c|c|c|c|}
\hline Properties & MSF & MED & SWRO & BWRO & ED \\
\hline $\begin{array}{c}\text { Typical plant size }(\times \\
\left.1000 \mathrm{~m}^{3} / \text { day }\right)\end{array}$ & $50-70$ & $5-15$ & Up to 624 & Up to 98 & $2-145$ \\
\hline Recovery ratio (\%) & $30-45$ & $30-45$ & $35-50$ & $50-90$ & $50-90$ \\
\hline $\begin{array}{l}\text { Tolerated feed salinity } \\
\text { (ppm) }\end{array}$ & $\begin{array}{l}\text { No } \\
\text { restrictions }\end{array}$ & $\begin{array}{l}\text { No } \\
\text { restrictions }\end{array}$ & $\begin{array}{l}30,000- \\
60,000\end{array}$ & $500-10,000$ & $<5000$ \\
\hline Brine temperature $\left({ }^{\circ} \mathbf{C}\right)$ & $90-120$ & $50-90$ & $\begin{array}{l}\text { Same as } \\
\text { inlet }\end{array}$ & $\begin{array}{l}\text { Same as } \\
\text { inlet }\end{array}$ & $<45$ \\
\hline $\begin{array}{l}\text { Electrical energy (kW- } \\
\left.\qquad \mathbf{h} / \mathbf{m}^{3}\right)\end{array}$ & $2.5-5$ & $2-2.5$ & $\begin{array}{c}\text { 4-6 with } \\
\text { ERD } \\
\text { 7-13 without } \\
\text { ERD }\end{array}$ & $0.5-2.5$ & $0.7-5.5$ \\
\hline Thermal energy $\left(\mathrm{MJ} / \mathrm{m}^{3}\right)$ & $190-282$ & $145-230$ & None & None & None \\
\hline $\begin{array}{c}\text { Equivalent electrical to } \\
\text { thermal energy at heat } \\
\text { conversion efficiency of } \\
\quad 30 \%\left(\mathrm{~kW}-\mathrm{h} / \mathrm{m}^{\mathbf{3}}\right)\end{array}$ & $15.8-23.5$ & $12.2-19.1$ & None & None & None \\
\hline
\end{tabular}




\begin{tabular}{|c|c|c|c|c|c|}
\hline Total energy $\left(\mathrm{kW}-\mathbf{h} / \mathbf{m}^{3}\right)$ & $18.3-28.5$ & $14.2-21.6$ & $4-6$ & $1.5-2.5$ & $\begin{array}{l}2.64-5.5 \\
0.7-2.5 \text { at } \\
\text { low TDS }\end{array}$ \\
\hline $\begin{array}{l}\text { Product water quality } \\
\text { (ppm) }\end{array}$ & $2-10$ & $<10$ & $\begin{array}{c}300-500 \\
\text { for single } \\
\text { pass }\end{array}$ & $200-500$ & $150-500$ \\
\hline
\end{tabular}

In RO, osmotic pressure is overcome by pressurizing the saline feed water in order to separate water from the salt [95]. RO is used for treating different types of feed water but mainly SW and BW. Between 2015 and June 2018, 57.5\% of the feed water of total contracted desalination capacity was from SW, whereas $18.5 \%$ was from BW [102]. This means that the main feed water source for RO is SW. However, energy required for desalting SW is higher than BW. This is because SW poses higher osmotic pressure than BW as it has higher salinity [103]. Thus more applied pressure is required. In this section we discuss the energy requirements for RO with more attention on SWRO. Back in the $19^{\text {th }}$ century, the capacity of RO desalination plants was small and the technology was still in its infant stage. For instance, in 1999, only $10 \%$ of water supplied by desalination was provided by RO [57]. The construction of RO plant with high capacities did not start until after 2000 when the process proved to be less energy consumer than the conventional thermal desalination technologies. Despite the low energy use and low cost of water in RO compared to thermal desalination processes, its real cost and total energy consumption continue to challenge its implementation $[104,105]$. In order to enhance the energy efficiency of a SWRO plant, first we need to identify the sources of energy consumption. Fig. 8 shows the energy consumption breakdown in a typical SWRO plant which uses SW with total dissolved solids concentration of $33,500 \mathrm{ppm}$. 


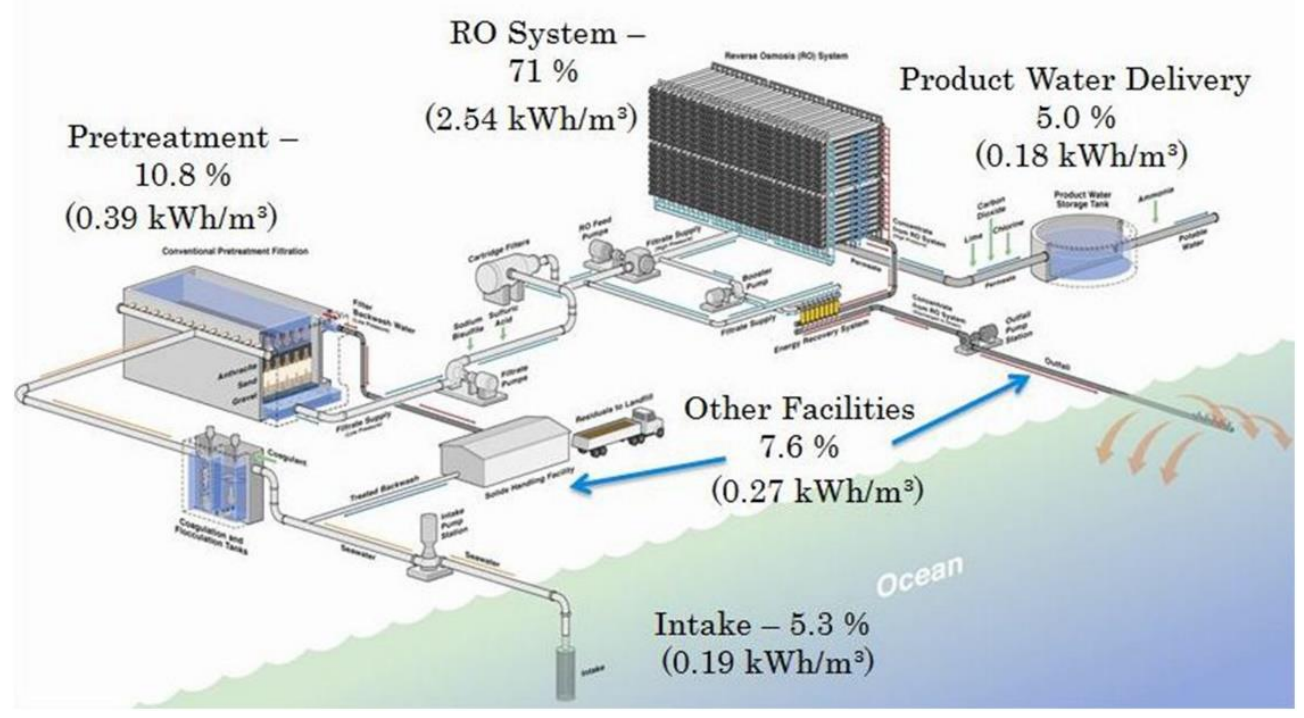

Fig. 8. Energy use breakdown in a typical SWRO plant [106]. Copyright @ 2018, Elsevier.

The highest percentage of energy consumption as shown in Fig. 8 is in the SWRO system. Usually, the second largest user of energy in SWRO plant is the pretreatment system [106]. Pretreatment is necessary to remove contaminants from SW feed before entering RO system to reduce fouling and scaling of the RO membrane [20, 107, 108]. Pretreatment is usually achieved using chemical addition followed by conventional or membrane filtration methods [20,107]. Energy consumption in the pretreatment process depends on several design factors. These factors include: type of the pretreatment technology (conventional or membrane-based), driving force (gravity or pressure), and the number of stages [14]. SEC for different pretreatments in a SWRO plant in Australia is shown in Table 5. The industry is currently moving to ultrafiltration (UF) pretreatment due to its ability to reject many different contaminants and lower SEC compared to other pretreatment technologies (Table 5) [20, 109]. However, frequent cleaning and backwashing of UF membranes requires around $0.3 \mathrm{~kW}-\mathrm{h} / \mathrm{m}^{3}$ which increases the total energy use in SWRO [109]. 
Table 5. SEC for different pretreatment technologies in the southern SW desalination plant in Australia. Adapted from [14].

\begin{tabular}{|c|c|}
\hline Configuration & SEC (kW-h/m $\left.\mathbf{m}^{\mathbf{3}}\right)$ \\
\hline Double stage filtration (pressurized) & 0.55 \\
\hline Gravity filtration + pressurized filtration & 0.54 \\
\hline Ultrafiltration & 0.46 \\
\hline
\end{tabular}

In some cases, SW intake and product water pumping stations require higher energy than their pretreatment [106]. Energy consumption in the intake and product pumping stations depends on the location of the desalination plant and desired delivery point. These are predetermined factors which cannot be changed after the plant is built and can cause increase in the energy consumption to be as high as the energy consumed in the desalination process itself. For instance, on the cost of Chile, the SWRO plant uses the same amount of energy $\left(2.5 \mathrm{~kW}-\mathrm{h} / \mathrm{m}^{3}\right)$ for desalination and product water pumping. This is attributed to the height and distance between the desalination plant and the delivery destination which are $700 \mathrm{~m}$ and $35 \mathrm{~km}$ respectively [14]. In such cases, energy use can be reduced by using pumps and motors with high energy efficiency, and designing pipes with minimum pressure losses [14]. Also, turbines can be installed to produce energy in SWRO plant where there is a significant difference in height between brine discharge and SW level [14]. Alternatively, energy consumption in any RO plant due to intake and product pumping should be taken into consideration when determining the location of the plant during the design stage [110]. This also applies to other desalination technologies. Generally, other facilities including ancillary equipment (compressors, instruments, lighting, etc.) and post-treatment do not contribute 
significantly to the total energy consumption of the SWRO plant. Therefore, advances in these energy sources have minimal effect on energy efficiency of RO.

As shown in Fig. 8, the highest percentage of energy use in a SWRO plant is in the RO desalination passes which consist of HPPs, membranes, and in some cases an ERD. In the 1970s, when the RO process was still in its initial stages of commercialization, the energy consumption in SWRO process was around $16 \mathrm{~kW}-\mathrm{h} / \mathrm{m}^{3}$ [45]. Since then, the process has undergone dramatic improvements to reduce its energy use. The Affordable Desalination Collaboration (ADC) in the United States performed long term tests of RO system with highly efficient commercially available membranes, pumps and energy recovery technology at the time of testing (2006-2007). The results showed that the lowest energy consumption at RO system recovery of 50\% and membrane flux of $15.3 \mathrm{~L} / \mathrm{m}^{2}-\mathrm{h}$, was around $1.85 \mathrm{~kW}-\mathrm{h} / \mathrm{m}^{3}$ [111]. Given the fact that the ideal theoretical minimum energy required for desalination of $\mathrm{SW}(35 \mathrm{~g} / \mathrm{L} \mathrm{NaCl})$ at $50 \%$ recovery is $1.06 \mathrm{~kW}-\mathrm{h} / \mathrm{m}^{3}$, process improvements to reduce energy consumption are becoming more challenging [45].

Enhancement of SWRO energy efficiency requires knowledge about the contributors to energy consumption. Karabelas et al. [112] quantified these contributors for typical single pass SWRO and BWRO systems with ERD. Fig. 9a shows that the highest contributor to the total SEC of SWRO is osmotic pressure $\left(\mathrm{SEC}_{\mathrm{min}}\right)$ which has to be overcome by applied pressure in order for the separation to take place. On the other hand, energy loss due to concentration polarization $\left(\mathrm{SEC}_{\mathrm{CP}}\right)$ is minor $(2.4 \%)$. The data depicted in Fig. 9a clearly show that membrane filtration resistance $\left(\mathrm{SEC}_{\mathrm{f}}\right)$ and inefficiency of HPPs and ERDs $\left(\mathrm{SEC}_{\text {ineff }}\right)$ are significant contributors to the total SEC. Distribution of SEC components in BWRO (Fig. 9b) is different from SWRO (Fig. 9a). In BWRO, the concentration of salt in feed water is much lower than SWRO and so is the corresponding osmotic pressure. Thus, less SEC is required to overcome osmotic pressure in 
BWRO compared to SWRO. Thus, the percentage contribution of SEC used to overcome osmotic pressure in BWRO is $19.6 \%$. It seems that in BWRO, the highest contributor to SEC is membrane filtration resistance $\left(\mathrm{SEC}_{\mathrm{f}}=51.2 \%\right)$. In general, as mentioned in section 2, applied pressure $\left(\mathrm{P}_{\mathrm{H}}\right)$ in RO should at least be equal to osmotic pressure $(\pi)$ in order to allow the passage of an infinitesimally small volume of water through a semipermeable membrane [113-115]. Therefore, there is no room for reducing SEC required to overcome osmotic pressure. However, as we can see from the study done by Karabelas et al. [112], there are other factors which if modified can enhance the RO process efficiency. This section covers the effect of different membrane performance factors on energy consumption in RO. Also, advances in HPPs, and ERDs to reduce SEC in RO are discussed.

a)

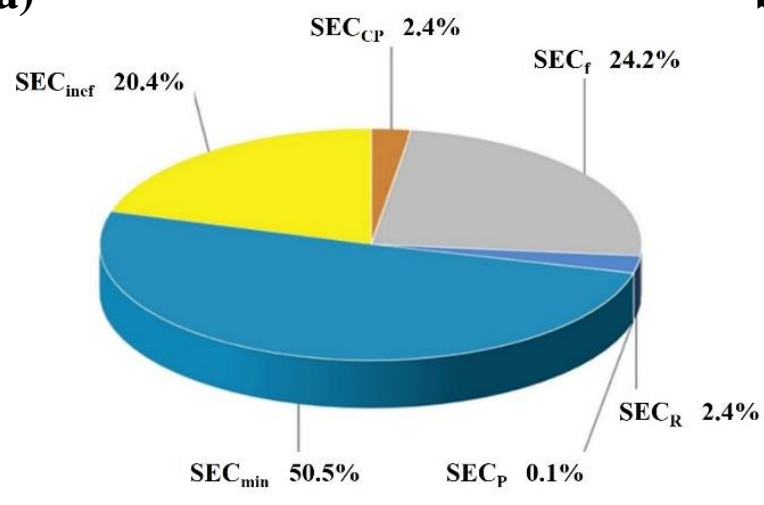

b)

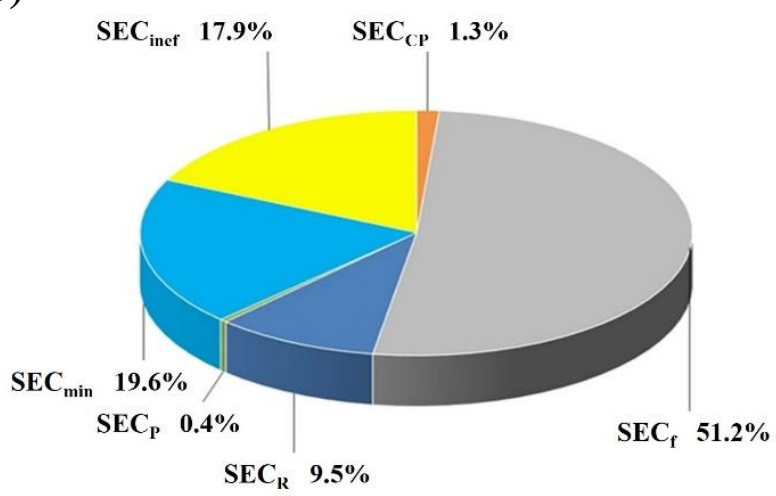

Fig. 9. Percentage contribution of different elements to SEC in (a) SWRO and (b) BWRO [112]. ( $\mathrm{f}=$ membrane filtration resistance, $\mathrm{R}=$ frictions losses by retentate, $\mathrm{P}=$ friction losses by permeate, min= osmotic pressure, $\mathrm{CP}=$ concentration polarization, inef= pump and ERD inefficiency). Copyright $\odot$ 2018, Elsevier.

\subsection{High pressure pumps}

HPPs are the major consumers of energy in any RO desalination process. Pressure required for desalination of $\mathrm{BW}$ ranges from 15 to 25 bar, whereas $\mathrm{SW}$ needs higher pressure ranging from 54 
to 80 bar $[57,116]$. There are several factors which affect the required applied pressure other than feed salinity such as membrane compaction and degree of surface fouling, temperature, recovery, and aging $[14,46]$. Membrane fouling causes a decline in membrane permeability with time. In order to operate at the same set flux, applied pressure should be increased. This means that during RO operation, pressure requirements are variable. Therefore, flexible HP pumping systems which can operate in a wide range of feed and concentrate pressures are needed to sustain the process efficiency. Usually, a variable frequency drive (VFD) is installed into the electric motor which drives the HPP. VFD is an electric motor controller which alters the frequency and the voltage supplied to the motor [117]. VFDs can help control the operation of the HPPs to avoid unnecessary energy losses and optimize the SEC. VFD can effectively enhance the RO process energy efficiency especially in plants where a wider range of pressures is required. However, the main drawback of VFDs is their cost which can sometimes be higher than the pump and motor costs [47]. Another way to incorporate VFD in the RO process is by installing it with a Low pressure booster pump (BP) placed before the HPP inlet [14]. This approach guarantees that the HPP always operates at its maximum efficiency (fixed point). In this case, the BP which operates at a lower pressure range manages the variation in pressure requirements. Also, capital costs are reduced because the VFD for BP is much cheaper than that for HPPs [14].

In a conventional RO plant, HPPs are dedicated for each membrane rack. Plants with a larger number of membrane racks require more HPPs. Another configuration for HPPs is pressure center where few number of HPPs feed one manifold which distributes the flow to separate membrane racks. The efficiency of pumps increases as their capacity increases [55]. Therefore, this configuration gives a more efficient system. Torre [118] showed a comparison between dedicated pump and pressure center arrangements in terms of pump efficiency. Recovery ratio was assumed 
to be $45 \%$ and BPs before the HPP and ERDs were used in the process. Data in Table 6 shows that the efficiency of HPPs and BPs is higher in the system which employs the pressure center configuration. Increased pump efficiency leads to reduced energy consumption which in return lowers the operating cost.

Table 6. Pumps efficiency in RO plants with different configurations for pump installation [118].

\begin{tabular}{|c|c|c|c|c|}
\hline $\begin{array}{c}\text { Plant design/number of } \\
\text { pumps }\end{array}$ & $\begin{array}{c}\text { Capacity } \\
\left(\mathbf{m}^{\mathbf{3}} / \mathbf{h}\right)\end{array}$ & HPP/number of stages & \multicolumn{2}{|c|}{ Reachable efficiency } \\
\hline $\mathbf{8}$ separated trains & 625 & 5 stages & $85 \%$ & $85.5 \%$ \\
\hline $\mathbf{5}$ separated trains & 1000 & 4 stages & $86 \%$ & $87 \%$ \\
\hline $\mathbf{2}$ HP pumps in pressure & 2500 & 2 stages & $88.5 \%$ & $88 \%$ \\
\hline \begin{tabular}{c} 
center \\
\hline
\end{tabular} & & & & BP \\
\hline
\end{tabular}

\subsection{Membrane properties}

Over the past decade, advancement in RO membranes has contributed significantly to the decrease in SEC of SW desalination [98]. Performance improvements can be achieved either by introducing new materials and methods to alter the membrane characteristics or modifying the membrane configuration (section 8) [14]. There are two main factors in RO membranes which affect the SEC of the process: water permeability and membrane fouling.

SEC in RO can be reduced by enhancing the membrane permeability. Basically, when feed water $\left(\mathrm{V}_{\mathrm{F}}\right)$ is pressurized it carries energy equal to $\left(\mathrm{P}_{\mathrm{H}} \mathrm{V}_{\mathrm{F}}\right)$ which drives the separation. When saline water is pushed against the membrane, fresh water product $\left(\mathrm{V}_{\mathrm{P}}\right)$ and concentrate $\left(\mathrm{V}_{\mathrm{C}}\right)$ which contains the 
rejected salts are produced. Part of the energy used to drive the process is carried by the concentrate and it is equal to $\mathrm{P}_{\mathrm{H}} \mathrm{V}_{\mathrm{C}}$. This energy is lost unless recovered by ERDs. Permeation of water through the membrane is driven by an energy equal to $\mathrm{P}_{\mathrm{H}} \mathrm{V}_{\mathrm{P}}$. Part of this energy is used to overcome the osmotic pressure of feed water $\left(\mathrm{V}_{\mathrm{P}} \pi\right)$ while the rest $\left(\mathrm{V}_{\mathrm{P}}\left(\mathrm{P}_{\mathrm{H}}-\pi\right)\right)$ is used to generate a reasonable water flux [45]. Enhancing the membrane permeability could reduce the gap between $\mathrm{P}_{\mathrm{H}}$ and $\pi$ by decreasing the magnitude of $\mathrm{P}_{\mathrm{H}}$ which in return reduces the amount of energy required to generate reasonable fresh water flux. However, no matter how low $\mathrm{P}_{\mathrm{H}}$ can reach, it should be always at least equal to the osmotic pressure of concentrate $\left(\pi_{\mathrm{C}}\right)$ [113-115]. This indicates that reducing SEC consumption in RO by enhancing membrane permeability is thermodynamically limited [119]. Cohen-Tanugi et al. [120] studied the effect of tripling the membrane permeability on SEC or number of required pressure vessels in RO system with given specifications using theoretical calculations. Both BWRO and SWRO were included in this study. Fig. 10a and Fig. 10b were obtained at fixed feed flowrate, membrane area, and recovery ratio. As shown in Fig. 10a, the required feed inlet pressure as well as SEC decrease as the membrane permeability increases. For SWRO, an increase in the permeability from 1 to $3 \mathrm{~L} / \mathrm{m}^{2}-\mathrm{h}$ bar causes a $10-15 \%$ reduction in the required inlet pressure and SEC, respectively. Similarly, the same change in permeability leads to $46 \%$ reduction in pressure and SEC which is much higher than SWRO. Nonetheless, the RO process is limited by thermodynamics. Therefore, at a certain point, when inlet pressure and osmotic pressure become equal, improvement in membrane permeability becomes no longer effective for reducing SEC (Plateau in Fig. 10a). The number of pressure vessels required to produce a specific output $\left(100,000 \mathrm{~m}^{3} / \mathrm{d}\right)$, reduces as the permeability increases (Fig. 10b). However, at a high flowrate, SEC would increase slightly due to energy dissipation by viscous losses. This study showed that enhancing membrane permeability is a promising approach for 
higher energy efficiency in RO. Research now is directed towards new type of membranes known as ultra-permeable membranes (UPMs) with permeability far higher than conventional RO membranes.
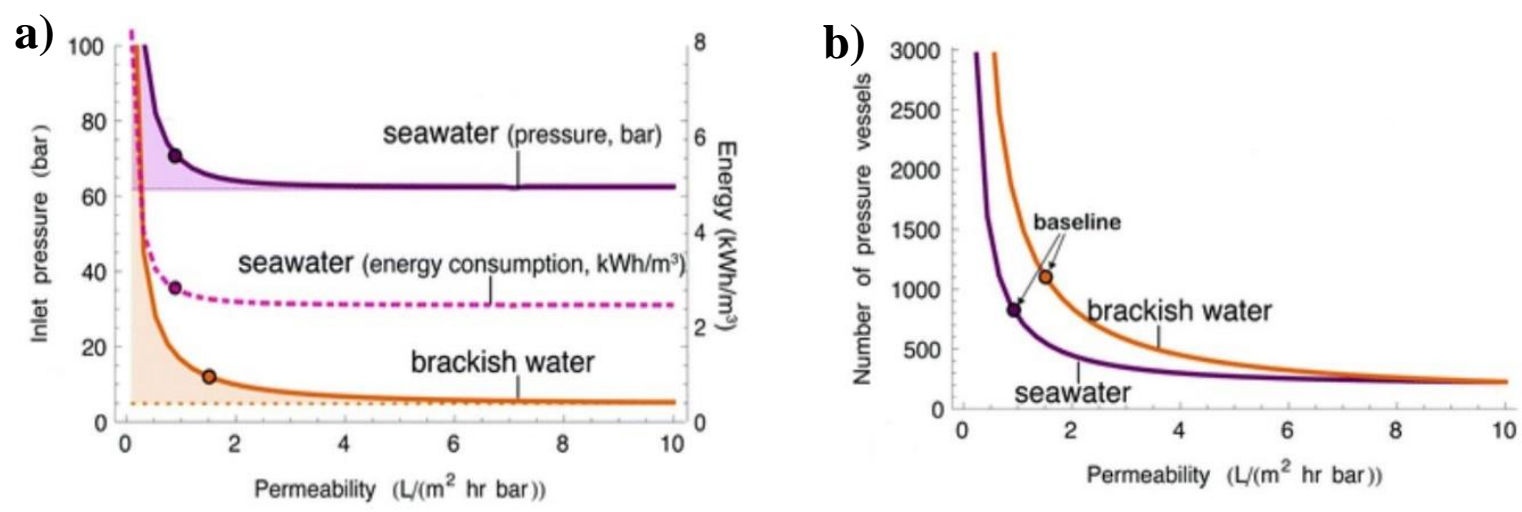

Fig. 10. (a) Effect of permeability on inlet pressure (solid lines) and SEC (dashed lines), (b) Number of required pressure vessels for production of $100,000 \mathrm{~m}^{3} / \mathrm{d}$ as a function of permeability [120]- Published by the Royal Society of Chemistry.

In an another study, Wilf [121] examined the effect of replacing BWRO membrane elements with the ones having $80 \%$ higher permeability. The results showed that $30 \%$ reduction in SEC was achieved at an average flux of $25.5 \mathrm{~L} / \mathrm{m}^{2}$-h Also, the SEC decreased by $47 \%$ at an average flux of $34 \mathrm{~L} / \mathrm{m}^{2}$-h. Franks et al. [122] also studied the change in SEC when BWRO membrane elements with a permeate flow of $34.1 \mathrm{~m}^{3} / \mathrm{d}$ were replaced with those having $45.4 \mathrm{~m}^{3} / \mathrm{d}$ of permeate flow. Their results showed that feed pump pressure reduced by $18 \%$ which in return lead to $17.1 \%$ decrease in SEC. The experiments were performed using a wastewater feed with $1167 \mathrm{ppm}$ salinity and an RO system with recovery ratio of $85 \%$ and efficient pumps. All these studied showed that enhancing the membrane permeability could effectively reduce the SEC and thus reduce the process economics. Zhu et al. [123] reported that increasing the permeability of RO membranes, which already operate close to their thermodynamic limit does not lead to considerable energy 
reductions. Furthermore, because electrical cost is higher than the membrane cost, there is noticeably less drive in developing novel membranes for this purpose. Other improvements which need to be considered are enhancing the fouling resistance of RO membranes, modification of process configuration (section 8), and coupling RO desalination with renewable energy (section 7).

Most of the studies which evaluate the effect of membrane permeability on SEC use theoretical models. These models are constructed based on certain assumptions which in most cases do not fairly represent the real conditions. For instance, RO membranes are prone to fouling [124] over long term operation which can significantly affect the SEC. There are only a few studies which couple the effect of both fouling and membrane permeability on SEC. Jeong et al. [125] studied the effect of fouling using numerical simulation. In their study, they used a cake filtration model to analyze the effects of colloidal fouling. They accounted for the fouling effect by adding the cake layer resistance to the total membrane resistance. Simulations were conducted with feed salinity of $32,000 \mathrm{ppm}$ and recovery rate of $40 \%$. Fig. 11 shows the change in SEC with time for membranes with different permeability. In the beginning, the membrane with the highest permeability requires the least SEC. As time passes, SEC increases due to membrane fouling. However, rate of increase in SEC was observed to be higher for membranes with higher permeability. By the end of the 90 days, as shown in Fig. 11, SEC of the least and most permeable membranes become equal. This is because the amount of foulants brought to the membrane surface increases with higher water flux which in return leads to higher resistance to permeation. In order to maintain the production at the set value, feed pumping pressure should be increased. Research similar to this study would help researchers develop a more realistic understanding of the effect of permeability enhancement on SEC and thus they are essential for the future of RO membrane 
development. Generally, fouling mitigation techniques involve surface modification of the membrane or coating $[126,127]$. Although, these modifications can protect the membrane from fouling, membrane permeability is compromised. Applying these techniques on UPMs could be one way to design robust higher permeability membranes which can operate for a long period of time without losing their productivity. Hence, increases in energy consumption and operational costs can be avoided.

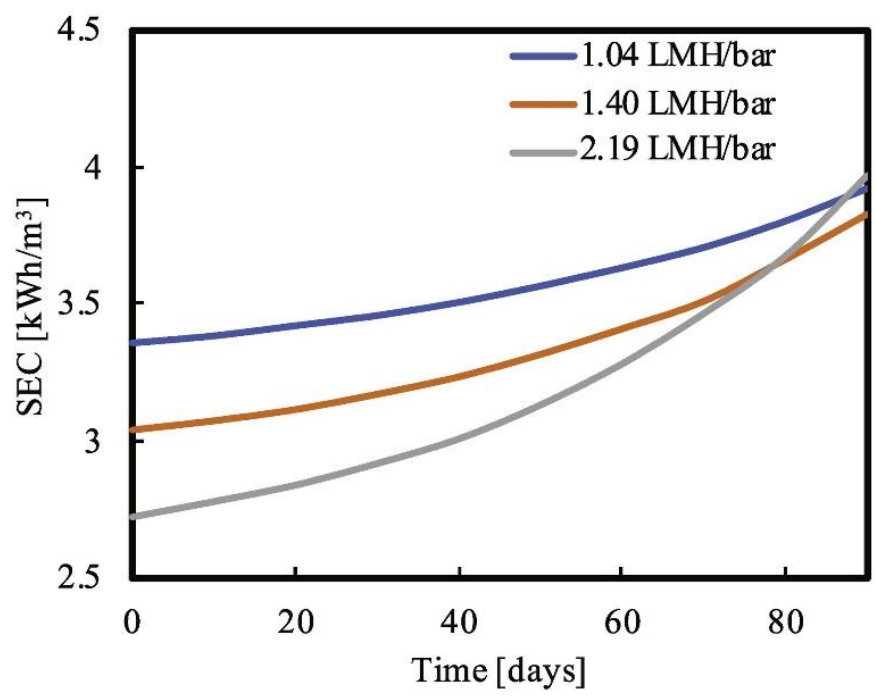

Fig. 11. SEC over time for different membrane permeability [125, 128]. Copyright ()$^{2} 2019$, Elsevier

\subsection{Energy recovery devices}

To overcome the high osmotic pressure of SW feed in the SWRO process, significantly high pumping pressure is required. This results in a highly pressurized brine stream as a byproduct of the SWRO process. ERDs have the potential to reduce the SEC by recovering part of the energy in the brine stream and redirecting it to the feed stream through a wide range of devices. These devices can be classified as centrifugal and isobaric (rotary-driven or piston-driven) ERDs [101]. 
The centrifugal-driven ERDs developed in the early eighties were amongst the first to be used in SWRO [129]. These types of devices harvest energy from the highly pressurized brine by directing it to a turbine which transfers its hydraulic energy to mechanical energy. Then, this mechanical energy which is transferred through a shaft drives the high-pressure pump and reduces its energy requirements (Fig. 12). However, this double energy conversion process (hydraulic-mechanicalhydraulic) significantly affects the efficiency of these types of ERDs.

The most common types of these ERDs are Francis Turbine, Turbocharger, and Pelton Wheel [130]. In the early nineties, Francis Turbines were first employed in SWRO with a maximum energy recovery efficiency of $75 \%$. At this value, the SWRO-ERDs process SEC was brought down to $4-5 \mathrm{~kW}-\mathrm{h} / \mathrm{m}^{3}$ [131]. Nonetheless, Francis Turbines suffered from increased maintenance requirements and inability to function properly when the operating conditions (e.g. SW temperature, salinity, feed flow) changed seasonally [130]. Turbocharger ERDs, which were specifically designed and built for the SWRO process, were also implemented shortly after Francis Turbine with proven energy recovery efficiency of $70-80 \%$, extended lifetime, more simple operation, and consistent performance [132]. However, due to their lower efficiencies, both Francis Turbines and Turbocharger ERDs were replaced with Pelton wheel turbines [132]. Pelton wheel ERDs were widely used in SWROs plants up till the early 2000s, due to their considerable energy recovery efficiency (85-90\%) which reflects on the SEC of the SWRO plants (Table 7). Despite this, due to their increased footprint (i.e. required large area to be installed), large design, and dual-shafted motor, their use in SWRO plants has dramatically decreased nowadays [130]. 


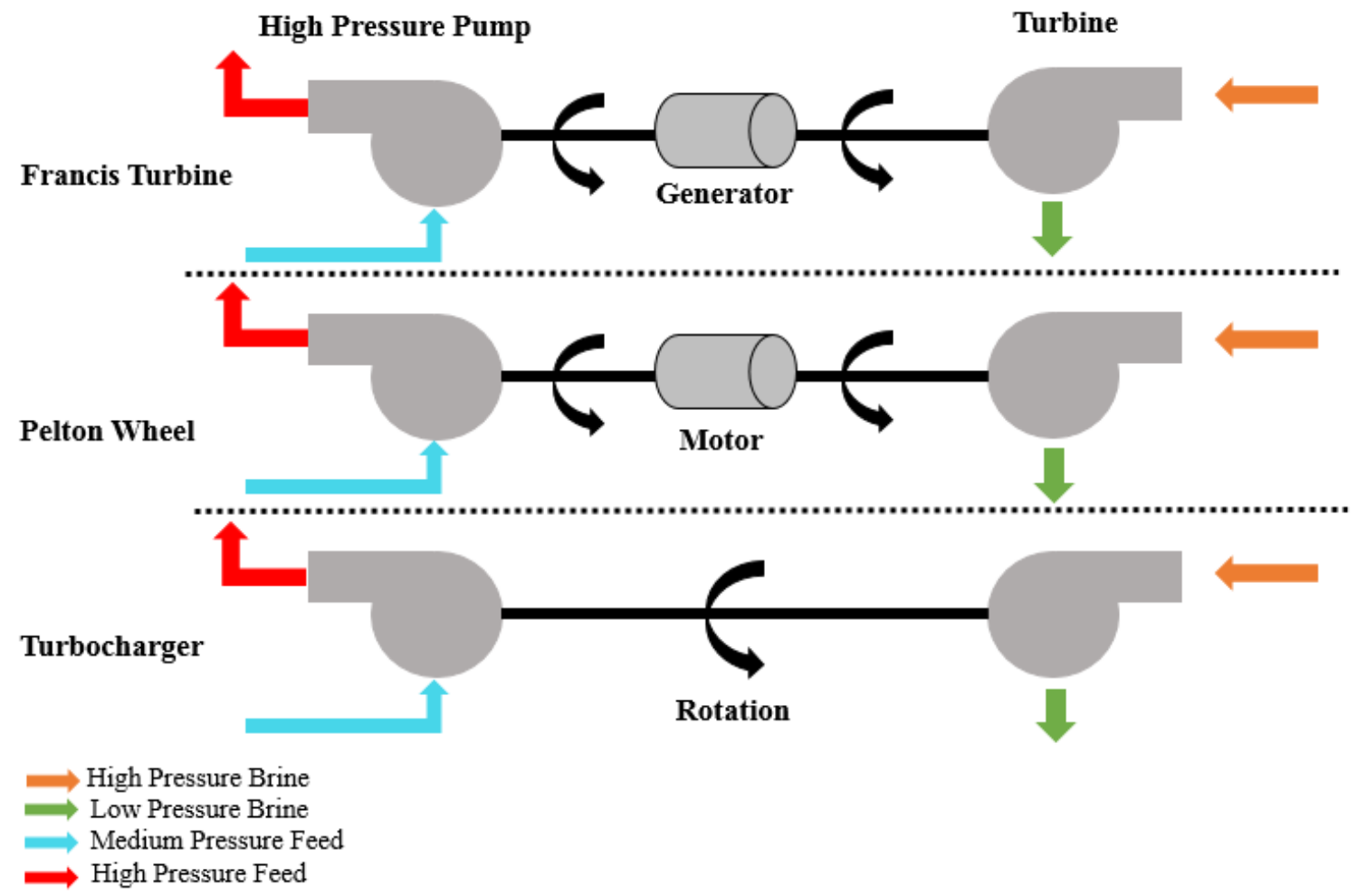

Fig. 12. Schematic representation of different centrifugal-driven ERDs.

In the early 2000s, most of the centrifugal-driven ERDs were replaced with isobaric ERDs. This shift to isobaric ERDs is owed to their astonishing energy recovery efficiency which is above $90 \%$ [133]. This high efficiency is attributed to their single energy conversion by which the hydraulic energy of the brine is directly transferred to the feed SW. There are two types of ERDs which are piston-based and rotary-based (Fig. 13). Examples of the most common piston-based ERDs are

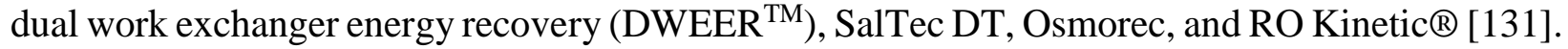
Similarly, the most common rotary-based ERDs are ERI® Pressure Exchanger (PX) and Danfoss iSave [131]. These ERDs are considered the state of the art of the isobaric ERDs which has proven to avoid the efficiency losses present in the centrifugal-based ERDs. 


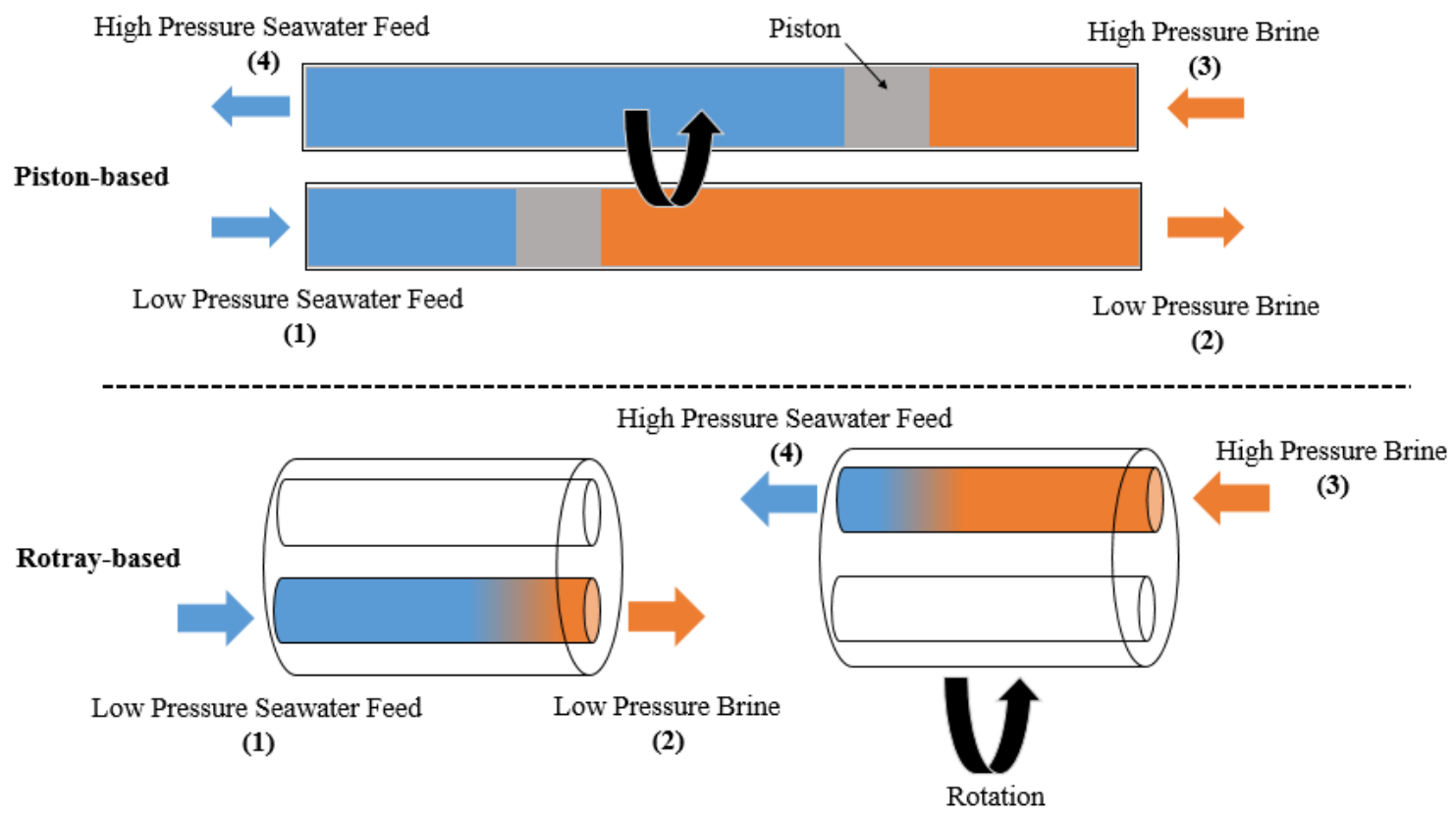

Fig. 13. Schematic representation of the piston and rotary-based isobaric ERDs working principles. 
Table 7. Comparison between the different types of ERDs used in SWRO desalination.

\begin{tabular}{|c|c|c|c|c|c|}
\hline ERDs Type & Advantages & Disadvantages & $\begin{array}{c}\text { Possible Energy } \\
\text { Recovery Efficiency } \\
(\%)\end{array}$ & $\begin{array}{c}\text { SEC of SWRO-ERD } \\
\left(k W-h / \mathbf{m}^{3}\right)\end{array}$ & Ref. \\
\hline Francis Turbine & Proven Technology & $\begin{array}{l}\text { Limited in operation } \\
\text { Difficult to maintain }\end{array}$ & 75 & $4.0-5.0$ & {$[130,131]$} \\
\hline Turbocharger & $\begin{array}{c}\text { Small footprint } \\
\text { Flexible in operation }\end{array}$ & Lower efficiency & $70-80$ & $3.8-5.6$ & $\begin{array}{l}{[129,131,} \\
134,135]\end{array}$ \\
\hline Pelton Wheel & $\begin{array}{c}\text { Proven reliable technology } \\
\text { Flexible in operation }\end{array}$ & $\begin{array}{c}\text { Large footprint } \\
\text { Efficiency is dependent } \\
\text { on plant capacity }\end{array}$ & $85-90$ & $3.0-4.0$ & {$[129,131]$} \\
\hline RO Kinetic® & $\begin{array}{l}\text { Minimum maintenance } \\
\text { Ease of operation }\end{array}$ & Not commercial" & Up to $98 \%$ & $2.1-3.3$ & [136] \\
\hline DWEER ${ }^{\text {TM }}$ & $\begin{array}{l}\text { Flexible in operation } \\
\text { Extended lifetime }\end{array}$ & $\begin{array}{l}\text { Moderate footprint } \\
\text { Control system of } \\
\text { pistons is required } \\
\text { Can increase feed } \\
\text { salinity }\end{array}$ & Up to $98 \%$ & As low as 2.1 & $\begin{array}{c}{[131,132,} \\
137]\end{array}$ \\
\hline
\end{tabular}




\begin{tabular}{|c|c|c|c|c|c|}
\hline ERI@ PX & $\begin{array}{l}\text { Autonomous device } \\
\text { Minimum maintenance } \\
\text { Compact design (Small } \\
\text { footprint) } \\
\text { Extended lifetime }\end{array}$ & $\begin{array}{l}\text { High noise }(92 \mathrm{~dB}) \\
\text { Can increase feed } \\
\text { salinity }\end{array}$ & Up to $98 \%$ & $2.2-4.0$ & {$[129,132]$} \\
\hline iSave & $\begin{array}{l}\text { Compact design (Small } \\
\text { footprint) } \\
\text { Minimum maintenance }\end{array}$ & High noise (87 dB) & NA & As low as 2.1 & [131] \\
\hline
\end{tabular}

*Installed in some small scale SWRO plants 
An example for a SWRO plant which uses Francis Turbine ERDs is the Las Palmas SWRO plant located in Spain which was built in 1989 , with an overall capacity of $36,000 \mathrm{~m}^{3} /$ day. At the beginning of its operation, this SWRO plant used to consume a total SEC of $6.67 \mathrm{~kW}-\mathrm{h} / \mathrm{m}^{3}$ (with an overall recovery of 45\%). A few years later, the Francis Turbine ERDs were replaced with Pelton Wheel which reduced the total SEC of the plant to around $5.85 \mathrm{~kW}-\mathrm{h} / \mathrm{m}^{3}$ (achieving around 12.30\% energy saving) [138]. Another example for a SWRO plant which uses Francis Turbine ERDs is Dhekelia which was built in 1998 in Cyprus. Without ERDs, the total SEC of the plant was around $6.20 \mathrm{~kW}-\mathrm{h} / \mathrm{m}^{3}\left(\right.$ Capacity $=40,000 \mathrm{~m}^{3} / \mathrm{d}$, Salinity $=41800 \mathrm{ppm}$, feed temperature $=17$ to $32^{\circ} \mathrm{C}$ ). After the installation of Francis Turbine ERDs, the SEC was reduced to around $5.2 \mathrm{~kW}$ $\mathrm{h} / \mathrm{m}^{3}$ (16\% energy savings) [139]. Furthermore, detailed energy analysis of the SWRO plant showed that further reduction in SEC of around $0.27 \mathrm{~kW}-\mathrm{h} / \mathrm{m}^{3}$ can be achieved by replacing the current Francis Turbine ERDs with Pelton wheel turbines due to their higher energy recovery efficiency [140].

Compared to the conventional Francis Turbine ERDs, Pelton Wheel turbines have a better performance [132]. For instance, in a standard 10,000 $\mathrm{m}^{3} / \mathrm{d} \mathrm{SWRO}$ plant replacing Francis Turbine with Pelton Wheel can reduce the SEC from 3.95 to $3.27 \mathrm{~kW}-\mathrm{h} / \mathrm{m}^{3}[129]$. Other examples of SWRO desalination plants equipped with Pelton wheel ERDs are summarized in Table 8. From the table, it can be observed that a considerable reduction in the overall SEC was achieved by installing Pelton wheel ERDs. 
Table 8. Different SWRO desalination plants equipped with Pelton wheel ERDs

\begin{tabular}{|c|c|c|c|c|}
\hline SWRO Plant & $\begin{array}{l}\text { Capacity } \\
\left(\mathrm{m}^{3} / \text { day }\right)\end{array}$ & $\begin{array}{c}\text { Recovery Ratio } \\
(\%)\end{array}$ & SEC $\left(k W-h / m^{3}\right)$ & Ref. \\
\hline Las Palmas III* & 79,000 & 53.3 & $3.35-3.50$ & {$[129,138]$} \\
\hline Lanzarote IV & 20,000 & 50.0 & $3.60-3.70$ & {$[141]$} \\
\hline Maspalomas II & 41,000 & 40 & 3.35 & {$[142]$} \\
\hline El Coloso & 45,360 & 50 & 4.3 & {$[139,143]$} \\
\hline La Chimba & 52,000 & 52 & 4.2 & [139] \\
\hline Rambla Morales & 60,000 & 58 & 3.8 & [139] \\
\hline
\end{tabular}

*2006 Expansion

Nowadays, most of the ERDs used in commercial SWRO plants are either ERI® PX or DWEER $^{\text {TM }}$. They both have advantages of high efficiency and superior performance compared to the other ERDs $[101,139]$. Both can reach an energy recovery efficiency of around 98\% (Table 7) which makes them the most preferable option in large scale SWRO desalination plants. The SWRO desalination plant near Kwinana beach, Perth, Australia is an example for a plant which uses ERI® PX (rotary-based) ERDs. The plant has a total capacity of $143,000 \mathrm{~m}^{3} / \mathrm{d}$ operating with $45 \%$ recovery efficiency and SW feed salinity of 34,000 ppm [144]. The deployment of ERI® PX ERDs, running with optimum efficiency of $97 \%$, allowed for low SEC of $2.47 \mathrm{~kW}-\mathrm{h} / \mathrm{m}^{3}$ [144]. The Tuas SWRO plant located in Singapore with a total capacity of $136,000 \mathrm{~m}^{3} / \mathrm{d}$ is an example of a desalination plant that utilizes 30 DWEER $^{\mathrm{TM}}$ ERDs (piston-based) [137]. The use of DWEER $^{\mathrm{TM}}$ ERDs allowed for the reduction of SEC in SWRO process to around $2.10 \mathrm{KW}-\mathrm{h} / \mathrm{m}^{3}$ $($ Recovery $=45 \%$, feed salinity $=35,000 \mathrm{ppm})$. Other examples for SWRO desalination plants which use the DWEER ${ }^{\mathrm{TM}}$ and ERI® PX are summarized in Table 9. 
Table 9. Examples for SWRO plants equipped with DWEER ${ }^{\mathrm{TM}}$ or ERI ® ERDs.

\begin{tabular}{|c|c|c|c|c|c|}
\hline SWRO Plant & $\begin{array}{r}\text { Capacity } \\
\left(\mathbf{m}^{3} / \text { day }\right)\end{array}$ & ERD Type & $\begin{array}{l}\text { Recovery } \\
\text { Ratio }(\%)\end{array}$ & $\operatorname{SEC}\left(\mathbf{k W}-\mathbf{h} / \mathbf{m}^{\mathbf{3}}\right)$ & Ref. \\
\hline Beni Saf, Algeria & 200,000 & ERI® PX & 45 & 2.6 & {$[139,145]$} \\
\hline $\begin{array}{c}\text { Marsa Matrouh, } \\
\text { Egypt }\end{array}$ & 24,000 & ERI@ PX & NA & 2.2 & [139] \\
\hline Las Palmas III, Spain* & 85,000 & $\mathrm{ERI} \circledast \mathrm{PX}$ & 51 & 2.7 & [138] \\
\hline $\begin{array}{c}\text { Las Palmas III, } \\
\text { Spain** }\end{array}$ & 86,000 & ERI® PX & 50 & 2.3 & [138] \\
\hline $\begin{array}{c}\text { Aguilas-Guadalentin, } \\
\text { Spain }\end{array}$ & 212,000 & DWEERTM & 45 & 2.9 & [139] \\
\hline Sorek (Soreq), Israel & 540,000 & DWEERTM & 45 & 2.6 & {$[146,147]$} \\
\hline Hadera, Israel & 350,000 & ERI@ PX & 45 & 2.7 & {$[146,147]$} \\
\hline
\end{tabular}

*2009 Expansion, **2011 Expansion

Over time, the use of ERDs in SWRO desalination plants has been receiving increased interest and this has led to a significant improvement in their energy recovery efficiency. This improvement was reflected on the total SEC which decreased significantly over time, as illustrated in Fig. 14. In 2005, the world started shifting towards using isobaric-based ERDs (Fig. 14). Nowadays, most of the ERDs used in commercial SWRO plants are either DWEER ${ }^{\mathrm{TM}}$ or ERI® PX. The potential for adopting other recent ERDs like RO Kinetic ${ }^{\circledR}$ has been investigated in small scale SWRO plants in Spain (capacities $<1000 \mathrm{~m}^{3} /$ day) such as El Fraile $\left(\mathrm{SEC}=2.3 \mathrm{~kW}-\mathrm{h} / \mathrm{m}^{3}\right)$, El Confital $(\mathrm{SEC}=$ $\left.2.1 \mathrm{~kW}-\mathrm{h} / \mathrm{m}^{3}\right)$, and Aguas de Ponta Preta $\left(\mathrm{SEC}=2.4 \mathrm{~kW}-\mathrm{h} / \mathrm{m}^{3}\right)$ SWRO plants [136]. Although further advances in the design and development of ERDs continue with time due to the increased interest in such devices, the room for development is narrow. Today, with ERDs such as 
DWEER $^{\mathrm{TM}}$ or ERI® PX (energy recovery efficiency up to $98 \%$ ), the maximum energy savings in SWRO plants with ERDs can reach up to $60 \%$ when compared to standard plant without ERDs $[129,133,139]$. Further advancements in ERDs would most probably have a minimal effect on the SWRO process energy consumption considering the current status of SWRO technological advancement. Hence, to further reduce the energy requirements of SWRO plants, other considerations such as plant design, configuration, hybridization, should be investigated.

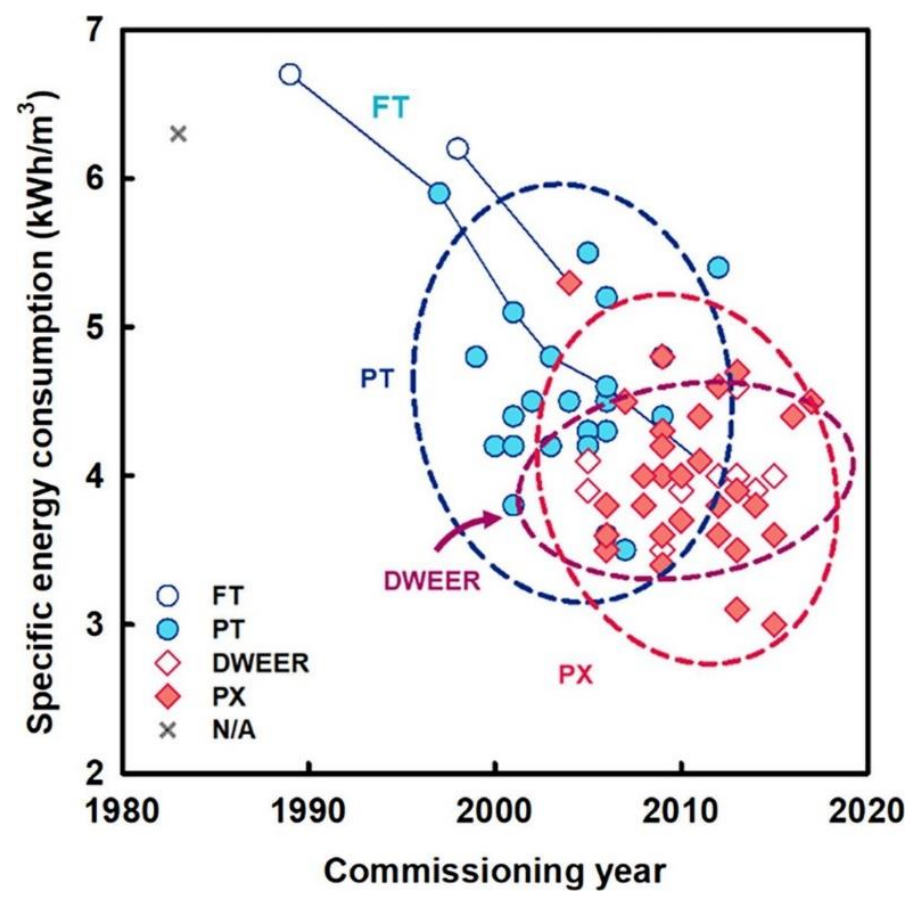

Fig. 14. The total SEC of different SWRO plants use centrifugal or isobaric-based ERDs (Francis turbine and Pelton turbine are denoted as FT and PT, respectively) [139]. Copyright (C 2019, Elsevier. 


\section{Energy requirements of emerging desalination technologies}

To ensure supply of fresh water resources, energy-efficient desalination technologies play a crucial role. There exist several emerging desalination technologies which have potential to be run at a near target threshold of $<3.0 \mathrm{~kW}-\mathrm{h} / \mathrm{m}^{3}$. These include FO, MD, PRO, AD, and CDI. The latter however is restricted to BW feeds. Significant improvements have been made in these technologies [148-151]. The Gibbs energy of free mixing puts a theoretical upper limit of extractable energy for any process. For example, the Gibbs free energy of mixing equals the energy available from a reversible PRO process. Nevertheless, a full scale PRO system may operate continuously with constant pressure modules that impose additional constraints on the extractable energy from the system [152]. PRO process utilizes a semipermeable membrane which is placed in between a high concentration draw solution and a low concentration feed solution [153]. The driving force for the process is the chemical potential difference between these two solutions. The membrane allows water molecules to pass from the feed to the draw solution, hence diluting the draw solution over time. Even though PRO technology is as old as the 1970s [154], the process did not receive significant research attention until the past decade $[155,156]$. Several studies suggest that PRO holds immense potential in terms of energy efficiency, power density, flux and cost when compared to its other rivals [157-159]. Nevertheless, PRO alone might not be able to achieve such reductions in energy as expected, and thus, hybrid RO-PRO systems have been proposed for desalination [160-163]. In RO-PRO hybrids, PRO serves two purposes; it simultaneously recovers the energy available from the RO brine stream while contributing to additional power into the system through the available impaired water sources. Straub et al. [164] 
analyzed in their study that a hybrid RO-PRO system is theoretically more favorable for larger quantities of impaired water sources and when medium to low water recoveries are required. It holds potential to reduce the SEC of desalination by half. Because the PRO technology is more favorable when used in conjunction with other technologies such as the RO, Section 6 provides a detailed review on its energy requirements. This section highlights energy requirements of two other emerging desalination processes such as FO and MD. It is important to understand the energy input in such processes for optimized system performances and developments in alternate technologies to RO, MSF and MED.

\subsection{Membrane Distillation (MD)}

Amongst the many upcoming desalination technologies, MD has attracted much attention due to its potential for increased sustainable water production. MD is a membrane based thermal desalination process [165] which uses a hydrophobic membrane to separate hot and cold stream of water. Instead of a pressure or concentration difference, the driving force for the MD processes is the vapor pressure difference across the membrane. The saline feed side is heated prior to contact with the cooled permeate side [166], after which the water evaporates at the membrane-solution interface. Thus, the membrane plays a critical role which prevents the passage of water through it, whilst allowing only water vapors through the membrane pores [167]. This results in a distillate which is of very high quality. One of the key characteristics of the process lies in the fact that its flux and permeate quality are unaffected by the feed salinity up to as high as $200,000 \mathrm{ppm}$. The MD process can harvest low-grade heat energy or waste heat to treat highly saline waters, thus proving to be an important process at the water-energy nexus. However, the feasibility of the MD technology in terms of energy efficiency is a question of great concern as it still remains uncertain. Even after rigorous research in MD technology over the past decades, the energy efficiency of the 
technology remains low compared to the other well-established desalination technologies such as MSF, RO and MED [168]. Nevertheless, ongoing efforts in MD membrane configurations have reported reductions transmembrane heat losses [169].

The energy efficiency of MD process is often limited by the thermal separation of salt from water. For MD, energy has to be input in terms of thermal input (for separation) and electricity (for feed, permeate and brine movement). Nevertheless, Like other thermal processes, evaporation of water consumes a large part of energy input [170]. Again, the SEC is dependent upon the salinity of water, with an average latent heat of vaporization varying around $667 \mathrm{~kW}-\mathrm{h} / \mathrm{m}^{3}$ [171]. This value is clearly higher than the specific Gibbs energy of separation for $35000 \mathrm{ppm}$ water with a $50 \%$ recovery which is $1.07 \mathrm{~kW}-\mathrm{h} / \mathrm{m}^{3}$ (see section 2). The most efficient RO plant today has a SEC which is only about 2-3 times higher than the one imposed by the lower thermodynamic limit. However, it has to be kept in mind that thermal processes such as MD are the most promising candidates for desalinating highly saline brines which the RO technology is not capable of doing so. With the recovery of latent heat, MD process can be tuned for optimized performance lowering the gap between the current SEC and the thermodynamic limit. In addition, just like in RO system which use ERDs, the heat stored in the permeate stream of MD can be utilized to warm up the feed stream, hence recovering more energy from the system. Guillén-Burrieza et al. [172] reported their study on direct contact MD (DCMD) energy consumption with heat recovery in an ideal situation with no losses and a perfect heat recovery. This condition gave a minimum SEC of about $7.7 \mathrm{~kW}$ $\mathrm{h} / \mathrm{m} 3$. This ideal value is far from reality as there exists no thermal process which can satisfy the requirements of thermodynamic reversibility. Like any other thermal desalination process, MD involves simultaneous mass and heat transfer. A highly unlikely scenarios is for a true reversible 
thermodynamic process, in which the driving forces for both mass and heat transfer needs to be zero.

MD energy efficiency is dependent upon several factors including membrane properties, operating conditions, plant capacity and the MD configuration [173, 174]. MD membrane characteristics include high permeability, hydrophobicity, low thermal conductivity and high liquid entry pressure (LEP). A wide spread of data has made it extremely difficult to conclude on the actual energy requirements in MD systems. Various MD configurations also impact the energy efficiency of the MD systems. These configurations include DCMD, sweeping gas membrane distillation (SGMD), vacuum membrane distillation (VMD) and air gap membrane distillation (AGMD). Detailed explanations on these can be found in [175-177]. The most common configuration, DCMD usually employs a heat exchanger for transferring heat from the permeate or retentate line to the feed stream $[178,179]$. The heat exchanger helps in improving MD system's efficiency substantially [167]. Jantaporn et al. [180] reported a detailed analysis on the SEC of DCMD as a function of several variables including membrane properties, system recovery, and operating conditions. Their study concluded a strong dependence of SEC on the recovery rate, and quite a weak dependence on membrane properties and temperature polarization. Two different membranes; Accurel which is a commercial polypropylene (PP) membrane and a lab-made polyvinylidene difluoride (PVDF) membrane were assessed in their study. The effect of hydrodynamic conditions was combined using a fixed temperature polarization on the feed and permeate sides. When they used their system without an external heat exchanger, the energy required to keep the average feed temperature $\left(\mathrm{TF}_{\mathrm{a}}\right)$ at a desired value decreased with an increasing $\mathrm{TF}_{\mathrm{a}}$, however it was reported to slightly increase in the presence of temperature polarization, owing to a higher conductive heat flux. The difference in bulk and membrane surface temperatures is known as temperature 
polarization, which plays a yet important role in mass and heat transfer across an MD membrane [181]. Nevertheless, a high performance membrane gives a lower conductive flux, requiring less internal energy required. Fig. 15a depicts the total SEC as a function of recovery for PVDF and Accurel with and without temperature polarization. The red and green solid lines in the Fig. 15a represent internal energies at $80^{\circ} \mathrm{C}$ and $35^{\circ} \mathrm{C}$ respectively. It can be inferred that at lower recovery rates, the SEC decreases dramatically because the energy required to heat the whole module inlet forms a significant portion of the total energy requirement. Nevertheless, the recovery rate remains almost constant for large recovery rates. A DCMD system can be said to be energy efficient when a high performance membrane is used. Also, preheating of the feed at high temperatures provided a higher yield when the recovery rate exceeded $10 \%$. At a lower recovery rate, their MD system needed a lower membrane area (which also implied less cost), while at a higher recovery, more SEC was required. Thus, this puts the MD technology in a position where a trade-off is necessary between the cost of the material and the energy. Clearly, this tends to drift towards higher recoveries as depicted by their study in Fig. 15b. Their [180] study also included DCMD specific energy requirements when a heat exchanger was involved. A heat exchanger was used to recover a part of the spare heat readily available in the distillate or retentate line [182]. Fig. 15c and Fig. 15d show SEC of the DCMD systems with a heat exchanger from distillate and retentate streams respectively using an Accurel membrane with no temperature polarization. The figures clearly reflect that the impact of using a heat exchanger decreases with an increasing recovery rate. Between the two lines, a clear advantage was formulated when the heat exchanger was used in the retentate line due to a higher temperature encountered. 

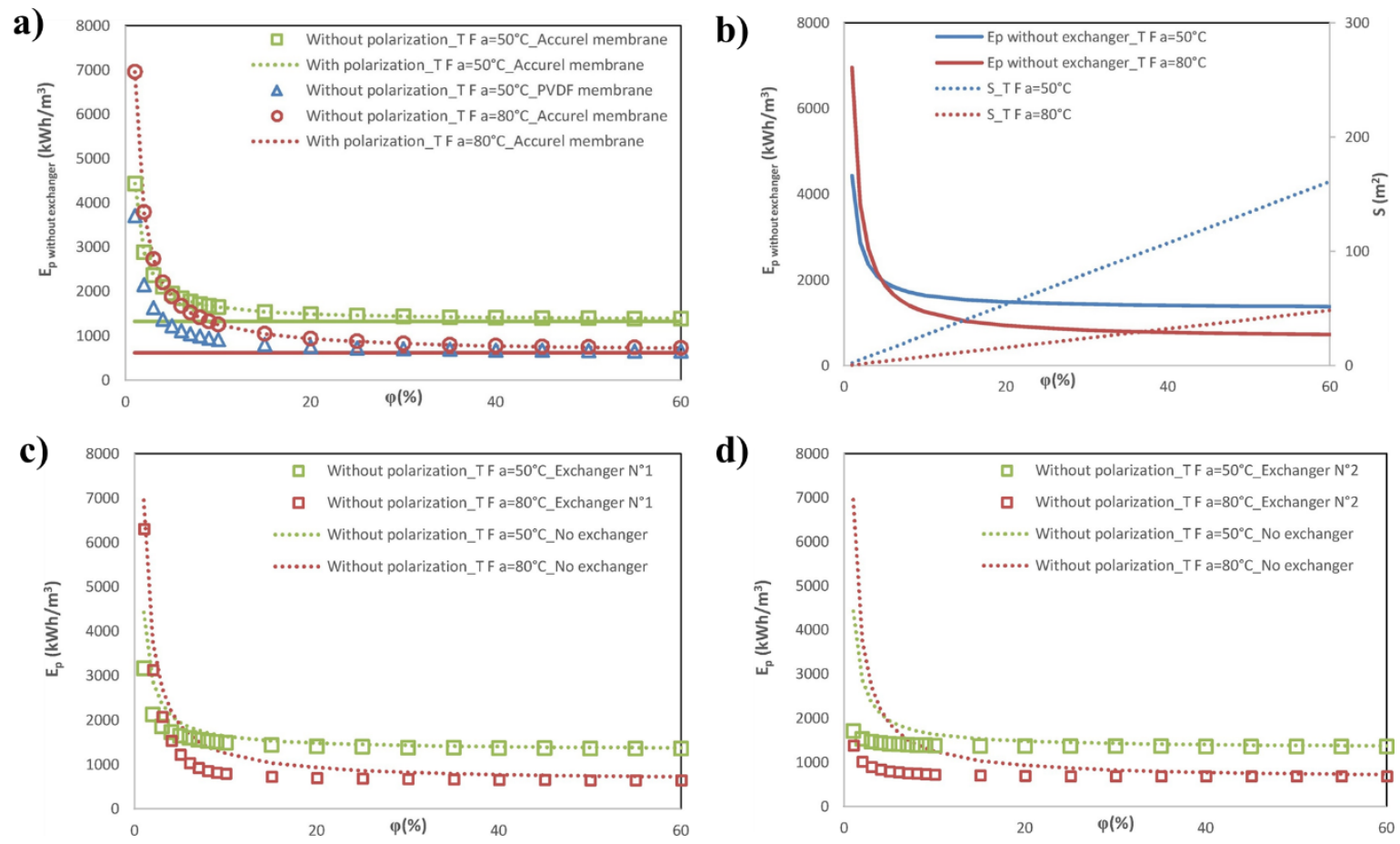

Fig. 15. (a) SEC as a function of recovery rate for MD systems when an external heat exchanger is not used, (b) SEC and membrane area as a function of recovery rate for MD when an external heat exchanger is not used, (c) SEC as a function of recovery rate for MD with an external heat exchanger with heat recovery from the distillate stream and no temperature polarization is not considered. (d) SEC as a function of recovery rate for MD with an external heat exchanger with heat recovery from the retentate stream and no temperature polarization is not considered [180]. Copyright (C) 2017, Elsevier.

Stressing further on the importance of membrane properties which determines the resistance to mass and heat transfer, the thermal efficiency $\left(\eta_{\mathrm{th}}\right)$ of the membrane can be determined by the convective heat flux divided by the total heat flux, $\left(\mathrm{Q}, \mathrm{W} / \mathrm{m}^{2}\right)[183,184]$ :

$$
\eta_{\mathrm{th}}=\frac{J \Delta H v[T p]}{Q} \quad \text { Equation } 4
$$

Where $\mathrm{J}$ is the water flux $\left(\mathrm{L} / \mathrm{m}^{2} . \mathrm{h}\right) \Delta H_{v}$ is the latent heat of water $(\mathrm{kJ} / \mathrm{mol})$, and Tp is the permeate temperature $(\mathrm{K})$. MD membranes with a high thermal efficiency have negligible mass transfer resistance. Apart from inherent membrane properties, membrane morphology plays a critical role. Increasing membrane porosity produced a significant impact on the system's exergetic 
performance, however with the cost of mechanical robustness [185]. In addition, reduction in membrane thickness lead to an increase in exergy efficiency, owing to a reduction in entropic losses. However, it was also reported that below a certain thickness, 50-100 $\mu \mathrm{m}$, exergy efficiency drops due to an increase in the wasteful conductive heat transfer. Keeping in mind the importance of membrane optimization for higher MD performance in terms of its energy requirements, Table 10 lists various MD membranes and their corresponding SEC. The Table also highlights MD configurations for each study. As can be seen from Table 10, other MD configurations such as AGMD has potentially shown better energy efficiency due to improved heat recoveries [186-188]. In AGMD, the cold source cools a condensing plate on the permeate line, after which the feed is heated by passing along this condensing plate before flowing across the membrane. The water passing through the membrane gets collected on the condensate plate. Several studies suggest superior performance of AGMD configuration over DCMD for high saline waters [177, 189]. Additional advantages of AGMD include more compactness owing to no heat exchangers in the overall system.

Table 10. SEC of various MD membranes.

\begin{tabular}{|c|c|c|c|c|}
\hline MD membrane & $\begin{array}{c}\text { MD } \\
\text { configuration }\end{array}$ & SEC (kW-h/m $\mathbf{~})$ & $\begin{array}{c}\text { Plant capacity } \\
\left(\mathbf{m}^{\mathbf{3}} \mathbf{h}\right)\end{array}$ & Ref \\
\hline Commercial membranes & DCMD & $\sim 697$ to 10,457 & - & {$[190]$} \\
\hline Spiral wound PTFE & DCMD & $600-1600$ & 0.05 & {$[191]$} \\
\hline PTFE & AGMD & $140-200$ & $0.2-20$ & {$[174]$} \\
\hline PVDF hollow fiber & DCMD & $\sim 130$ to 1700 & - & {$[192]$} \\
\hline PTFE with PP support & DCMD & 1500 & 3.85 & {$[193]$} \\
\hline
\end{tabular}




\begin{tabular}{|c|c|c|c|c|}
\hline $\begin{array}{c}\text { Low density polyethylene } \\
\text { (LDPE) }\end{array}$ & AGMD & $\sim 65$ to $\sim 127$ & $0.0034-0.0094$ & {$[194]$} \\
\hline PP & VMD & $8100.8-9089.5$ & $2.67-6.94$ & {$[195]$} \\
\hline PTFE & AGMD & $200-300$ & $3.46-19$ & {$[196]$} \\
\hline
\end{tabular}

It is evident from Table 10 that the overall specific energy requirement of MD is extremely high compared to other technologies such as MSF $\left(70 \mathrm{~kW}-\mathrm{h} / \mathrm{m}^{3}\right)$ and RO $\left(3-7 \mathrm{~kW}-\mathrm{h} / \mathrm{m}^{3}\right)$. Deshmukh et al. [168] compared various desalination technologies in terms of energy efficiency, level of pretreatment required, fouling and selectivity. Fig. 16a shows that MD surpasses some characteristics when compared to other technologies such as treatment of high salinity feeds and system compactness $[1,9,197,198]$. They [168] also compared the impact of system capacity on the GOR and SEC for MD, MED and MSF. GOR represents the enthalpy of vaporization multiplied by the mass flow of pure water divided by the heat input into an MD system. Where latent heat may be recovered such as by using heat exchangers and other means, a GOR $<1$ is usually attained. It is interesting to note that GOR in MD is largely independent of the system size, unlike in MED and MSF where the SEC, cost and other system characteristics heavily rely on system size (Fig. 16b). Thus these technologies cannot be used on ships, where they are limited to a single stage or effect, hence providing low performance efficiencies. Thus, for small-scale systems ( $<1000 \mathrm{~m}^{3} /$ day), MD's performance is much superior to MSF and MD in terms of energy. However, for large-scale, MD technology needs substantial research and technological advancement in terms of membrane and system designs $[9,36,199]$. There is variant literature linking the energy efficiency of MD with its water cost [76, 197, 200-204], as shown in Fig. 16c. These values confirm to the fact that over the past years, variability in the reported SEC has 
increased considerably. There is variant literature linking the energy efficiency of MD with its water cost [76, 197, 200-204]. These large variations are mostly due to the varying operating conditions and non-standardized cost analysis [205, 206]. Many researchers argue that minimizing MD's SEC might not necessarily reduce the associated water cost. In addition, because other desalination technologies are so well-established and commercialized, reliable data comparing MD with those technologies restrict cost comparisons and hence forms a gap in consistency of data [207].

a)

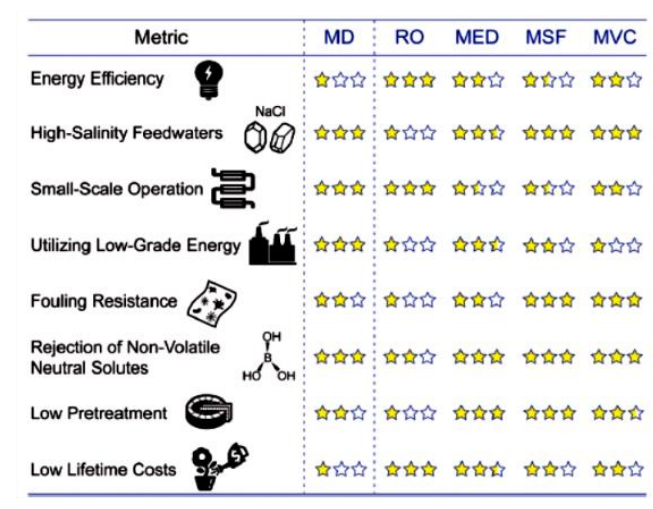

b)

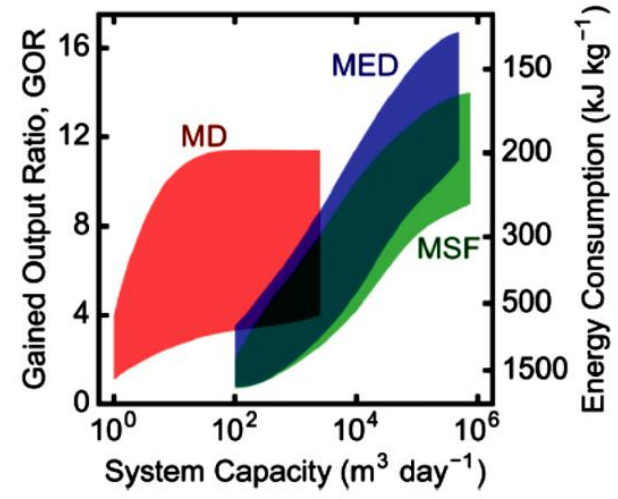

c)

\begin{tabular}{|c|c|c|c|c|c|c|c|c|c|c|c|c|}
\hline MD configuration & AGMD & NF/RO/DCMD & VMD & LGMD & AGMD & LGMD & LGMD & AGMD & VMD & AGMD & DCMD & DCMD \\
\hline $\operatorname{SEC}\left(k W-h / m^{3}\right)$ & 1.25 & 2.58 & 3.2 & $68.8-49.2$ & $\approx 1$ & $\approx 1$ & $8100.8-9079.5$ & 6.8 & 109.2 & 90 & 58 & 1037 \\
\hline Year & 1983 & 1999 & 2003 & 2005 & 2007 & 2008 & 2009 & 2011 & 2013 & 2016 & 2018 & 2019 \\
\hline
\end{tabular}

Fig. 16. (a) Qualitative comparison of MD with other technologies where one star refers to poor and three stars refer to excellent, (b) GOR and SEC as a function of system capacity. Reproduced from Ref [168] with permission from The Royal Society of Chemistry. (c) Variation in SEC for MD systems reported over the years. Data is taken from [194, 208-216].

Nevertheless, MD has huge potential in treating highly saline brines, those above $80,000 \mathrm{ppm}$, which are practically impossible to do so through RO [217]. In addition, the compactness of the setup and the advantage of running it through sustainable energy sources makes MD a further 
attractive technology for desalination. Hence, it is important for researchers to realize the urgent need in investing resources for finding factors impacting the water cost in MD including MD configurations, pretreatment requirements, operating conditions and membrane performance. More importantly, to reliable compare MD with other desalination technologies for its economic viability, standardization in cost calculations should be facilitated. One solution to optimized performance and energy might lie in hybridization with other technologies.

\subsection{Forward Osmosis (FO)}

FO is an another emerging technology which has been a target of great research and discussion over the past years $[218,219]$. The process involves separation of solutes from water through a difference in the osmotic pressure gradient. Water flows through a semi-impermeable membrane from a lower-osmotic pressure feed solution into a higher-osmotic pressure draw solution. Significant progress has been made in FO technology in terms of increasing the flux, with several novel FO membrane being commercialized recently [119]. Even though FO hold great potential to desalt SW at low pressures $[220,221]$, the energetics involved are usually not favorable. McGinnis and Elimelech [26] predicted the energy requirements of ammonia-carbon dioxide FO desalination by using a process modeling software. They calculated the thermal and electrical energy requirements of the FO process with single and multiple distillation columns for the separation of solute in the draw solution from the product water. Fig. 17a shows the equivalent work of the FO desalination process relative to temperature. The equivalent work was seen to increase with the quality of heat supplied. Fig. 17b shows the relationship between the supplied heat and the draw solution concentration. Two operating columns, a multi stage distillation at $160^{\circ} \mathrm{C}$ and a single vacuum distillation column operating at $40-44^{\circ} \mathrm{C}$ were compared. The vacuum distillation column was concluded as the most efficient distillation method for equivalent work, 
due to its usage of low quality heat. In addition, they also compared their simulation results with the existing desalination technologies such as MSF, LT-MED (low temperature MED), MEDTVC and FO-LT (single column low temperature vacuum FO), as shown in Fig. 17c. Ammoniacarbon dioxide FO process was projected to save about $72 \%$ to $85 \%$ of the energy savings (Table 11). The draw solute concentration used was $1.5 \mathrm{M}$, with reduced values leading to significant additional energy reductions in the FO equivalent work.

a)

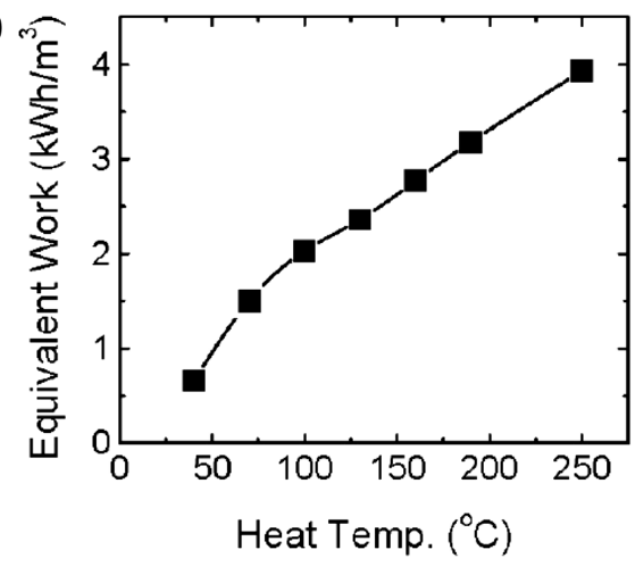

c)

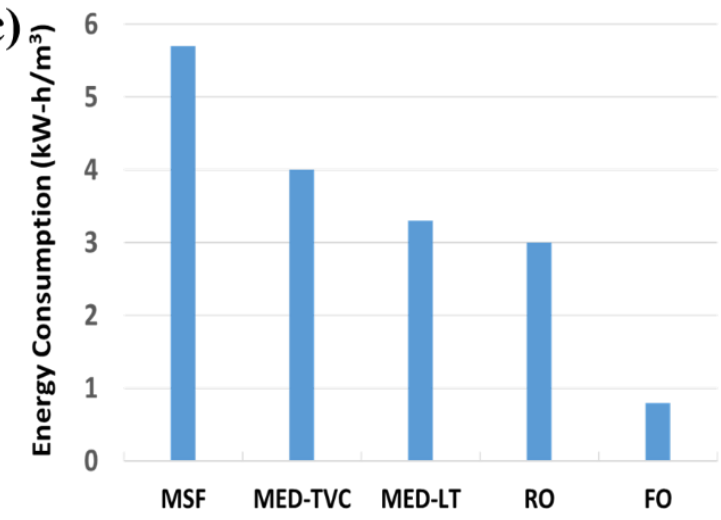

b)

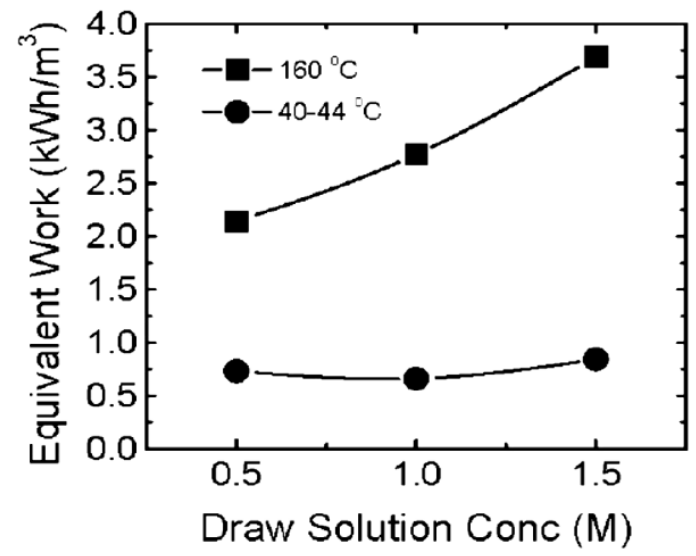

d)

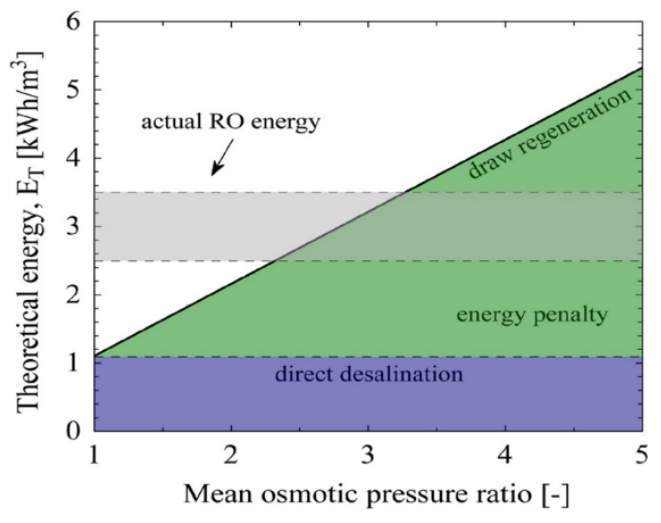

Fig. 17. (a) Equivalent work of FO as a function of supplied heat, (b) Influence of draw solute concentration on FO equivalent work, (c) Comparison of energy consumption between FO and other leading SW desalination technologies [26] Copyright (C) 2007, Elsevier and (d) Effect of the energy efficiency of the FO draw regeneration on the overall energy requirements [222] Copyright (C) 2014, Elsevier. 
Table 11: Energy requirement comparisons of low temperature ammonia-carbon dioxide FO process. with current SW desalination technologies. Adapted from Ref [26].

\begin{tabular}{|c|c|c|c|c|c|}
\hline Technology & GOR & $\begin{array}{c}\text { Electrical } \\
\text { energy }(\mathbf{k W}- \\
\left.\mathbf{h} / \mathbf{m}^{\mathbf{3}}\right)\end{array}$ & $\begin{array}{l}\text { Steam } \\
\text { pressure } \\
\text { (psi) }\end{array}$ & $\begin{array}{c}\text { Energy } \\
\text { consumption } \\
\left(\mathbf{k W}-\mathbf{h} / \mathbf{m}^{\mathbf{3}}\right)\end{array}$ & $\begin{array}{c}\text { Percent energy savings } \\
\text { using low temperature } \\
\text { FO }(\%)\end{array}$ \\
\hline MSF & 12 & 2.65 & 25.7 & 5.66 & 85.1 \\
\hline MED-TVC & 14.73 & 1.60 & 25.7 & 4.05 & 79.2 \\
\hline LT-MED & 12 & 1.60 & 6 & 3.21 & 73.8 \\
\hline RO & $\mathrm{n} / \mathrm{a}$ & 3.02 & $\mathrm{n} / \mathrm{a}$ & 3.02 & 72.1 \\
\hline FO $(1.5 \mathrm{M})$ & 4.4 & 0.24 & 1.07 & 0.84 & - \\
\hline
\end{tabular}

On the contrary, McGovern et al. [222] critically analyzed and compared the theoretical and actual energy efficiency between FO and RO. They argued that RO is much more energy efficient than FO for SW desalination, and that current research efforts on FO should in turn be directed for possible FO alternate applications [223-225]. They compared FO and RO in terms of their thermodynamic efficiencies $\left(\bigcap_{R}\right)$ by fixing certain parameters such as salinity of 35,000 ppm and recovery rate of $50 \%$. For RO, Equation 5 was used which is basically the ratio of theoretical energy $(\mathbf{J})$ and actual energy $(\mathrm{J})$ required to convert certain amount of feed water into product water [226]:

$$
\eta_{\mathrm{R}}^{\mathrm{RO}}=\frac{\mathrm{E}_{\mathrm{T}}^{\mathrm{RO}}}{\mathrm{E}^{\mathrm{RO}}}=\frac{\frac{1}{\mathrm{RR}^{\mathrm{tot}, \mathrm{RO}} \int_{0}^{\mathrm{RR}}{ }^{\mathrm{tot}, \mathrm{RO}} \pi_{\mathrm{SW}}(\mathrm{RR}) \mathrm{dRR}}}{\mathrm{E}} \quad \text { Equation 5: }
$$

For FO, the efficiency included the osmotic pressure $(\pi)$ of the draw solution instead of the osmotic pressure of SW: 


$$
\eta_{\mathrm{R}}^{\text {regen }}=\frac{\mathrm{E}_{\mathrm{T}}^{\text {regen }}}{\mathrm{E}^{\text {regen }}}=\frac{\frac{1}{\mathrm{RR}^{\text {tot,regen }}} \int_{0}^{\mathrm{R} \mathrm{R}^{\text {tot,regen }}} \pi_{\mathrm{draw}}(\mathrm{RR}) \mathrm{dRR}}{\mathrm{E}^{\text {regen }}} \quad \text { Equation } 6
$$

$E^{\text {regen }}(\mathrm{J})$ describes the required exergy for driving the actual regeneration process. Fig. 17d compares the energy consumption between RO and FO. The green area depicts the actual energy penalty which was calculated by dividing the theoretical energy penalty by the FO/RO desalination efficiency. It signifies that the actual energy consumed by the FO process is always greater than the RO process. For a comprehensive comparison between the two technologies, they [222] also compared the energy requirements of an FO system to that of a two-pass RO system which included a pretreatment step. Table 12 shows the results of their study, which suggests comparatively lower irreversible fouling rates for FO [227]. When assumed that the FO draw regeneration process was equally as efficient as to the $\mathrm{RO}$, an energy of $3.48 \mathrm{~kW}-\mathrm{h} / \mathrm{m}^{3}$ was required compared to $2.34 \mathrm{~kW}-\mathrm{h} / \mathrm{m}^{3}$ for the first RO pass. Even with a second RO pass, the total energy consumption of FO came out to be greater than the overall RO process.

Table 12. Comparison of energy consumption between FO and two-pass RO process. Adapted from [222].

\begin{tabular}{|c|c|c|c|}
\hline \multicolumn{2}{|c|}{ Two-pass RO } & \multicolumn{2}{|c|}{ FO } \\
\hline UF & $\mathbf{k W}-\mathbf{h} \mathbf{m}^{\mathbf{3}}$ & & $\mathbf{k W}-\mathbf{h} / \mathbf{m}^{\mathbf{3}}$ \\
\hline RO- $\mathbf{1}^{\text {st }}$ pass & 0.16 & Diluted draw & 0.10 \\
\hline RO-2 $^{\text {nd }}$ pass & 2.34 & Regenerated draw & 3.48 \\
\hline Total & 0.50 & - & - \\
\hline
\end{tabular}


Mazlan et al. [228] also used a customized simulation software to compare the SEC of FO and RO. Various process variables were considered, including an UF pretreatment step. Fig. 18 compares a single-pass RO, FO with NF recovery, FO with a two-pass NF recovery, two-pass RO, FO-UF hybrid and an FO-distillation hybrid in terms of their SEC and specific membrane areas. The comparisons were made at $50 \%$ and $75 \%$ product recoveries. Energy contributions from the pretreatment stage, low pressure pumps (LPPs), HPPs, ERD and distillation are detailed in Fig. 18. Their results obtained for the RO simulations were consistent with the literature studies [45]. At $50 \%$ recovery, the FO stage energy consumption was low, $\sim 0.11 \mathrm{~kW}-\mathrm{h} / \mathrm{m}^{3}$. This was attributed to the absence of any hydraulic pressure requirements and the fact that the LPP only needed to overcome feed channel pressure drops. The SEC of processes at 50\% product recovery are found to decreasing in the order of two-pass $\mathrm{RO}<$ single-pass $\mathrm{RO}<\mathrm{FO}$ with two-pass $\mathrm{NF}$ recovery $<$ FO with NF recovery. Nevertheless, not much difference was observed between FO with NF recovery and the RO process at 50\% recovery. However, a high membrane area was required for FO to obtain a similar SEC to RO. This factor needs to be taken into account when cost analysis and comparisons are carried out. No difference was seen between FO with two-pass NF recovery process at $75 \%$ product recovery. The $\mathrm{CO}_{2}-\mathrm{NH}_{3}$ draw solution recovery process utilizing distillation [26] as detailed in the above discussions showed the lowest SEC compared to all the other processes. However, the purity of the product water was compromised. It should be mentioned here that even with the FO, NF and RO membranes giving $100 \%$ rejection and infinite permeability, the SEC would be little affected. Hybrid FO processes have immense potential to operate at high product recoveries and lower energy consumptions. Other FO hybrid alternative may include FO-low pressure RO [229] which is achieved through indirect desalination by diluting SW with wastewater. Also, just like MD, FO hybrids are considered as a future technology for 
treating high salinity feeds which cannot be achieved by RO. The process can be cost optimized if a low-cost thermal energy process is considered for the draw solution regeneration step.

The FO technology has seen a large boom in this past decade with several studies focusing on optimizing FO membranes [230-234] and draw solutions [235-239]. One potential energy efficient draw solution is super hydrophilic nanoparticles which can be fully recovered through UF after use. This recovery in turn positively affects the transmembrane pressures requirements when compared to RO for draw solution regeneration [240]. A rough calculation showed that a FO-UF system operating at $75 \%$ product recovery, using an ERD a consumed $3.2 \mathrm{~kW}-\mathrm{h} / \mathrm{m}^{3}$. This value was much higher than the $\mathrm{CO}_{2}-\mathrm{NH}_{3}$ recovery process, and similar to the FO-NF recovery process. The FO-UF energy consumption requirements are also expected to be similar to FO-RO hybrid and RO stand-alone processes [241]. Nevertheless, a further research is necessitated in this direction by inquiring potential hydrophilic nanoparticles such as aluminosilicates [242, 243], silica [244], carbon-based [245], and various metallic nanoparticles [246, 247]. 


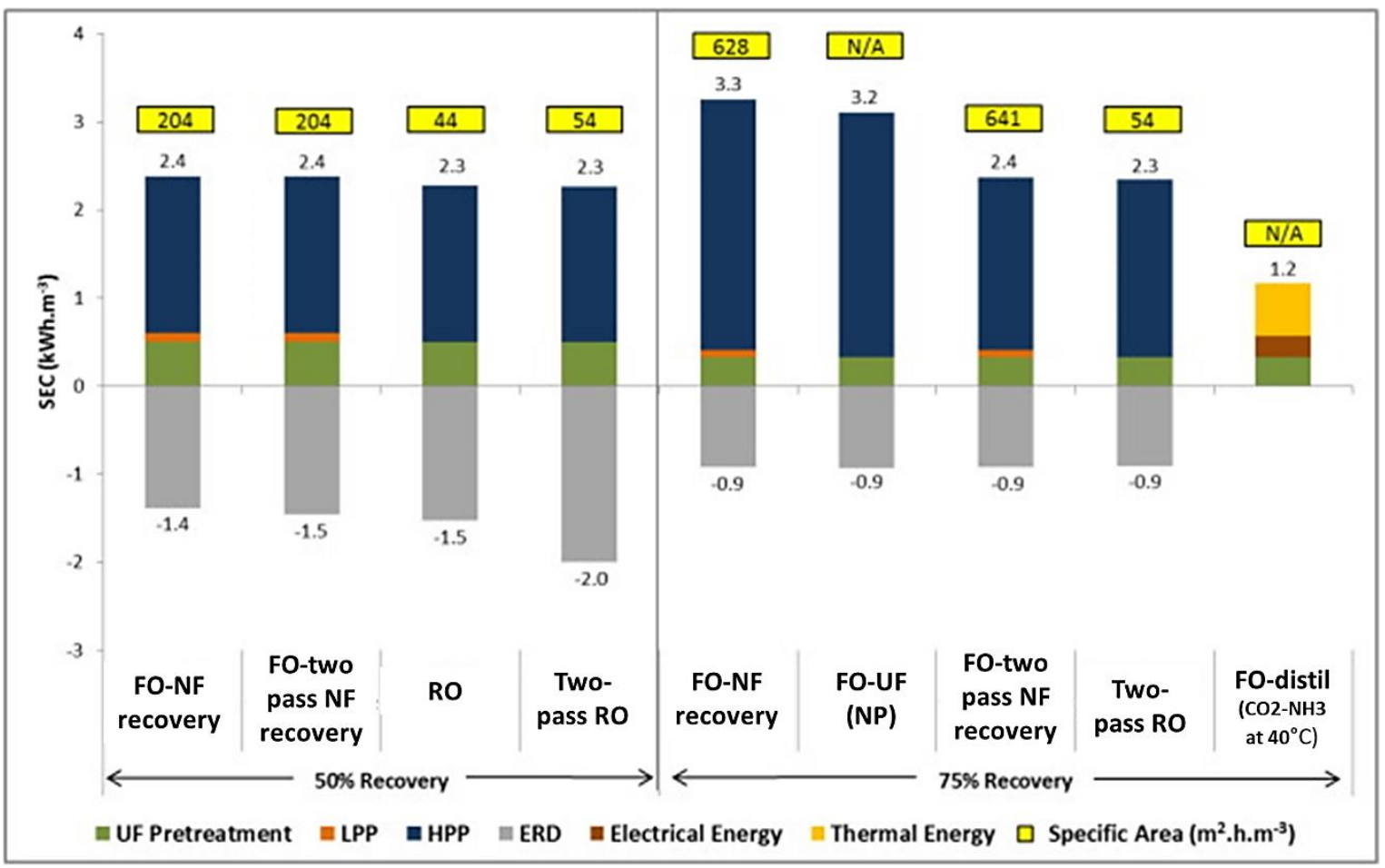

Fig. 18. Comparison of SEC and specific membrane area for FO and several other stand alone and hybrid technologies [228]. Copyright @ 2016 , Elsevier.

\section{Hybrid desalination technologies: a solution for improved energy efficacy?}

\subsection{Hybrid reverse osmosis systems}

Due to advances in membrane technology and implementation of efficient ERDs and HPPs, energy required in a typical SWRO has reached as low as $2 \mathrm{~kW}-\mathrm{h} / \mathrm{m}^{3}$ at $50 \%$ recovery, [248]. Advances in the RO process for energy reductions might have reached its limit as the current SWRO energy figures are approaching the minimum practical energy needed for SW desalination [248]. Other alternatives such as hybridization must be targeted to enhance the overall energy efficiency of SWRO. 


\subsubsection{Osmotic dilution by forward osmosis}

HPPs are the major energy consumers in any SWRO process. The high energy consumption in HPPs is ought to the applied pressure required to overcome the osmotic pressure of SW. Reducing the energy requirements in HPPs can be realized by decreasing the osmotic pressure of the feed. This is achievable by diluting the SW feed using FO [249, 250]. In some FO-RO hybrid systems, SW is used as the draw solution in the FO stage and low salinity wastewater is used as the feed [229, 251]. Yangali-quintanilla et al. [229] performed a long-term, 14 days test on FO-RO process with a secondary wastewater effluent feed and SW from the red sea draw solution. The results showed that the hybrid system consumed $1.5 \mathrm{~kW}-\mathrm{h} / \mathrm{m}^{3}$ which is approximately half the amount of energy required in a typical standalone SWRO process $\left(2.5-4 \mathrm{~kW}-\mathrm{h} / \mathrm{m}^{3}\right)$. They also conducted a cost analysis which showed that the hybrid FO-RO system is economically feasible only when the water flux in the FO stage is at least $5.5 \mathrm{~L} / \mathrm{m}^{2}$-h. In another study, Choi et al. [252] evaluated the performance of a pilot-scale FO-RO process during 5 months of testing in terms of fouling behavior and energy requirements. The results showed that fouling of the RO membrane in the FO-RO system was reduced compared to SWRO alone. Also, the integration of FO reduced the energy consumption by $15 \%$ relative to typical SWRO.

The performance of FO-RO hybrid systems was analyzed also using numerical modelling. Seo et al. [251] developed a numerical model for FO-RO process to compare its performance to the standalone SWRO. Fig. 19a shows how the SEC changes over a wide range of RO applied pressure. The SEC reduction in FO-RO relative to standalone RO is dependent on the applied pressure in RO. The reduction becomes more significant at lower applied pressures or in other words when the draw solution fed to the RO system is more diluted. The performance of FO-RO 
system is better than standalone RO also in terms of recovery rate (Fig. 19b). The difference in recovery rate between the hybrid and RO systems increases as the RO applied pressure decreases.
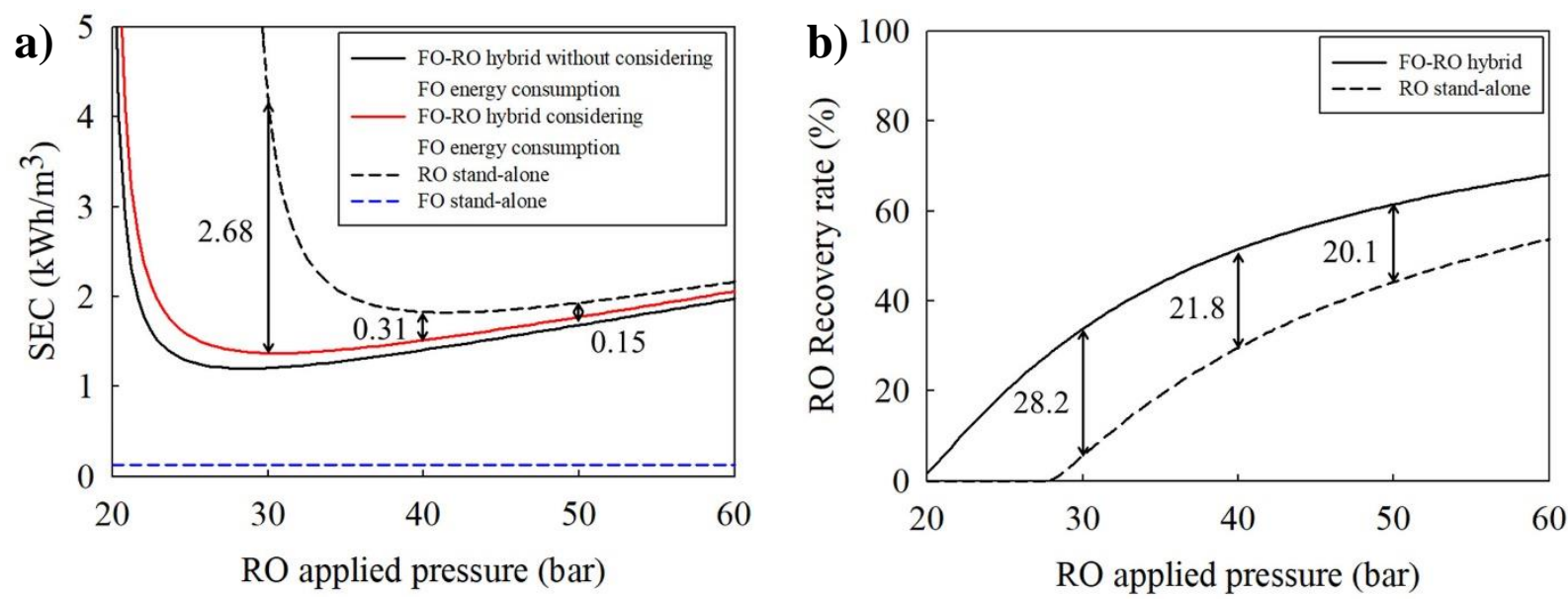

Fig. 19. Comparison between hybrid FO-RO and standalone RO in terms of a) SEC and b) RO recovery [251]. Copyright @ 2019, Elsevier.

Fair evaluation of the FO-RO process relative to standalone RO should involve cost analysis which accounts for capital and operating costs. The economic feasibility of FO-RO process was evaluated by Choi et al. [253]. The effects of several operation and process factors on the water cost was analyzed. The results showed that the cost of fresh water produced from the FO-RO system is mainly dictated by the flux and recovery of the FO stage. In order for the FO-RO process to be economically more feasible than standalone RO, the flux and recovery of FO membranes should be high. Similarly, Blandin et al. [254] assessed the economic feasibility of FO-RO. Their results showed that, compared to RO, economic savings are not achievable in hybrid FO-RO process with FO flux of $5-10 \mathrm{~L} / \mathrm{m}^{2}-\mathrm{h}$. FO flux of $30 \mathrm{~L} / \mathrm{m}^{2}-\mathrm{h}$ is required for the hybrid process to become economically more feasible than RO. The authors also proposed a possible approach to achieve this high flux by using pressure assisted forward osmosis (PAFO). At first glance, one might think 
that using PAFO instead of FO in the hybrid system would reduce the economic savings due to the added energy required for feed pressurization. However, the required membrane surface area in PAFO is 3 times lower than FO. Thus, capital expenditures in PAFO are lower than FO. Also, for overall cost savings, the results indicated that the applied pressure on the PAFO stage should not exceed 6 bar.

A hybrid FO-RO process which uses wastewater to dilute SW seems to be an attractive alternative to conventional SWRO. Firstly, this scheme combines desalination with water reuse [253, 255]. Secondly, it requires less SEC than standalone SWRO. Third, scaling and membrane fouling are less as SW is diluted before being pressurized against the RO membrane. Despite these advantages, there are some limitations that need to be considered for this hybrid technology to become commercialized. The wastewater and desalination plants should coexist at the same site to avoid additional costs and reduced process efficiency. Also, to ensure economic feasibility of the process, we should focus on designing high flux FO membranes. Moreover, the amount of wastewater feed required for dilution is high. In order to achieve $50 \% \mathrm{FO}$ recovery to theoretically save $0.63 \mathrm{~kW}-\mathrm{h} / \mathrm{m}^{3}$ of energy, the amount of wastewater feed should be double the amount of SW. Obtaining this amount of wastewater in large-scale desalination plants is challenging [249].

Another approach for coupling FO with RO is by recycling the rejected brine in $\mathrm{RO}$ to be used as the concentrated draw solution in FO (Fig. 20a). In this hybrid scheme, FO acts as a pretreatment stage for RO. This type of hybrid systems can be used to produce agricultural irrigation water. SWRO for agricultural irrigation consumes more energy than SWRO for potable use. This is because additional post-treatment is required to meet the restrictive boron and chloride standards for agricultural irrigation water. According to the World Health Organization, the concentrations of boron and chloride in potable water should be less than $2.4 \mathrm{ppm}$ and $250 \mathrm{ppm}$, respectively 
[256]. These values are even lower for agricultural irrigation water in which the boron and chloride concentrations should be less than $0.5 \mathrm{ppm}$ and $105 \mathrm{ppm}$, respectively [257]. Shaffer et al. [258] created a model for the FO-RO process and 2-stage RO to study the changes in SEC and total membrane area as a function of total system recovery (Fig. 20b). It is important to note that in the FO-RO process, pretreatment was achieved by FO membranes and post-treatment was not required. Also, in the 2-stage RO model, pretreatment energy was assumed to be $0.15 \mathrm{~kW}-\mathrm{h} / \mathrm{m}^{3}$ and in the FO-RO model, the energy required in FO was assumed to be equal to UF [255, 259]. The results showed that SEC in FO-RO is lower than 2-stage RO at all recoveries. This reduction in SEC is attributed to the decrease in the osmotic pressure of feed water entering the RO system. However, this reduction in energy is associated with increased total membrane area which in return affects the total capital cost of the process. Given the reduction in SEC and operating cost, the payback period for capital expenditures for each $\mathrm{m}^{3}$ of produced fresh water with the FO process is expected to be shorter than RO systems with UF pretreatment. The authors chose to compare the hybrid FO-RO with 2-stage RO which consumes more energy than single pass RO. This is because post-treatment ( $2^{\text {nd }}$ RO stage) as well as pretreatment were replaced with FO. Since the quality of fresh water produced by FO-RO is comparable to that produced by 2-stage RO, comparing FO-RO to 2-stage $\mathrm{RO}$ rather than single pass $\mathrm{RO}$ is more reasonable. 

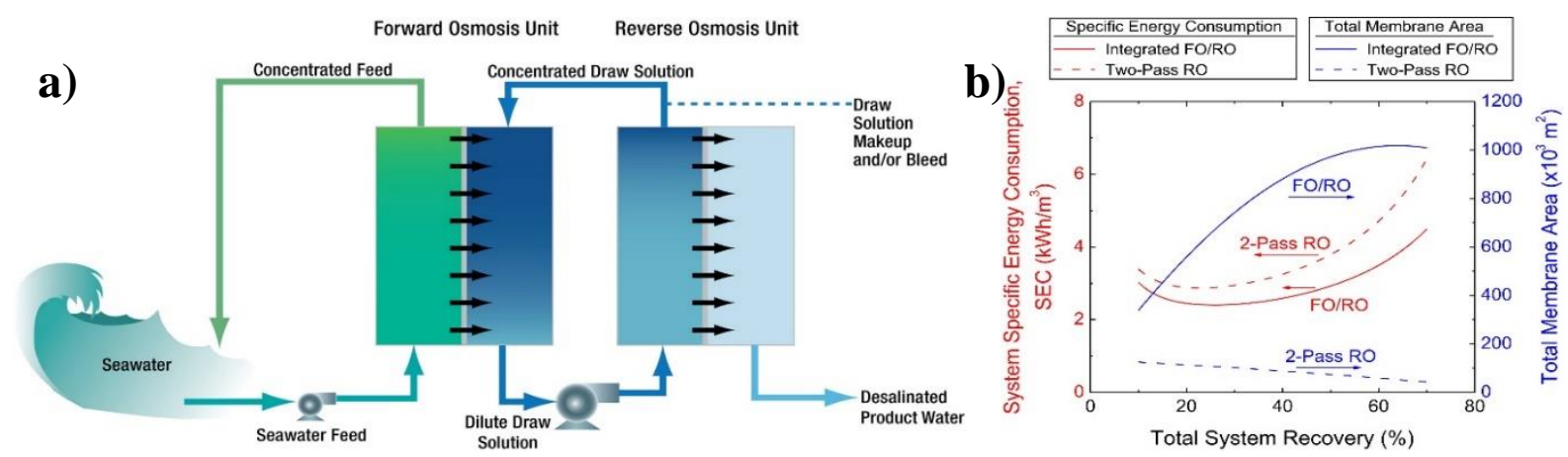

Fig. 20. a) Schematic diagram for an integrated FO-RO process, b) Comparison between the 2-stage RO and FO-RO process in terms of SEC and total membrane area as a function of total system recovery

[258]. Copyright (C) 2012, Elsevier.

\subsubsection{Energy recovery from brine by pressure retarded osmosis}

The rejected brine in RO carries osmotic energy which if harvested can reduce the SEC of the process [139]. Utilizing the osmotic power in the brine can be achieved using PRO [260]. With the integration of PRO in RO technology, brine can be considered as a source of energy rather than just waste [260]. The basic principle of energy recovery from brine is based on salinity gradient energy (SGE) which is the energy produced when two solutions with different salt concentrations are mixed [261]. In a typical PRO process, water from fresh water or low salinity wastewater passes through the membrane to be mixed with brine on the other side [262]. Meanwhile, pressure is applied on the brine side and hydraulic energy is generated from Gibbs free energy of mixing [263]. Hydraulic energy can be either converted to mechanical energy by PX [163, 264] or electrical energy by hydro-turbine [265]. It is important to note that water permeation across the membrane continues as long as the difference in osmotic pressure between the solutions is higher than the applied pressure on the brine side.

Back in 1998, Sidney Loeb [266] proposed the simplest hybrid SWRO-PRO system in which brine from SWRO was used as the draw solution in PRO. Following his work, many studies have 
focused on integrating PRO with SWRO in order to reduce the overall SEC of the SWRO process which in return affects the cost of desalination. Prante et al. [163] investigated the potential for saving energy in SWRO-PRO compared to state-of-the-art SWRO by modeling SWRO-PRO system. Total SEC of the hybrid system as a function of PRO dilution at different RO recoveries is shown in Fig. 21a. Positive values indicate that the system produces energy whereas, negative values indicate that it consumes energy. SEC approaches zero when all the energy consumed in the SWRO stage is recovered in the PRO stage. This is only achievable assuming a thermodynamically reversible process (ideal). As the PRO dilution increases, more energy is recovered and less SEC is required. At higher RO recoveries, SEC is higher. The results showed that at $50 \%$ RO recovery, the minimum overall SEC of the hybrid SWRO-PRO system was 1.2 $\mathrm{kW}-\mathrm{h} / \mathrm{m}^{3}$ which is $40 \%$ lower than standalone SWRO. In another study, Chun et al. [267] developed a mathematical model to compare the performance of a hybrid SWRO-PRO system with standalone SWRO in terms of SEC. PX was used to convert the hydraulic pressure of brine in PRO to mechanical energy to be used for pressurizing SWRO feed. As shown in Fig. 21b, the minimum SEC of SWRO-PRO with PX $\left(\eta_{P}=80 \%, \eta_{E}=90 \%\right)$ is $1.08 \mathrm{~kW}-\mathrm{h} / \mathrm{m}^{3}$ at $25 \%$ RO recovery and $1.14 \mathrm{~kW}-\mathrm{h} / \mathrm{m}^{3}$ at $50 \% \mathrm{RO}$ recovery. These values are $40 \%$ and $50 \%$ lower than SEC of SWRO with PX at 25\% and 50\% RO recovery, respectively. RO-PRO hybrid system was also tested in pilot-scale plant as part of the Japanese Megaton Water System project. The RP-PRO process achieved a $10 \%$ reduction in SWRO energy using PRO membrane with power density of $13.3-13.5 \mathrm{~W} / \mathrm{m}^{2}[268,269]$. 

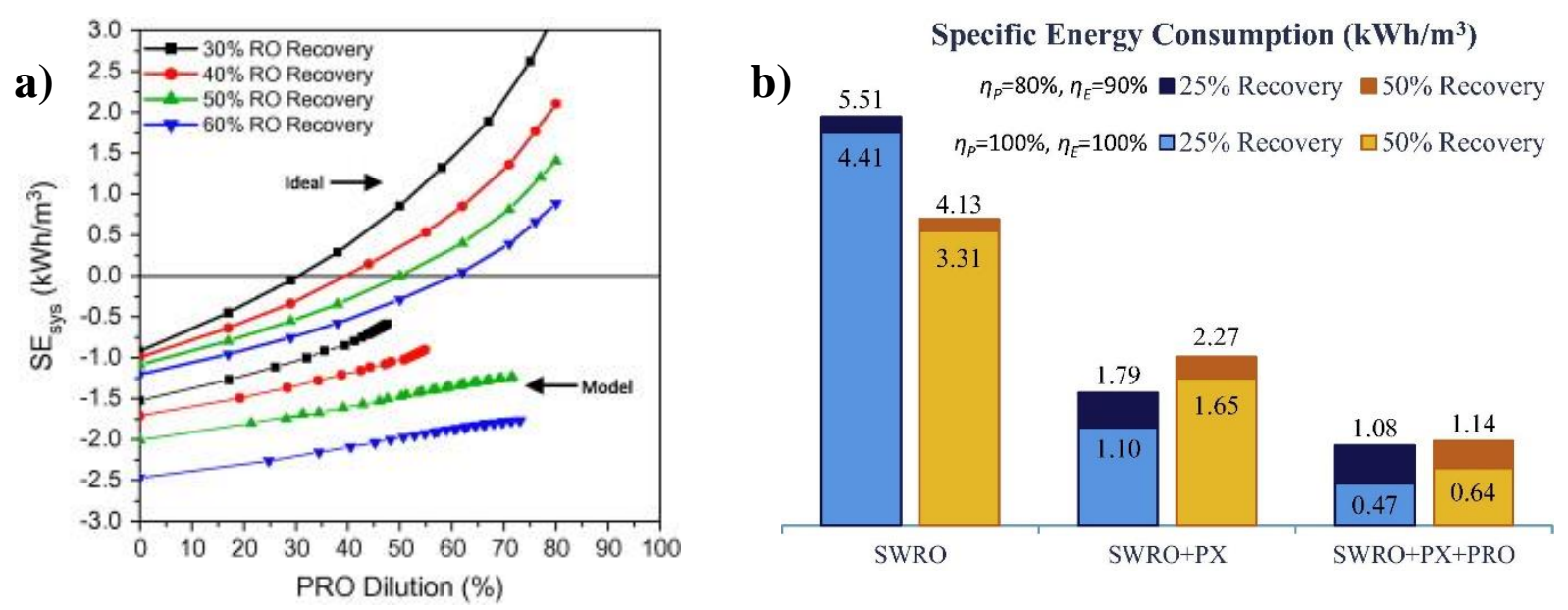

Fig. 21. (a) Change in SEC of hybrid SWRO-PRO with PRO dilution at different RO recoveries [163] and (b) SEC of standalone SWRO, SWRO with PX, and hybrid SWRO-PRO with PX using different $\operatorname{HPP}\left(\eta_{P}\right)$ and PX $\left(\eta_{E}\right)$ efficiencies [267]. Copyright @ 2014 , Elsevier. Copyright @ 2016 , Elsevier.

Although PRO performs very well in small-scale experiments by achieving a power density of 24 $\mathrm{W} / \mathrm{m}^{2}$, the commercialization of RO-PRO is still challenging as scaling up the process reduces the power density in PRO to $10-15 \mathrm{~W} / \mathrm{m}^{2}[270,271]$. Another challenge in commercializing PRO is the lack of membranes designed to be used specifically in PRO. Also, RO-PRO should be located close to the low saline water source. In addition, the hybrid system requires more membrane area than standalone SWRO [272]. This might be critical as energy savings might not be high enough to compensate for the increase in the membrane cost. The energy feasibility of RO-PRO process was investigated by Park et al. [249]. As shown in Fig. 22, at 60\% dilution in concentrate, the maximum amount of recoverable energy is $0.56 \mathrm{~kW}-\mathrm{h} / \mathrm{m}^{3}$. This value was obtained by assuming ideal conditions. As reported by Straub et al. [164, 273], non-ideal conditions can reduce the maximum extractable energy by $45 \%$. Therefore, at a $60 \%$ brine dilution, the calculated practical extractable energy is $0.31 \mathrm{~kW}-\mathrm{h} / \mathrm{m}^{3}$. For a more realistic estimation, the amount of energy required to operate RO-PRO (minimum of $0.17 \mathrm{~kW}-\mathrm{h} / \mathrm{m}^{3}$ ) should be considered. Thus, the practical extractable energy becomes $0.14 \mathrm{~kW}-\mathrm{h} / \mathrm{m}^{3}$. These values are not motivating for the 
commercialization of RO-PRO although the previously developed models for RO-PRO showed significant reduction in SEC [163, 267, 274, 275]. Therefore, energy requirements in RO-PRO should be evaluated experimentally rather than theoretically. Also, SEC should be studied in pilotscale plants where more realistic data can be obtained. Long term tests would provide a clearer understanding for the effect of factors such as concentration polarization, membrane fouling and equipment inefficiency on SEC.

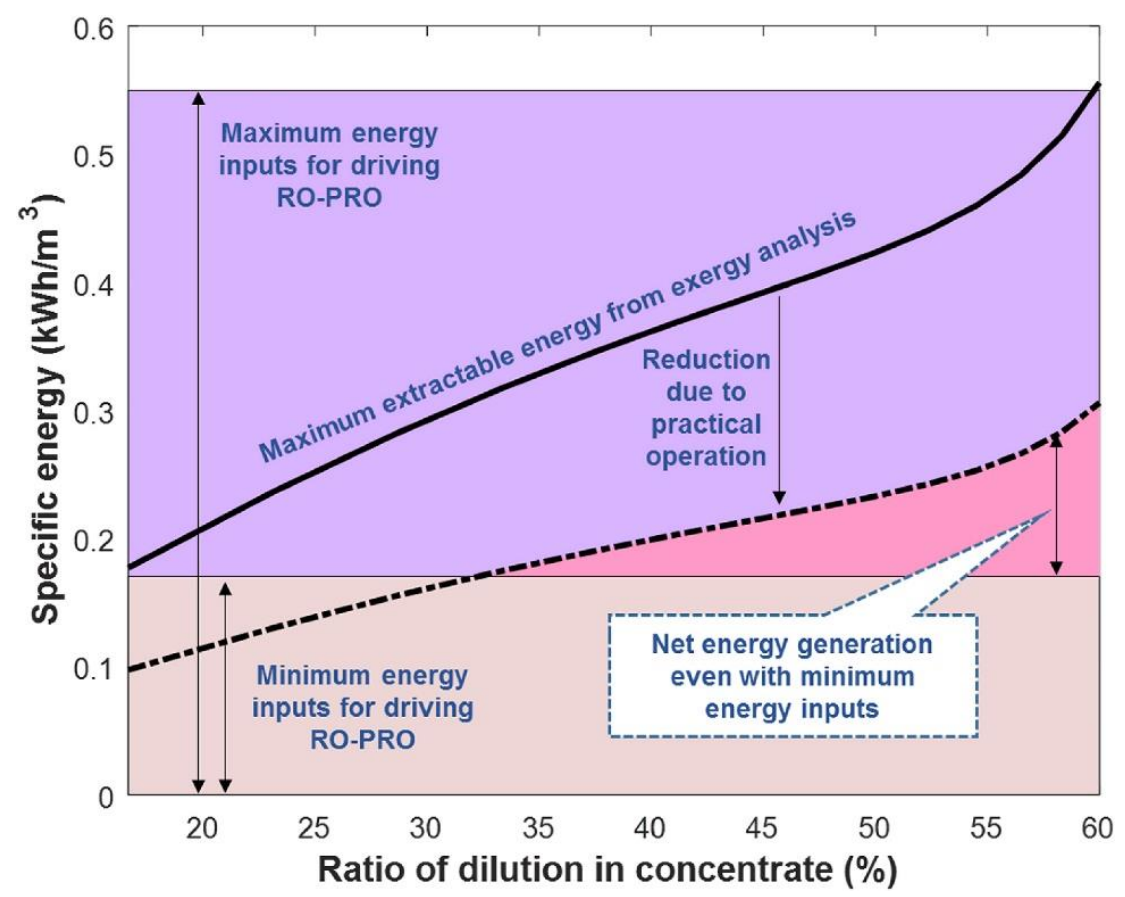

Fig. 22. Energy feasibility in RO-PRO assuming a feed solution with concentration of $2000 \mathrm{ppm}$ and flowrate equal to SW feed stream [249]. Copyright (C) 2020, Elsevier.

Another approach for coupling PRO with RO to reduce SEC is by using PRO before the RO stage. Kim et al. [276] proposed a model for PRO-SWRO in which SW is used as the draw solution in PRO and low salinity wastewater is used as the feed. In this scheme, the salinity of SW is reduced before it is fed to the SWRO stage and thus less applied pressure is required. Also, energy 
generated from mixing is converted to mechanical energy using PX and utilized to pressurize the SWRO feed. The results showed that SEC of PRO-SWRO was $1.1 \mathrm{~kW}-\mathrm{h} / \mathrm{m}^{3}$ which is almost $50 \%$ lower than SEC of SWRO. This reduction in energy suggests that SEC of SWRO can be substantially reduced by integrating PRO before the SWRO process. However, this study was performed theoretically and might not give a close representation for the real energy savings. Also, fouling experiments revealed that flux was significantly affected by membrane fouling.

\subsection{Hybrid thermal systems}

\subsubsection{Pretreatment by nanofiltration and forward osmosis}

The performance of MSF and MED processes can be enhanced by increasing TBT. However, at higher TBT, scaling and fouling become more severe [116, 277]. This is because the divalent ions present in saline water tend to form scale deposits at high temperatures [66]. These deposits reduce the active heat transfer area which in return increases the SEC required to maintain the same production $[67,278]$. The ions responsible for scale formation can be filtered out from SW using NF [279-281]. Integrating NF with thermal desalination technologies has gained notable attention due to the high rejection rates for bivalent ions in NF [282]. Al-Sofi et al. [281] carried out threshold experiments on brine, SW, and NF permeate to confirm that scaling can be reduced when NF permeate is used as feed to MSF. The samples were heated in a reaction vessel and flashed gently under controlled vacuum. The total alkalinity of each sample which gives an indication for scale formation was monitored for $30 \mathrm{~min}$. The results showed that the reduction in total alkalinity was the highest in brine and lowest in NF permeate. Less reduction in total alkalinity indicate less scale formation. These results were also supported with a pilot-scale test on MSF for 5 weeks $\left(\mathrm{TBT}=120^{\circ} \mathrm{C}\right)$. The scaling was insignificant even though the operation was performed without 
chemical dosing for scale control. In another study, Hassan et al. [279] proposed NF-MSF hybrid system in which scale forming ions are removed from SW in the NF stage before it enters the MSF unit. They also proposed a trihybrid NF-SWRO-MSF system where the MSF unit was operated with SWRO reject as the feed. The pilot-scale experiments on NF-MSF showed that the MSF unit can be operated successfully at TBT of $130{ }^{\circ} \mathrm{C}$ without the addition of an antiscalant. Operating at a TBT led to enhanced water recovery and produced a GOR of 13. More information about these hybrid systems can be found in Ata M. Hassan's patents [280, 283]. The integration of NF with thermal desalination technologies reduces hardness and removes turbidity from SW. Thus, energy and chemical consumption become lower. In addition, in these hybrid systems, thermal processes can be safely operated at higher TBT to increase water production and GOR. Hamed et al. [284] showed that coupling NF with MSF allows for operating MSF at TBT of $130^{\circ} \mathrm{C}$. NF-MSF system yielded a water recovery of 70\% which is higher than that obtained from conventional MSF (35\%). Many studies considered NF as a potential process for the pretreatment of SW before it is fed to the thermal stage. Alternatively, FO can be used as it requires less operation energy than NF. Altaee and Zaragoza [285] proposed a hybrid FO-MSF system in which the brine rejected from MSF is used as the draw solution in FO. Power consumption of FO was estimated using a simple model and compared to NF. The results showed that FO requires less SEC than NF at a wide range of recovery rates. Also, as the salinity of the feed increases, SEC required for NF increases. On the other hand, increasing the feed salinity does not affect SEC of FO but rather increases the water permeability as the osmotic pressure difference across the membrane increases. The performance of FO and NF processes was also compared at fixed recovery rate (24\%) and different feed salinities (32,000 and 50,000 ppm). It was found that water flux and SEC were higher in NF than FO in both cases. Therefore, the membrane area should be increased in FO to achieve higher water 
flux. Detailed cost analysis should be performed in order to evaluate the economic feasibility of FO relative to NF. FO can be also coupled with MED. Altaee et al. [286] evaluated the performance of FO-MED at high TBTs. They studied the tendency for scale formation using Ryznar Scale Index (RSI) (RSI <5, high tendency; 6<RSI<7, low tendency) [287]. RSI estimations were used to determine the desirable FO recovery for different TBTs to avoid scaling issues. The results showed that with a feed salinity of $45,000 \mathrm{ppm}$, the MED process can operate safely at TBT of $85^{\circ} \mathrm{C}$ when the FO recovery rate is $40 \%$ or less. Most studies on hybrid FO-MSF or FO-MED used theoretical models which are not sufficient to prove the potential for performance enhancement. Recently, for the first time, Thabit et al. performed experimental tests on FO using real SW and brine reject to evaluate the feasibility of using FO as a pretreatment process for MSF. Circulation flowrates of feed SW and draw solution as well as the temperature of the draw solution were changed in order to study their impact on the performance of FO. The results from this study confirmed that employing FO in the pretreatment of MSF is promising. However, long-term pilotscale tests of FO-MSF are still needed for more realistic performance evaluation.

Although, we have already established that the pretreatment of SW feed using NF or FO can help reduce the potential for scaling in thermal processes and give us room to operate at higher TBTs, we still lack fundamental understanding of the effect of pretreatment on the overall SEC of these hybrid systems. We theoretically expect that pretreatment can reduce the operating costs since scale formation on heat exchanger surfaces is significantly reduced. Thus, cleaning is required less frequently, the equipment life time is extended, and less SEC is required to maintain the same water production over time. To consider these hybrid systems effective, the overall SEC and costs should be lower than thermal processes alone. 


\subsubsection{Multi-effect distillation-adsorption desalination}

$\mathrm{AD}$ is a technique which is reported by several researchers [288, 289], employing a lowtemperature heat source to power the sorption cycle [290]. Feed water is fed to an evaporator at ambient temperature, hence omitting any need for feed heating. The heat source is circulated inside the evaporator tubes. Vapors are formed when SW is sprayed on the evaporator tubes. An adsorbent (usually silica gel or zeolite) sucks in the vapor produced in an evaporator at a very low pressure and temperature. On saturation, adsorbent releases the vapor and condenses it. Recently, the hybridization of MED with AD has been investigated by many researchers [22, 288, 291-294].

Energy efficiency of MED can be improved by increasing the number of effects [63]. However, the number of effects is limited by the temperature difference between the first effect and last effect [57]. The hybridization of MED with $\mathrm{AD}$ can lower the downstream temperature in the last effect in MED. In hybrid MED-AD systems, AD is attached to the last effect in MED where brine is rejected. The adsorbent in $\mathrm{AD}$ extracts all the vapors from the last effect which causes a reduction in pressure and consequently drop in the saturation temperatures of MED effects. Hybridized MED-AD system was first proposed by Thu et al. [288]. In their study, the authors created a model to analyze the performance of MED-AD. The results showed that water production rate was doubled and GOR increased by 40\%. In another study, Shahzad et al. [292] developed a numerical model to compare the performance of MED-AD with conventional MED. The temperature profiles of MED-AD effects is shown in Fig. 23a. Temperature of the last effect was found to be less than $3{ }^{\circ} \mathrm{C}$ which is much lower than that in conventional MED $\left(\approx 40{ }^{\circ} \mathrm{C}\right)$. The increased gap between TBT and temperature in the last effect upon hybridization with AD allows for inserting additional effects while supplying the same amount of heat to the system. This can lead to increased water production and enhanced performance. In addition, even though the heat input was the same in 
both systems, water production in the hybrid system was found to be triple that in MED. This is because the temperature drop across the effects in MED-AD was 2 to $3{ }^{\circ} \mathrm{C}$, whereas it was $1{ }^{\circ} \mathrm{C}$ in conventional MED. Similar results were obtained by Thu et al. [291]. They investigated the effect of modifying the MED cycle by hybridization with AD. They also simulated multiple scenarios for MED-AD at different water inlet temperatures and number of effects in MED. As shown in Fig. 23b, the maximum increase in water production rate in MED-AD compared to MED is $89 \%$ without changing the number of effects in MED which is assumed to be 8 in this model. To utilize the added temperature gap between TBT and the last effect in MED upon hybridization with AD, more effects are added to the MED process. Increasing the number of effects in MED results in further improvement in water production rate. Additionally, the model results showed that the percentage enhancement in water production rate when additional effects are inserted to MED decreases as the hot inlet temperature increases. This is because the heat source to the AD cycle was maintained constant in all simulations.
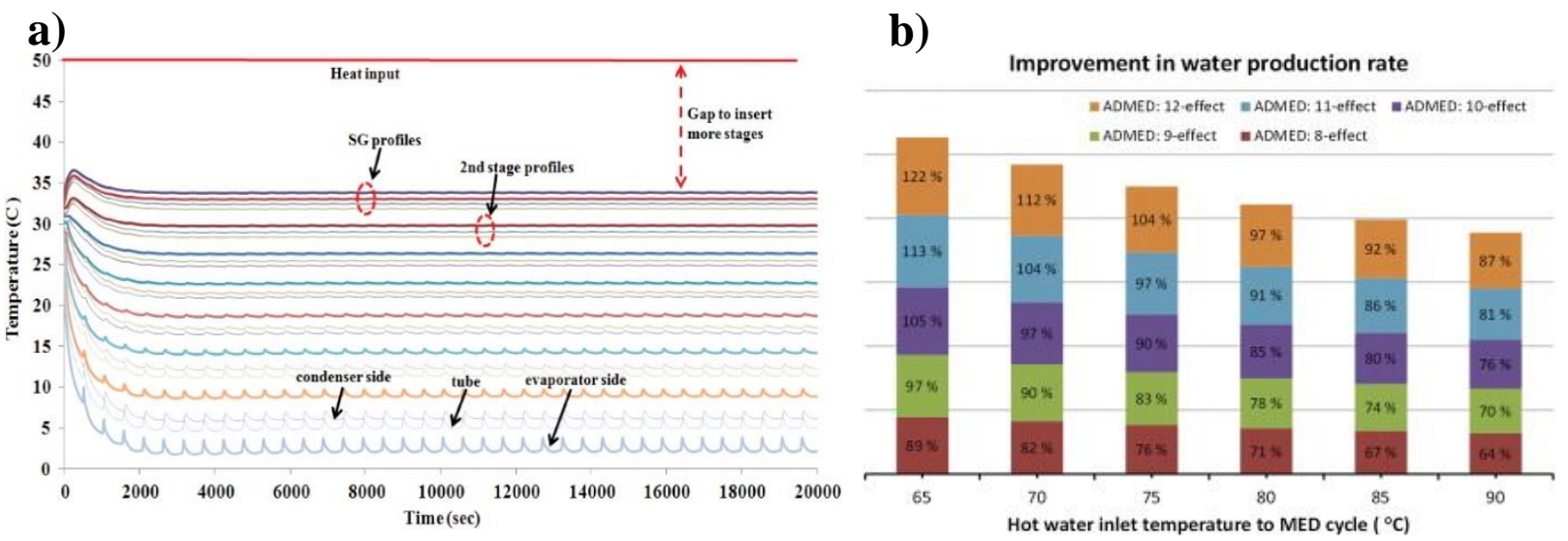

Fig. 23. a) Water production from MED-AD and MED [292] and b) Percentage increase in water production rate the hybrid MED-AD system compared to MED [291]. Copyright (C) 2014, Elsevier. Copyright (C) 2014, Elsevier. 
The integration of AD cycle with MED can potentially enhance the performance of MED. However, the effect of hybridization on SEC of MED is still not yet addressed. In order to consider the hybrid system more energy efficient that conventional MED, SEC of MED and AD together should be less than standalone MED. The economic feasibility of the hybrid system is still in question. Thus, detailed economic analysis is required. In addition, pilot-scale plants are needed to confirm the significant performance enhancement when $\mathrm{AD}$ is added to MED. Recently, $\mathrm{Ng}$ et al. [22] installed a 3-stage MED process with AD. Their experiments confirmed the significant increase in water production in the hybrid system relative to MED. The future research on MED$\mathrm{AD}$ should be focused on performing long-term tests on pilot-scale plants and analyzing the process economics. With more gained knowledge about MED-AD and given the incredible performance enhancement, the technology will be few steps away from commercialization in the near future.

\subsubsection{Multi stage flash - multi effect distillation}

The benefits of standalone MSF and standalone MED can be combined in one system by hybridization [295]. Different configurations of hybrid MSF-MED systems were proposed by researchers $[53,296]$. Fath [296] invented a hybrid MSF-MED system, in which MED was superimposed on MSF. Also, brine was reheated after the brine heater or/and within each flashing stage with external heat in order to increase the flashing range in MSF. The author claimed that the hybrid system had larger capacity and better performance than conventional MSF. However, the system economics and technical structure were not addressed.

In a typical MSF process, when the distillate is transferred to a successive stage with lower pressure, part of it is forced to re-flash. This re-flashing distillate occupies a portion of the heat transfer area which is supposed to be available for the condensation of flashing saline water. As 
the number of stages increases, the amount of distillate re-flashing increases leading to reduced process efficiency. This issue is even more pronounced in the heat rejection section. To solve this problem, Awerbuch and Sommariva [53] suggested coupling MSF with MED or RO such that the energy of the distillate in the last stages of heat recovery section in MSF is recovered in MED or RO. This is expected to maximize the water production and increase the efficiency of the process according to the authors. Comparative performance analysis of MSF with and without the distillate extraction showed that no significant changes occurred in the process. However, to understand the effect of hybridization on process efficiency, the performance of both MSF and MED should be studied. Another MSF-MED configuration was investigated by Nafey et al. [297]. In this hybrid system, each module consists of one flash evaporator and one boiling evaporator. Hot brine exiting the brine heater is split into two streams. One of the streams enters the first MED cell to form vapor. Brine leaving the first MED cell is mixed with the second stream from the brine heater. Then it is fed to the first MSF stage. Brine leaving this stage is split into two streams where one is fed to the second MED effect and the second is mixed with brine leaving the second MED effect. The process is repeated until the last module. The results from this study showed that water cost of the hybrid MSF-MED system was 31\% lower than MSF-BR and 9\% lower than MED. In a more recent study, Mabrouk and Fath [295] performed a techno-economic analysis on MSF-MED compared to standalone conventional systems including MED, MED-TVC, MSF-BR, and MSFOT. In the hybrid MSF-MED system, each three MSF stages were coupled with three MED effects. The results showed that $58 \%$ and $16 \%$ decrease in the pumping power of the hybrid system were achieved relative to MSF-BR and MED-TVC, respectively. However, GOR of the hybrid system was lower than MSF-BR by 3\% and higher than MED-TVC by only $9 \%$. 
Each one of the studies we reviewed proposed a different MSF-MED configuration. This continued effort to come up with new configurations for the hybrid MSF-MED system rises from the fact that the performance enhancement in the hybrid systems is not significant enough to replace conventional thermal processes. In fact, given the complexity of the hybrid MSF-MED system, it does not seem to be an attractive alternative to conventional thermal desalination. Besides the process economics which was not discussed in most of the studies, SEC of the proposed hybrid systems was not mentioned. There is less incentive to design and test a process with high complexity like MSF-MED knowing that our understanding for the process economics, energy consumption and technicality is still limited.

\subsection{Hybrid Reverse osmosis-thermal processes}

Thermal desalination plants are usually collocated with power plants to achieve high energy efficiency. High exergy steam which has high temperature and pressure is used to generate electricity in the power plant while bled steam of low exergy is utilized in the thermal desalination plant [22]. The contribution of the low exergy bled steam to power generation in the power plant is insignificant. Therefore, rather than being wasted, it is used to supply thermal energy for heating in MSF and MED. Energy efficiency can be further enhanced if the power plant is coupled with both $\mathrm{RO}$ and the thermal process. There are different configurations for hybridizing $\mathrm{RO}$ and thermal processes but the simplest one is when SW is fed to each process separately and output from both processes is combined [51]. The hybridization of RO and MSF with power plants is well-established as many commercial desalination plants today employ this hybrid system. Coupling RO with MSF presents many advantages including: low construction cost, combined pretreatment and post-treatment, and less SEC compared to the standalone processes [51]. Usually, in RO desalination plants, two RO stages are required to obtain a high quality product. In hybrid 
RO-MSF systems, single stage RO can be used as products from MSF and RO are blended [50]. In addition, blending products allows for operating RO at relatively high TDS. Thus, membrane replacement becomes less frequent which in turn affect the process economics [298].

The lower energy requirements in MED compared to MSF makes it a more attractive candidate for hybrid systems. However, studies on coupling RO-MED hybrids with power plants are limited. Mahbub et al. [299] studied the effect of combining MED and RO together with the same power plant. Their results showed that the thermal efficiency of the plant increased from $44 \%$ to $63 \%$. In addition, the SEC of a power plant combined with MED and RO was $17 \%$ less than that combined with MSF and RO. In a more recent study, Filippini et al. proposed several configurations for combining MED-TVC with RO. The study involved a performance comparison between hybrid systems and individual processes in terms of SEC, water production rate, product water quality, and recovery ratio. The results showed that the simple hybrid configuration requires the least SEC. However, when considering water recovery as well, the most favorable configuration involves RO and MED-TVC in series where the inlets to MED-TVC are brine from RO and SW. An example for a power plant coupled with MED and RO is in the Fujairah $2\left(591,000 \mathrm{~m}^{3} / \mathrm{d}\right)$ in the United Arab Emirates. Hybridizing MED with RO is still not mature as the main commercial hybrid system is RO-MSF.

\section{Energy considerations in renewable energy driven desalination processes: Is renewable energy the future of seawater desalination?}

After highlighting major energy consumptions for conventional and non-conventional desalination technologies in the previous sections, it is evident that tremendous improvements are still 
necessary owing to high energy requirements primarily due to the use of non-renewable energy sources such as fossil fuels. These fossil fuels also contribute to air pollution and global warming, affecting the overall ecosystem [300-302]. Furthermore, increasing fossil fuel prices, global dependencies of countries with little fossil fuel resources and environmental restrictions are increasing concerns for its usage [303]. Nevertheless, major oil producing countries in the Gulf have also realized their vulnerability to any future energy crisis, and thus aim to diversify their dependence on energy resources [304].Thus, in the past few decades, tremendous research and academic effort has been directed in utilizing renewable energy (RE) sources to desalinate SW. Fig. 24 shows an overall scheme of the different RE sources when coupled with various common desalination technologies. However not all seem promising in regard with economic and technological feasibility. Nevertheless, these RE sources such as the solar, wind and geothermal energies, will hopefully bring about environmental sustainability, water security, and energy sustainability. Not every RE is applicable for all desalination technologies, while some being more suited for small-scale units rather than large plants. In addition, it depends upon several factors including energy accessibility [305], cost considerations [306, 307], infrastructure [308-311] and government regulations [312].

Due to growing environmental concerns and strict governmental regulations being placed globally [313-316], the future of renewable desalination technologies deem promising. However, until now, the current installed desalination capacity using RE is quite negligible in comparison to global total capacity. Roughly over 130 desalination plants are utilizing RE producing only $1 \%$ of the total desalinated water. Amongst the several desalination technologies highlighted in Fig. 24, solar photovoltaic (PV) forms about $43 \%$ of the total utilization, followed by solar thermal (27\%), wind (20\%) and numerous hybrids (10\%) [317, 318]. 
This section reviews the energy requirements for the major RE technologies utilized so far for desalination. However, owing to it higher total capacity, solar energy is given special attention. By the end of this section, we discuss the future roadmap for RE utilized for desalination in the quest to overcome the current energy challenges involved.

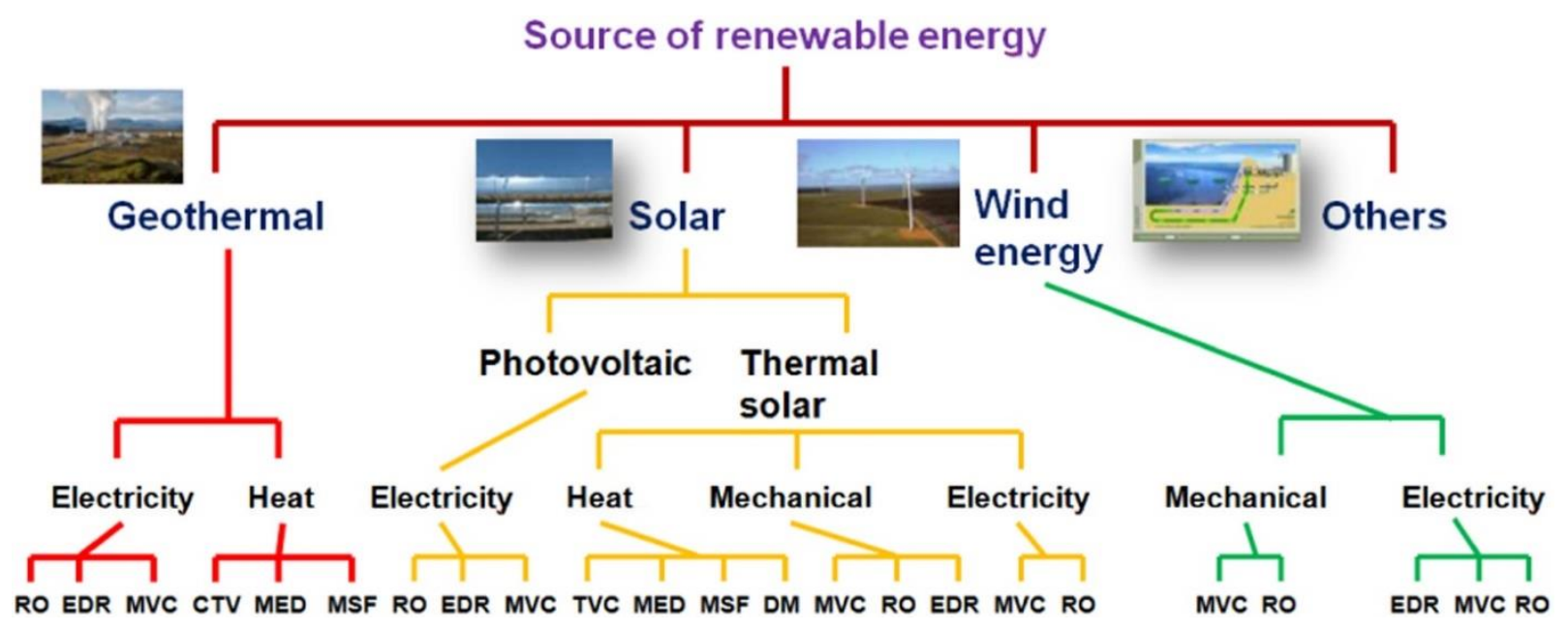

Fig. 24. Various renewable energies coupled with different desalination technologies [14]. Copyright ()$^{\circ}$ 2018, Elsevier.

\subsection{Solar}

By far, solar energy is the most widely used RE source for desalination, and hence has been used to power several existing desalination technologies such as MSF, VC, RO, ED and NF [207]. Solar energy can either be used as solar thermal energy to drive turbines, or can be harnessed directly as electricity. The technology can be categorized into PV and solar thermal. The latter may be further divided into direct heating for low-temperature uses, or concentrated solar power (CSP) for electricity generation. During the past years, solar PV has potentially surpassed other RE sources such as wind energy and hydropower [319]. Rapid technological advances have seen a rapid cost 
decline by $80 \%$ in PV modules in the past decade, with further cost reductions expected, bringing the average cost down to $\$ 0.05-\$ 0.06$ per $\mathrm{kWh}$ in the near future [320]. With these significant cost reductions, it is no surprise that solar PV is the leading RE technology used for desalination today. The most frequently combination is PV with RO. Since heat losses are more significant in smaller desalination units, larger units are more attractive for solar-PV. Apart from solar PV, solar collectors are also gaining considerable attention, with a thermal efficiency between $60 \%$ and $75 \%$. Their levelized cost is around $\$ 0.05-0.09$ per $\mathrm{kWh}_{\mathrm{th}}$, which varies significantly with collector type, efficiency and price [321].

The selection of using either direct solar energy or converting it to electricity for desalination depends upon the compatibility with the selected desalination process. For example, solar stills are the simplest and oldest forms of solar desalination units, where saline water is evaporated by the solar energy and collected as a condensate [322]. The energy requirements in such systems is most precisely understood by the conversion efficiency of solar-to-heat. Several new materials have facilitated higher solar-to-heat efficiency in direct desalination. For example, Kim et al. [323] reported a three-dimensional graphene network (3DGN) coated wood which had a solar-to-vapor conversion efficiency of $91.8 \%$ under a solar simulation power density of $1 \mathrm{~kW} / \mathrm{m}^{2}$. Shang et al. [324] achieved a conversion efficiency of $63.9 \%$ using a porous CuS/polyethylene (PE) hybrid membrane. The membrane also showed good regeneration ability, and low thermal conductivity leading to lower thermal losses. Finnerty et al. [325] took inspiration from nature to develop a system which used a synthetic leaf made from graphene oxide (GO). The leaf was placed in contact with a water absorbing sheet, in which water was transported from the bulk to the leaf through capillary action. Efficiency as high as $78 \%$ was achieved. Their study was reported to be a great 
potential for zero liquid discharge solar desalination. Numerous other novel ways and materials are reported for direct solar desolation for improved energy performances [326-328].

CSP is another category of solar thermal which generates electricity by using mirrors which reflects sunlight, and heat is collected by a thermal energy carrier. Presently, four different CSP technologies exist, parabolic trough collector (PTC), solar power tower (SPT), linear Fresnel reflector (LFR) and parabolic dish systems (PDS), details of which can be found elsewhere [329, 330]. Table 13 compares these technologies, which can be helpful to conclude on which ones to use for desalination, leading to overall higher thermodynamic efficiencies. It is evident from the table that CSP required large amounts of water for cooling, thus adding to costs, compared to about $2000 \mathrm{~L} / \mathrm{MW} \mathrm{h}$ for a coal-fired power plant. Wagner and Rubin [331] evaluated the economic implications of thermal energy storage for CSP. Using thermal energy storage instead of a natural gas-fired heat transfer fluid heater was shown to increase the total plant capital costs, however with a concurrent decrease in the annual operation and maintenance costs. They reported a price of \$US 153 per ton $\mathrm{CO}_{2 \mathrm{eq}}$ or higher can put this technology in competition with coal electricity generation. The challenge remains to reduce the levelized cost of solar thermal technology. According to DeCanio and Fremstad [332], solar costs considerably reduces over time if significant research input is put in this area.

Table 13. Comparison between leading CSP technologies. Adapted from [333]

\begin{tabular}{|c|c|c|c|c|}
\hline CSP technology & Relative cost & $\begin{array}{c}\text { Cooling water } \\
\text { (L/MW-h) }\end{array}$ & $\begin{array}{c}\text { Thermodynamic } \\
\text { efficiency }\end{array}$ & Improvement potential \\
\hline PTC & Low & 3000 or dry & Low & Limited \\
\hline LFR & Very low & 3000 or dry & Low & Significant \\
\hline
\end{tabular}




\begin{tabular}{|c|c|c|c|c|}
\hline SPT & High & 1500 or dry & High & Very significant \\
\hline PDC & Very high & None & high & $\begin{array}{c}\text { High potential through } \\
\text { mass production }\end{array}$ \\
\hline
\end{tabular}

Despite significant improvements in RO through efficient ERDs, an important fraction of RO costs is associated with the electrical energy required to pressurize the feed [334]. Both electrical and mechanical means can be used to achieve this, and thus both solar PV and solar thermal find great potential in this area. In solar PV powered units, the power is supplied by the PV panels which may be operated with or without batteries. It may be considered as desalination by an electromechanical process, where PV converts sunlight directly into electricity. The PV cell is made up of a semiconducting material such as silicon which generate electrical charges when exposed to sunlight [39]. Solar PV powered RO units have reported to have better socio-economic benefits compared to those powered by diesel [335]. The efficiency of the RO unit powered by solar PV depends upon the efficiency of all its individual components. The cost factor can be optimized by using high efficiency PV cells. Thus, persistent research focusing on developing PV cells with high durability, robustness and efficiency is desirable. A Spanish company did a theoretical energy calculation of a solar-powered SWRO plant with a capacity of $240,000 \mathrm{~m}^{3} /$ day. The SEC of such a plant requiring 51.2 MW of electricity came out to be $4.78 \mathrm{~kW}-\mathrm{h} / \mathrm{m}^{3}$ [14]. There exists numerous solar PV powered RO desalination plants worldwide. For example, the one in Jeddah, Saudia Arabia is the first of its kind, having a capacity of $1.2 \mathrm{gal} / \mathrm{min}$ [336] sufficient to fulfil the drinking water demands of about 250 residents. Al-Suleimani and Nair [337] reported that for a similar capacity RO plant, the solar PV powered one was more economical, with water production cost $/ \mathrm{m}^{3}$ of USD 6.52 , compared to the one operated by diesel, USD 8.68. A solar 
thermal and PV powered RO system, with a capacity of $0.2 \mathrm{~m}^{3} /$ day was developed by Khayet $e t$ al. [338]. It consisted of both high and LPPs, with a thin film composite (TFC) polyamide (PA) spiral wound membrane. The RO unit showed a low energy consumption of $1.3 \mathrm{~kW}-\mathrm{h} / \mathrm{m}^{3}$ when optimum operating conditions of 7.7 bar feed pressure, $252.8 \mathrm{~L} / \mathrm{h}$ feed flow rate and $33{ }^{\circ} \mathrm{C}$ temperature were used for $6 \mathrm{~g} / \mathrm{L}$ feed concentration. Variation as large as 1.1 to $16.3 \mathrm{~kW}-\mathrm{h} / \mathrm{m}^{3}$ has been reported for PV operated RO units. This variation was a result of system size, type of batteries, feed salinity and ERD design [339]. Few studies focus on increasing the efficiency of PV-RO combination, instead most studies deal with them separately [340]. A novel method was reported by Raval and Maiti [341, 342], where they captured the thermal energy from the PV cells and used it to heat the feed water, simultaneously decreasing the PV module temperature. Energy consumption was reduced by almost $28 \%$ through this method, simultaneously increasing the membrane flux by $3 \%$. Thus, temperature had a positive effect on RO productivity. However, it is reported that a temperature increase has a negative effect on the electrical efficiency of PV [343]. Nevertheless, an optimized hydrophilic membrane, together with heat transfer from the PV module to the RO feed bought about 40\% reductions in the energy cost [342]. Monnot et al. [344] used a battery to store energy in a high-recovery small-scale PV-RO system. The extra cost of the battery was compensated by reducing the number of RO modules and other efficient ERDs, bringing down the SEC to $<3 \mathrm{~kW}-\mathrm{h} / \mathrm{m}^{3}$. The energy management strategies for solar PV-RO as proposed by Herold et al. [345] is shown in Fig. 25. 


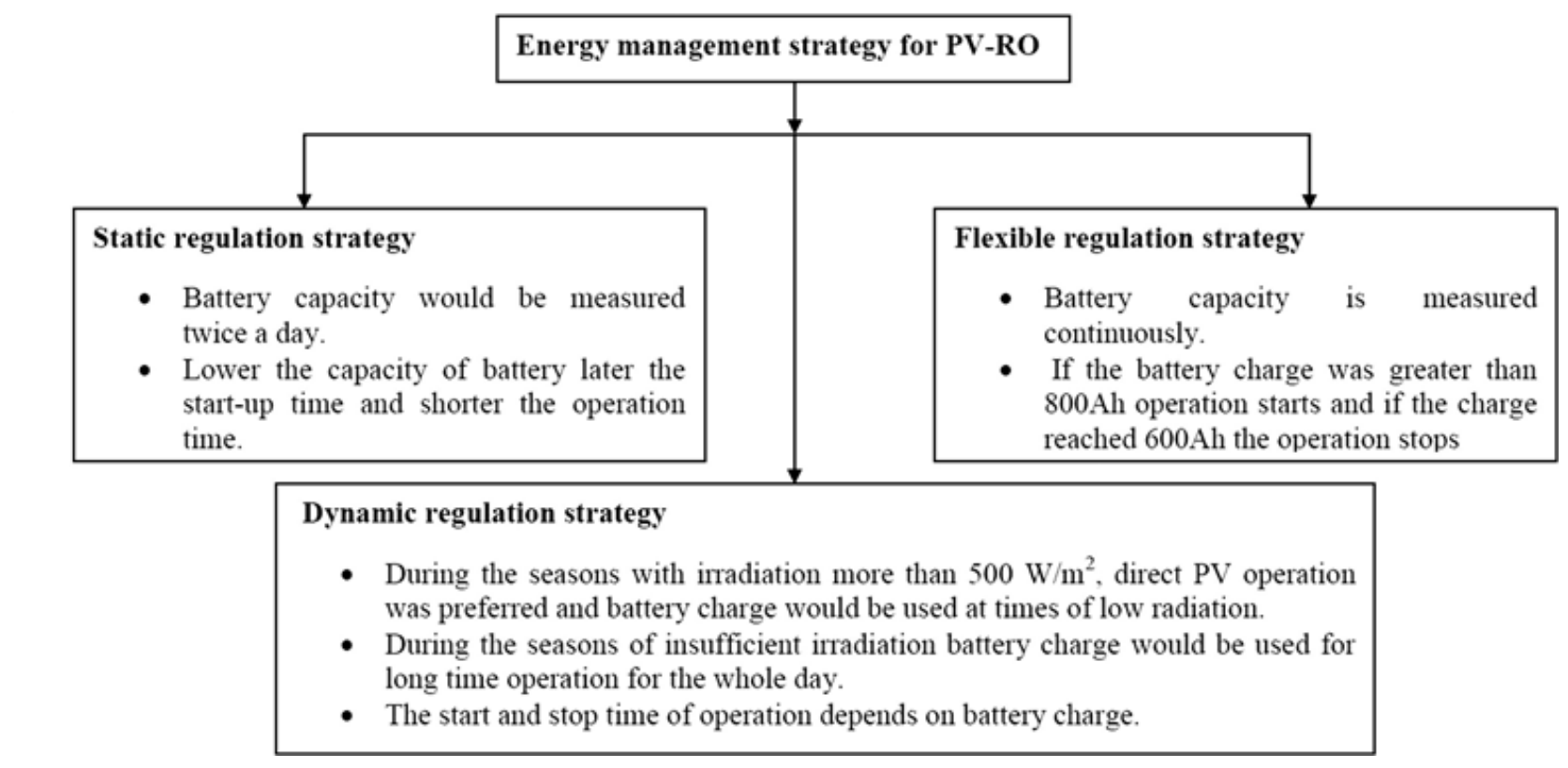

Fig. 25. Energy management strategy for solar PV-RO [345]. Copyright @ 2018, Elsevier.

Often, in solar thermal powered RO desalination, the organic Rankine cycle (ORCs) is used to produce the mechanical energy to run the pressure pumps [346]. This power cycle derives the required electrical energy from solar thermal collectors. ORCs have gained considerable attention in small as well as large desalination plants (200-2000 kWe) due to its ability to use lowtemperature heat [347]. A low temperature Rankine cycle was proposed by Manolakos et al. [348] which derived the mechanical power from the expander to run the RO pumps. Mass and energy balances showed that water production from such a system would be around $1012 \mathrm{~m}^{3} /$ year, with a SEC of $2.5 \mathrm{~kW}-\mathrm{h} / \mathrm{m}^{3}$. For a system with energy recovery unit like the Pelton wheel turbine, the unit water production cost was about $24 \%$ less than the one without recovery [349]. Nafey and Sharaf [350] carried out an exergy, energy and cost evaluation of the solar ORC by considering different working fluids such as butane, toluene and hexane. Best results, with reduced costs and energy were obtained with water and toluene. 
Apart from RO, solar PV finds applications in other desalination processes such as MD and ED. The first small scale PV-ED system was proposed by Lundstorm [351]. These systems were found to be quite promising for rural and remote locations, such as in the Thar Desert, India [352]. Ishimaru [353] reported solar PV-ED units with a water production capacity of 200-375 $\mathrm{m}^{3} /$ day installed in Nagasaki, Japan. The overall system efficiency was between $6.0-8.2 \%$, while the electric power consumption was found to be lower than the designed value of $1.92 \mathrm{~kW}-\mathrm{h} / \mathrm{m}^{3}$. Recently, several studies have also been published on solar energy powdered MD units [195, 354357]. Summers et al. [177] compared theoretical models based on GOR of various MD systems. An increasing GOR was noticed with increasing feed temperature and increased effective membrane length. A solar DCMD plant in Canara Island, Spain was investigated for five years for its performance. Distillate of high quality was produced, with water production varying between 5-120 L/day. Thermal energy consumption range was found to be between $140-350 \mathrm{~kW}-\mathrm{h} / \mathrm{m}^{3}$ [211].

Kim et al. [358] studied numerical simulations of a large scale solar DCMD system. They assessed the SEC requirements versus SW storage tank volumes $\left(V_{s t}\right)$ for different solar collector areas $\left(A_{c}\right)$ (Fig. 26a). The SEC was seen to reduce by increasing the $A_{c}$, however with a simultaneous increase in the specific electrical energy consumption due to high pumping power requirements. With an increase in $A_{c}$ from $1983 \mathrm{~m}^{2}$ to $3360 \mathrm{~m}^{2}$. However, regardless of $A_{c}$, a higher $V_{s t}$ resulted in a reduction of specific thermal energy consumption (STEC). Also, a pronounced effect of $\mathrm{V}_{\text {st }}$ was observed on the STEC at a higher $A_{c}$ [359]; it decreased by $13.2 \%$ for a decreasing $A_{c}$ from $1983 \mathrm{~m}^{2}$ to $3360 \mathrm{~m}^{2}$, with increasing $\mathrm{V}_{\mathrm{st}}$. Banat et al. $[196,360]$ reported that for both large and small scale solar-MD plants, the water production cost mainly depends upon membrane and plant lifetime. They compared (Table 14) the performances of two solar MD plants, the one in Aqaba, 
Jordan, and the other in Irbid, Jordan. Moore et al. [361] reported his simulation results for a solar powered SGMD system powered by both solar thermal and solar PV. The water cost for such a system was found to be $\$ 85 / \mathrm{m}^{3}$, however, much lower costs are reported, $\$ 5.16 / \mathrm{m}^{3}$ for AGMD due to its better energy efficiency. Cipollina et al. [362] developed a lab-scale solar AGMD module for SW desalination. Fig. 26b shows that the SEC increased linearly with the feed flow rate, while decreased with the inlet temperature. They also compared various MD configurations for SEC versus the hot inlet temperature (Fig. 26c). The permeate gap configuration showed the lowest specific thermal, with a reducing trend with increasing inlet temperature. This superior performance may be attributed to a larger vapor flux, reaching $\approx 12 \mathrm{~L} / \mathrm{m}^{2}-\mathrm{h}$ in the permeate gap configuration. Zaragoza et al. [356] analyzed several commercial MD modules, SC, M33, PT5, Oryx 150 and WTS-40A fed by solar energy. The modules were supplied with solar energy at temperatures between 60 and $90{ }^{\circ} \mathrm{C}$. They assessed the thermal energy requirements of fresh water per unit volume, considering several operating conditions, such as the feed salinity, feed flow and inlet and outlet temperatures. Energy efficiency was calculated using STEC:

$$
\mathrm{STEC}=\frac{\mathrm{Q}}{\mathrm{m}_{\mathrm{p}}} \quad \text { Equation 7 }
$$

Where $m_{p}$ is the mass flow rate of the produced distillate $\left(\mathrm{m}^{3} / \mathrm{s}\right)$, and $Q$ is the rate of thermal energy added to the system $(\mathrm{kW}-\mathrm{h} / \mathrm{s})$. Lowest STEC, $210 \mathrm{~kW}-\mathrm{h} / \mathrm{m}^{3}$ was obtained for Oryx 150. Several small scale, as well as large scale solar desalination plants have been installed worldwide, with the total capacity expected to increase [363-365]. 
Table 14. Small and large scale solar MD systems- performance comparison. Adapted from [32].

\begin{tabular}{|c|c|c|c|c|c|c|}
\hline $\begin{array}{l}\text { System } \\
\text { type }\end{array}$ & $\begin{array}{l}\text { Recover } \\
\text { ratio }(\%)\end{array}$ & $\begin{array}{c}\text { Gained } \\
\text { output } \\
\text { ratio }\end{array}$ & $\begin{array}{c}\text { Thermal } \\
\text { recovery } \\
\text { ratio }\end{array}$ & $\begin{array}{c}\text { Energy } \\
\text { consumption } \\
\left(\mathbf{k W h} / \mathbf{m}^{3}\right)\end{array}$ & $\begin{array}{c}\text { Distillate } \\
\text { yield } \\
\left(\mathbf{l} / \mathbf{d} / \mathbf{m}^{2}\right)\end{array}$ & $\begin{array}{l}\text { Conductivity of } \\
\text { distillate }(\mu \mathrm{s} / \mathrm{cm})\end{array}$ \\
\hline $\begin{array}{l}\text { Large } \\
\text { scale }\end{array}$ & $\begin{array}{l}\text { Between } 2 \\
\text { and } 5\end{array}$ & $0.4-0.7$ & $0.4-1$ & $200-300$ & $2-11$ & $20-250$ \\
\hline $\begin{array}{l}\text { Small } \\
\text { scale }\end{array}$ & $\begin{array}{l}\text { Between } 1 \\
\text { and } 4\end{array}$ & $0.3-0.9$ & $1-2$ & $200-300$ & 19 & 5 \\
\hline
\end{tabular}

a)

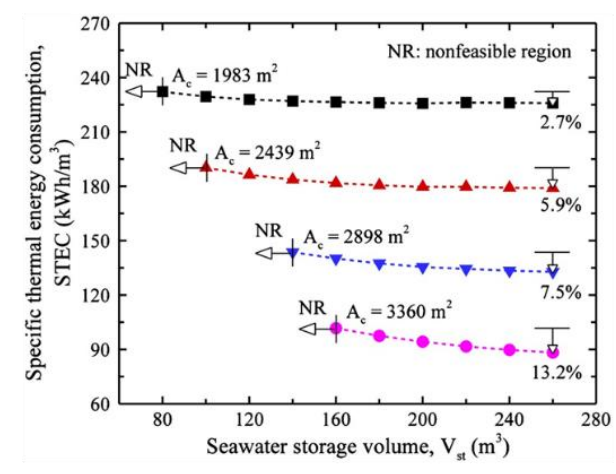

b)

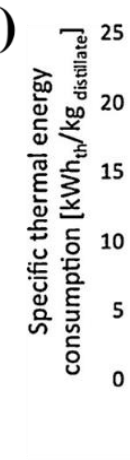

$\mathrm{F}=1.2 \mathrm{I} / \mathrm{min}$

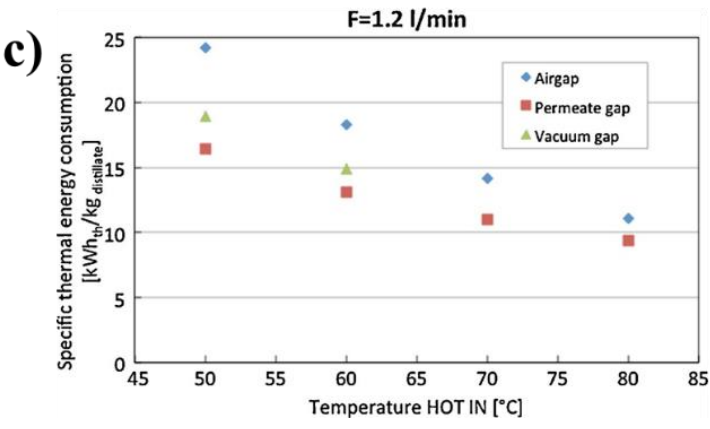

Fig. 26. (a) SEC versus SW storage volume for various solar collector areas [358] (b) Change in SEC versus feed flow rates and hot inlet temperature, Copyright (C) 2013, Elsevier, and (c) Comparison of SEC

for different MD configurations versus hot inlet temperature [362], Copyright (C) 2012, Elsevier

\subsection{Wind}

Wind energy has emerged as a valuable sustainable energy resource since the first inception of wind turbines in the 1970s [34]. With wind turbines being commercially available, desalination using wind energy has become a promising technology, especially at places where there is high 
availability of the resource [366, 367]. Huge development in this sector was observed from 2004 to 2015, whereby the installed wind energy capacity increased by almost 9 times [368]. Mostly, wind powered desalination systems are on a small-scale. Isolated regions, such as islands are a potential site for wind energy to power SW desalination plants [369]. Such systems have the advantage of reduced water cost due to negligible water transport costs. Fresh water production cost from stand-alone units have been reported be in the range from $\$ 1.35-\$ 6.7$ per $\mathrm{m}^{3}$, compared to $\$ 1.0$ per $\mathrm{m}^{3}$ for $\mathrm{RO}[19,198]$. The water cost is directly related to the efficiency of the wind turbines, which in turn generate the electricity. Theoretically reported maximum aerodynamic conversion efficiency for such wind turbines is reported to be 59\% [96]. With improved blades, efficiency as high as $45 \%$ have been achieved. Improved blade materials and efficient power storage systems can provide further improvements [370]. For example, it was reported that about 40\% decrease in blade weight can decrease capital cost by 20-25\% [39]. Dehmas et al. [371] performed a theoretical economic analysis of a wind farm with five wind turbines of $2 \mathrm{MW}$ each. Results showed that in a region of northern Algeria, wind energy could successfully power a SWRO desalination plant.

The wind-powered desalination system can either be connected to a grid, or might be directly coupled with each other in case of remote locations [372]. Several commissioned wind operated desalination plants are operational including the Kwinana desalination Plant in south of Perth in Western Australia, which is an example of a grid connected RO plant. It possesses a total of 48 turbines, generating $80 \mathrm{MW}$, out of which roughly $28 \mathrm{MW}$ is used to operate the RO system, producing almost 140 mega liters of drinking water each day [36, 363]. Garcia-Rodriguez et al. [366] analyzed the levelized cost of fresh water produced by a RO unit, by studying serval associated parameters such as the wind turbines nominal power, climate conditions, RO modules, 
plant capacity and wind turbine cost. They used three commercial wind turbines, NM600/43, NM600/48 and NM750/44 possessing nominal powers of $600 \mathrm{~kW}, 600 \mathrm{~kW}$ and $750 \mathrm{~kW}$ respectively. Table 15 details the main characteristics of their [366] wind powered RO plant. Apart from RO, wind energy can be used to drive several other desalination technologies. It can be used to mechanically drive the MVC compressor. The reported water production costs for small scale units ranges from 5.2 to $7.8 \mathrm{US} \$ / \mathrm{m}^{3}$ [373-377]. Forstmeier et al. [378] studied two different windpowered systems, one with RO with an electrical grid connection, and the other with MVC without any grid. Wind-powered MVC plants are similar to the ones operated by conventional fuels, except that electricity to the compressor and other equipment is supplied by the wind-turbine. The economics of a conventional plant and a wind-powered desalination system are different with the main cost for the latter based on the fixed costs of the system. Thus, the fuel cost is replaced by the wind turbine cost. Thus, energy efficiency is not just determined by the operation and maintenance $(\mathrm{O} \& \mathrm{M})$ costs, but rather on the mean annual water production rate. They concluded the RO system as the best choice if some grid connection is available to supply energy for lower water production costs due to lower SEC, while MVC was suitable as a stand-alone system for remote locations.

Numerous wind powered RO plants have been designed and tested until now. Table 16 lists a few other RO plants operated by wind energy. Water production costs for medium sized (1000 to 2500 $\mathrm{m}^{3} /$ day) plants range from 1.8 to $5.2 \mathrm{US} \$ / \mathrm{m}^{3}$, while about 3.9 to $9.1 \mathrm{US} \$ / \mathrm{m}^{3}$ for small scale ones $\left(\approx 100 \mathrm{~m}^{3} /\right.$ day). In addition, several hybrid wind-solar plants have also been investigated, details of which can be found in [374, 379-383]. A stand-alone hybrid RO system design was presented by Mohamed et al. [384, 385]. Fresh water production cost of $5.2 € / \mathrm{m}^{3}$ was reported, with an energy saving up to $50 \%$ through a pressure-exchanger energy recovery unit. Gilau and Small 
[386] also analyzed a similar hybrid system for water production capacity of $35 \mathrm{~m}^{3} / \mathrm{d}$. A SEC of $2.33 \mathrm{~kW} \mathrm{~h} / \mathrm{m}^{3}$ was reported for this system.

Table 15: Wind-powered RO plant characteristics. Adapted from [366].

\begin{tabular}{|c|c|c|}
\hline Wind-powered RO & Range of values & Representative values \\
\hline \multicolumn{3}{|l|}{ RO plant } \\
\hline Plant capacity, $\mathrm{m}^{3} / \mathrm{d}$ & $200-3000$ 200-3000 & $200-3000$ \\
\hline $\begin{array}{l}\text { Specific energy consumption, } \\
\mathrm{kW}-\mathrm{h} / \mathrm{m}^{3}\end{array}$ & $3.5-6.5$ & 5.0 \\
\hline $\begin{array}{l}\text { Membrane replacement cost, } \\
\mathrm{c} \$ / \mathrm{m}^{3}\end{array}$ & $3-10$ & 6 \\
\hline Investments cost, $\$ / \mathrm{m}^{3} / \mathrm{d}$ & $2400-1400$ & 1400 \\
\hline Chemicals, c $\$ / \mathrm{m}^{3}$ & $4-0$ & 6 \\
\hline Availability, $\%$ & $85-95$ & 90 \\
\hline $\mathrm{O} \& \mathrm{M}, 200-3000 \mathrm{~m}^{3} / \mathrm{d}, \mathrm{c} \$ / \mathrm{m}^{3}$ & $60-20$ & 20 \\
\hline O\&M, $3000 \mathrm{~m}^{3} / \mathrm{d}, \mathrm{c} \$ / \mathrm{m}^{3}$ & $15-25$ & 20 \\
\hline $\begin{array}{l}\text { Conventional energy cost, } \\
\mathrm{c} \$ / \mathrm{kWh}\end{array}$ & $6-10$ & 6 \\
\hline \multicolumn{3}{|l|}{ Wind energy resource } \\
\hline $\begin{array}{c}\text { Annual average wind speed at } \\
\text { hub height, } \mathrm{m} / \mathrm{s}\end{array}$ & $5-10$ & 7 \\
\hline Wind turbine & NM600/43, 48, 750/44 & NM600/43 \\
\hline Investment cost, $\$ / \mathrm{kW}$ & $900-1200$ & 1050 \\
\hline Availability & $85-95$ & 90 \\
\hline $\mathrm{O} \& \mathrm{M}, \mathrm{c} \$ / \mathrm{kWh}$ & $0.5-1.5$ & 1.0 \\
\hline
\end{tabular}


Table 16. Summary of a few RO plants powered by wind energy. Adapted from [7, 387].

\begin{tabular}{|c|c|c|c|}
\hline Plant & $\begin{array}{c}\text { Capacity } \\
\left(\mathbf{m}^{\mathbf{3}} / \mathbf{d a y}\right)\end{array}$ & Water type & $\begin{array}{c}\text { Wind turbine } \\
\text { nominal power (MW) }\end{array}$ \\
\hline De Planier, France & 12 & SW and BW & 4 \\
\hline Fuerteventura Island & 56 & SW & 225 \\
\hline $\begin{array}{c}\text { Therasia island, } \\
\text { Greece }\end{array}$ & 19.2 & SW & 15 \\
\hline Crest, UK & 12 & SW & 2.5 \\
\hline
\end{tabular}

\subsection{Geothermal}

Energy generation from on-shore high-enthalpy geothermal resources $\left(>150{ }^{\circ} \mathrm{C}\right)$ has become a mature technology over the past decades [37]. One of the first studies on geothermal-based desalination was reported in 1976 by Awerbuch et al. [388]. Geothermal reservoirs can be used to generate heat and electricity from their steam and hot water, thus, making it a potential RE source for both thermal and membrane desalination processes. One major advantage of geothermal energy is that there is no need for thermal storage, and thus can supply quite stable energy output compared to the other RE sources such as the solar and wind [389]. Table 17 compares the three major RE sources discussed in this paper. A relatively constant ground temperature is encountered below a certain depth, and thus geothermal reservoirs below $100 \mathrm{~m}$ can be used to power desalination plants [96]. Geothermal energy can provide both electricity and thermal energy. This makes it easier to couple with almost all the existing desalination technologies, both thermal and membrane-based. Huge energy savings through geothermal heating are reported, which otherwise not possible through other RE sources, as shown in Fig 27 [390]. Various projects have been implemented all over the world [391-393], which showed that a geothermal source having temperatures between 
$80-100{ }^{\circ} \mathrm{C}$, is enough to produce fresh water at a cost of $2 \mathrm{US} \$ / \mathrm{m}^{3}$. Geothermal has potential to power small-scale, middle-scale and large-scale desalination plants, with the present largest one having a productivity of about a million $\mathrm{m}^{3} /$ day [394].

Table 17. Comparison of RE resources for desalination. Adapted from [39].

\begin{tabular}{|c|c|c|c|}
\hline $\begin{array}{c}\mathbf{R E} \\
\text { resource }\end{array}$ & Application & Advantages & Disadvantages \\
\hline \multirow{3}{*}{ Solar } & $\begin{array}{l}\text { Solar still: Direct conversion of } \\
\text { saline water to potable water } \\
\text { through evaporation- } \\
\text { condensation. }\end{array}$ & $\begin{array}{c}\text { Inexpensive, simple } \\
\text { process. }\end{array}$ & $\begin{array}{c}\text { Energy loss in the form } \\
\text { of latent heat of } \\
\text { condensation }\end{array}$ \\
\hline & CSP: solar to electricity & Efficient & $\begin{array}{l}\text { High capital cost. } \\
\text { Output is intermittent }\end{array}$ \\
\hline & $\begin{array}{l}\text { Solar PV: conversion of sunlight } \\
\text { directly into electricity to power } \\
\text { RO desalination. }\end{array}$ & $\begin{array}{l}\text { Most widely utilized } \\
\text { method, hence mature } \\
\text { technology }\end{array}$ & $\begin{array}{l}\text { High capital cost. Large } \\
\text { land area requirement. }\end{array}$ \\
\hline Wind & $\begin{array}{c}\text { Wind turbine: Wind energy } \\
\text { generates electricity to power RO } \\
\text { desalination. }\end{array}$ & $\begin{array}{c}\text { Well suited for desalination } \\
\text { plants requiring electrical } \\
\text { power. }\end{array}$ & $\begin{array}{l}\text { Unpredictable resource. } \\
\text { Output is intermittent. }\end{array}$ \\
\hline Geothermal & $\begin{array}{c}\text { Geothermal steam to generate } \\
\text { electricity to power RO } \\
\text { desalination. }\end{array}$ & $\begin{array}{l}\text { Predictable resource. No } \\
\text { thermal storage required. }\end{array}$ & $\begin{array}{l}\text { Resource is limited to } \\
\text { certain locations }\end{array}$ \\
\hline
\end{tabular}




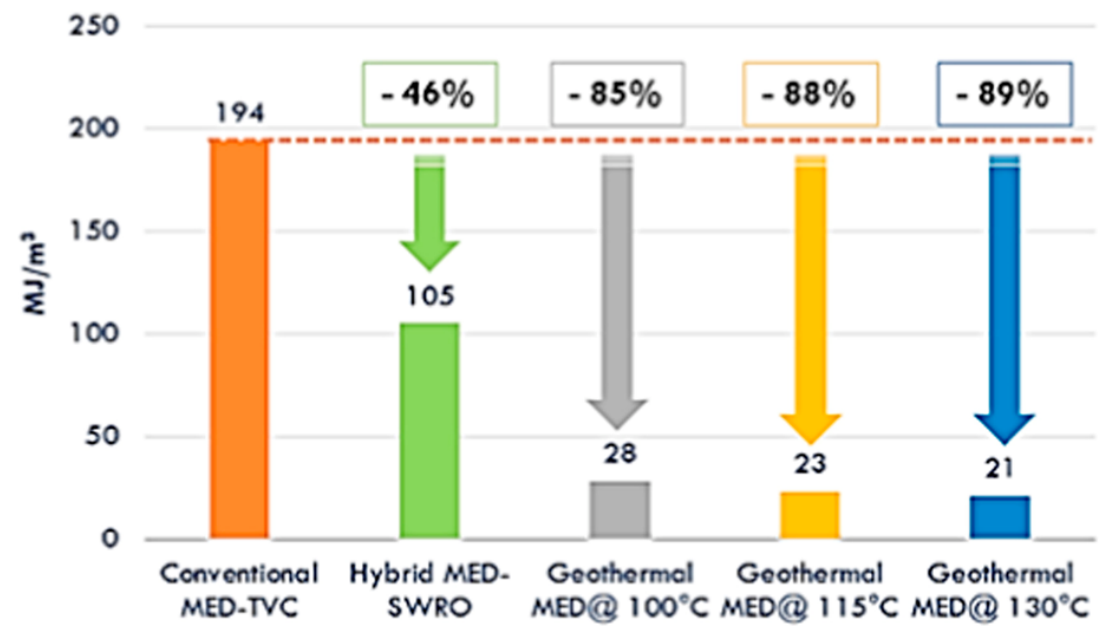

Fig 27: Potential energy savings on using geothermal-assisted MED at different source temperatures [390]. Copyright (C) 2016, Elsevier

Several geothermal-based desalination units have been installed worldwide [395, 396]. The AlJubail MSF plant has a fresh water production capacity of about $90,000 \mathrm{~m}^{3} /$ day. The possibility of using geothermal for thermal desalination makes this technology competitive to RO and other membrane-based technologies. In Mexico, where geothermal energy having a temperature of 80 ${ }^{\circ} \mathrm{C}$ is found, Rodriguez et al. [397] studied a combination of MED/boiling and MSF systems. 14 $\mathrm{m}^{3}$ of geothermal water was required to desalinate $1 \mathrm{~m}^{3}$ of $\mathrm{SW}$. Fresh water production costs for geothermal energy range from 0.65 US\$ at the Salton Sea [37], to about 1.5-2 US\$ for the Aegean islands [398]. Sarbatly and Chiam [399] presented energy evaluations of geothermal-assisted VMD units using lab-synthesized PVDF membranes and a commercial Westran S PVDF membrane. Membranes were tested with both distilled water and geothermal water as feed solutions. About $95 \%$ of the total energy was reported to be consumed in heating the heat. Thus, using a geothermal source could bring about huge energy savings compared to when an external heating source was used. If geothermal water is pumped directly from the reservoir, the SEC could reduce from $87-89 \mathrm{~kW} / \mathrm{kg}-\mathrm{h}^{-1}$ to $4.2 \mathrm{~kW} / \mathrm{kg}-\mathrm{h}^{-1}$. However, owing to concentration polarization 
arising from the various dissolved substances in the geothermal water, lower flux was achieved then the distilled water feed. Nevertheless, permeate had a total dissolved solid (TDS) content of below $500 \mathrm{ppm}$. The total water cost with a plant capacity of $20,000 \mathrm{~m}^{3} / \mathrm{d}$, with geothermal was estimated to be $0.5 \$ / \mathrm{m}^{3}$, while $1.22 \$ / \mathrm{m}^{3}$ without the geothermal energy. Loutatidou and Arafat [400] presented a techno-economic analysis of geothermal powered MED and RO desalination systems. They concluded that a geothermal-RO has a lower levelized cost of water (LCOW), $\$ 2.06 / \mathrm{m}^{3}$, compared to the geothermal MED $\$ 2.48 / \mathrm{m}^{3}$ system. Table 18 compares the technical design parameters for the MED and RO plants. However, it was calculated that the LCOW in a grid-powered RO plant was found to be $40 \%$ lower than the geothermal-assisted RO plant. Similarly, in a grid operated MED plant, the LCOW was $4 \%$ lower.

Table 18. Comparison between geothermal operated RO and MED desalination plants. Adapted from [400].

\begin{tabular}{|c|c|c|c|}
\hline \multicolumn{2}{|l|}{ RO } & \multicolumn{2}{|l|}{ MED } \\
\hline $\begin{array}{c}\text { Number of membrane } \\
\text { modules }\end{array}$ & 2205 & Top brine temperature & $67.59^{\circ} \mathrm{C}$ \\
\hline Number of pressure vessels & 315 & Gain output ratio GOR & 7.86 \\
\hline Permeate salinity & $271.63 \mathrm{ppm}$ & $\begin{array}{c}\text { Specific heat transfer area } \\
\text { As }\end{array}$ & $400.25 \mathrm{~m}^{2} . \mathrm{s} / \mathrm{kg}$ \\
\hline Feed pressure & $7243.63 \mathrm{kPa}$ & Cooling water flow rate & $2513 \mathrm{~m}^{3} / \mathrm{s}$ \\
\hline Concentrate pressure & $7083.25 \mathrm{kPa}$ & $\begin{array}{l}\text { Feed (make-up water) } \\
\text { volume flow rate Mf }\end{array}$ & $1010 \mathrm{~m}^{3} / \mathrm{s}$ \\
\hline Feed flow rate & $2778.86 \mathrm{~m}^{3} / \mathrm{h}$ & $\begin{array}{c}\text { Total SW volume flow rate } \\
\text { to the MED }\end{array}$ & $3527 \mathrm{~m}^{3} / \mathrm{d}$ \\
\hline Specific heat consumption & NA & Specific heat consumption & $82.4 \mathrm{~kW}-\mathrm{h} / \mathrm{m}^{3}$ \\
\hline
\end{tabular}




\section{Specific electricity} consumption
$4.46 \mathrm{~kW}-\mathrm{h} / \mathrm{m}^{3}$
Specific electricity consumption
$1.93 \mathrm{~kW}-\mathrm{h} / \mathrm{m}^{3}$

A combination of either desalination process or RE source has proved to be more energy efficient, rather than using a single system or a single source. For example, Missimer et al. [401] reported that a hybrid combination of solar and geothermal energy alternately for $12 \mathrm{~h}$ can reduce the possibility of depleting the geothermal reservoir heat. Up to $89 \%$ energy savings were reported for MED coupled SWRO systems utilizing a geothermal heat source [390]. The feed water can possible be replaced by the geothermal water, thus serving as a feed and a heat transfer medium during desalination. A SW MED unit coupled with a low temperature geothermal energy source was studied with temperature ranging between $75^{\circ} \mathrm{C}$ to $90{ }^{\circ} \mathrm{C}$. A low temperature energy source was reported to save an equivalent of $5000 \mathrm{TOE} / \mathrm{year}$ for a water production capacity of 600 $800 \mathrm{~m}^{3} /$ day [390]. For very low temperature heat sources, a heat pump may be utilized to convert it into high quality heat by extracting the enthalpy. Similarly, for a very high heat source, the heat cab be simultaneously utilized to produce electricity in a co-generation scheme. This reduces the overall costs, along with reduced environmental impact and land footprint. Geothermal energy has shown huge potential to bring down the total water production costs as a major portion of the energy for heating is supplied by the geothermal reservoir. Table 19 collates the performance of various RE desalination technologies which can be helpful for the readers for a quick comparison highlighting energy requirements and water production costs.

Table 19. Energy requirements and water production cost of several RE coupled desalination technologies. Adapted from $[9,37]$. 


\begin{tabular}{|c|c|c|c|}
\hline $\begin{array}{l}\text { Desalination- } \\
\text { solar } \\
\text { technology }\end{array}$ & $\begin{array}{l}\text { Typical } \\
\text { capacity }\end{array}$ & Energy demand $\left(k W-h / m^{3}\right)$ & Water cost $\left(\mathrm{US} \$ \mathbf{m}^{3}\right)$ \\
\hline Solar still & $<0.1$ & Solar passive & $1.3-6.5$ \\
\hline Solar MEH & $1-100$ & $\begin{array}{l}\text { Thermal: } 100 \\
\text { Electrical: } 1.5\end{array}$ & $2.6-6.5$ \\
\hline Solar MSF & 1 & Thermal: $81-144$ & $1-5$ \\
\hline $\begin{array}{c}\text { Solar tower } \\
\text { MSF }\end{array}$ & 1 & Total: 53.7 & - \\
\hline $\begin{array}{l}\text { Solar/CSP } \\
\text { MED }\end{array}$ & $>5000$ & $\begin{array}{l}\text { Thermal: } 60-70 \\
\text { Electrical: } 1.5-2 \\
\text { Total: } 50-94\end{array}$ & $\begin{array}{c}2.3-2.8 \\
\text { (prospective cost) } 2-9\end{array}$ \\
\hline $\begin{array}{c}\text { Solar tower } \\
\text { MED }\end{array}$ & 1 & $\mathrm{~T}: 42.4$ & - \\
\hline Solar tower VC & 1 & Elec: 55.5 & - \\
\hline PV-RO & $<100$ & $\begin{array}{c}\text { Electrical: BW: } 0.5-1.5: \mathrm{SW}: 4-5 ; \mathrm{BW}- \\
\text { SW: } 1.2-19 \\
\text { Electrical: } 41-45\end{array}$ & $\begin{array}{c}\text { BW: } 6.5-9.1 ; \text { SW: } 11.7- \\
15.6,3-27\end{array}$ \\
\hline Solar tower RO & 1 & & - \\
\hline Solar PV-EDR & $<100$ & $\begin{array}{l}\text { Electrical: BW: } 3-4 \\
\text { BW: } 0.6-1\end{array}$ & $\begin{array}{c}10.4-11.7(159] \\
3-16\end{array}$ \\
\hline Solar MD & $0.15-10$ & $\begin{array}{c}\text { Thermal: } 150-200 ; 100-600 ; 436 ; 180- \\
2200\end{array}$ & $\begin{array}{c}10.4-19.5 \\
13-18\end{array}$ \\
\hline Solar AD & 8 & Electrical: 1.38 T: 39.8 & 0.7 (electrical cost only) \\
\hline Wind MVC & $<100$ & $7-12$ & $5.2-7.8$ \\
\hline Wind RO & $50-2,000$ & $\begin{array}{l}\text { SW: } 4-6 \\
\text { BW: } 1.5-4\end{array}$ & $\begin{array}{l}6.6-9.0 \text { small capacity } \\
1.95-5.2 \text { for } 1000 \mathrm{~m}^{3} / \mathrm{d}\end{array}$ \\
\hline
\end{tabular}


Geothermal

MED

\subsection{Current status, challenges involved and possible future road map}

One of the most challenging issues associated with RE sources such as the wind and solar is their intermittent nature. This poses problems on the smooth and steady running of desalination plants. This drawback poses a major limit on transitioning from fossil fuels to RE sources for desalination application where a continuous operation is essential. Solutions to this lies in managing and coalescing the power supply and demand-side [402]. Power management might include using hybrid power sources, where the plant can make use of RE resource when it is available, while shifting to conventional sources during RE non-availability. Another approach can be to use energy storage devices such as electro-mechanical, and grid energy [403]. Nevertheless, when integrated into the grid, the balancing process becomes very complex. For this reason, energy storage devices such as batteries like lithium-ion and flow batteries seem more promising and feasible [404-406]. Thus, as a part of RE source for driving desalination, one area to focus on is the development of low-cost batteries with good power density and long lifecycles for reduced SEC. One technology which has come forward is the compressed air energy storage system in which the compressed air stores the energy reserve for a short time. This can be applicable when for example energy produced from a wind turbine exceeds the supply of electrical energy.

One significant drawback with solar-PV is the availability of area for installation of the PV modules. Roughly, to operate a small RO plant ( $1 \mathrm{~m}^{3} /$ day, SEC of $\left.8 \mathrm{~kW}-\mathrm{h} / \mathrm{m}^{3}\right)$, PV installations 
require an area of about $26.5-28 \mathrm{~m}^{2}$ [7]. With solar-powered MD, the LCOW is still a long way from competing economically with other RE-desalination combinations. Energy and corresponding cost reductions can be brought about by advanced MD membranes and lowering the thermal energy requirements. At present, the water production costs for RE assisted desalination systems still remain on a higher end, compared to conventional fossil fuels (Table 20). Nevertheless, combining RE sources with desalination systems holds immense potential for regions with water scarcity such as in the Middle East and North Africa (MENA) [407-410]. RE is already becoming competitive in remote locations where previously fresh water was transported to the habitants through ships and trucks [363]. Even though there is clear increasing trend in RE powered desalination technologies, there are still several challenges which need to be addressed:

- Meeting the energy demand for large production capacities is difficult.

- Intermittent RE source may require high-cost storage systems and grid lines, hence adding to the overall water production costs; not every time the desalination plant can be located near the direct energy source.

- Different countries might have different legal frameworks for a new technology, hence making the implementation of Res sources difficult to establish itself in new markets.

- Scalability of certain technologies such as solar PV is a big issue.

- High capital costs.

Table 20. Water production costs relative to the type of energy used for desalting BW and SW. Adapted from [198]

\begin{tabular}{|l|c|c|}
\hline Feed water type & Energy type & Cost/m $\mathbf{m}^{\mathbf{3}}$ (USD) \\
\hline & Conventional fuel & $0.27-1.38$ \\
\hline
\end{tabular}




\begin{tabular}{|c|c|c|}
\hline Brackish water & PV & $5.85-13.42$ \\
\hline \multirow{2}{*}{ Seawater } & Geothermal & 2.6 \\
\hline & Conventional fuel & $0.46-3.5$ \\
\hline & Wind energy & $1.3-6.5$ \\
\cline { 2 - 3 } & PV & $4.08-11.7$ \\
\hline
\end{tabular}

Clearly, reasons for restricted RE-desalination progress and market sweep is practically limited by technology, cost, and availability. For mature desalination technologies such as RO and MSF, difficulty in RE implementation still lies with storage problems and design improvements. Even with gradual decreasing prices, their capital expenditure still remains high, hence proving a bottleneck in their implementation. Fig. 28 illustrates the cost, capacity and the development stages of various RE powered desalination technologies [393, 411], where most of them lie in the advanced research and development (R\&D) stage. 


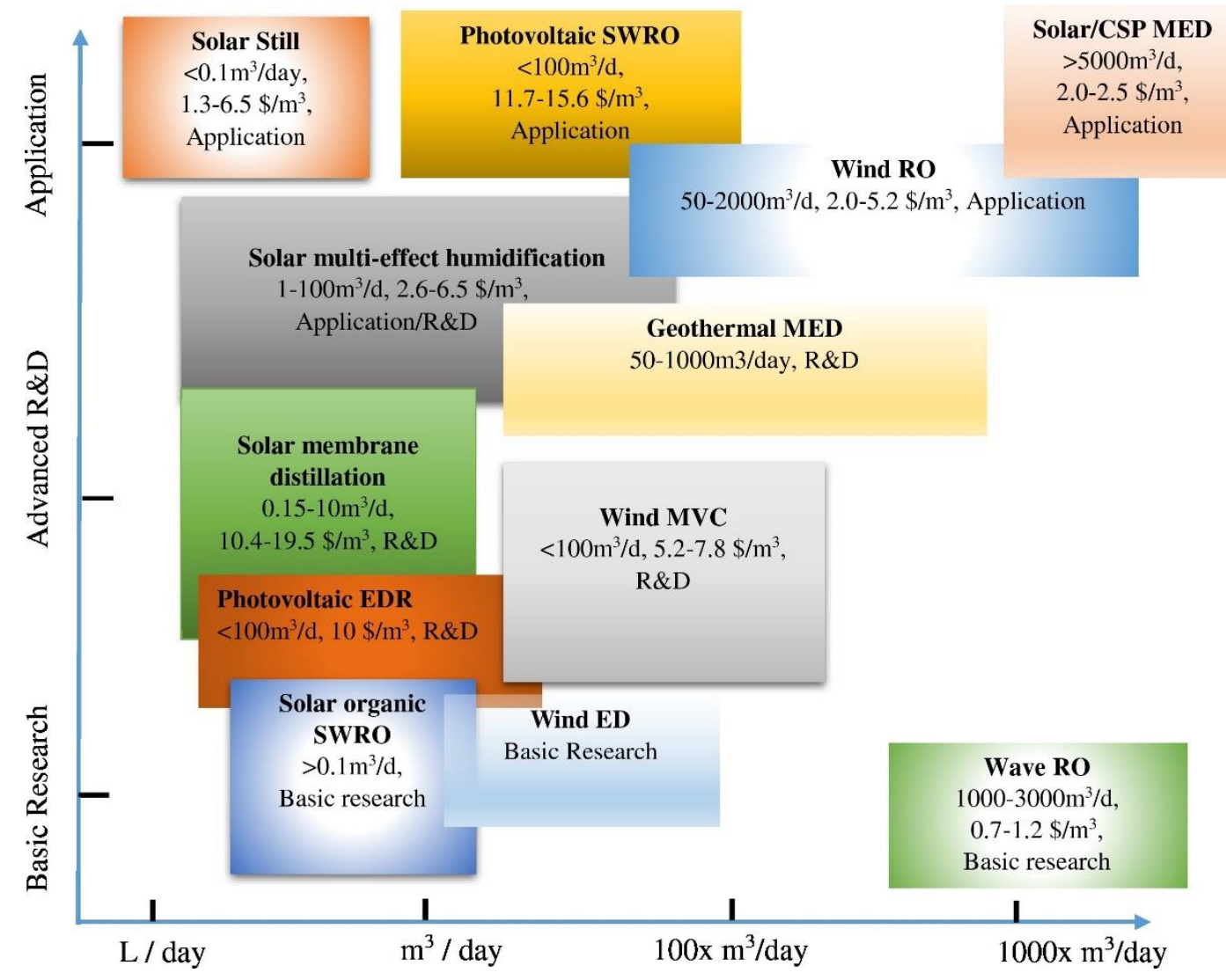

Fig. 28. RE-powered desalination technologies current status [7]. Copyright @ 2017, Elsevier.

\section{The quest for innovative systems and novel materials for reduced energy demands}

Conventional desalination technologies are operating far from their thermodynamic limit and need improved processes, most likely through hybridization and RE operated sources for energy reductions. For membrane based technologies, RO is the most established one till now, working near its theoretical limit, while others like MD and FO, still have a long way to go. Nevertheless, efforts are still required in all membrane-based processes for advanced membrane development. This is the reason, most of the research is focused on novel RO and FO membranes for enhanced membrane flux and selectivity. To lower the total water production cost, it should be kept in mind 
that other processes such as feed pretreatment and post-treatment also play a crucial role. When using membrane-based technology for RO feed pretreatment, advanced membranes can play a yet significant role in bringing down the total water production cost [20]. However, the applicability of energy reductions through novel membranes during feed pretreatment is not discussed in this review. This section focuses on the practicality of using advanced membranes and new technologies in solely the desalination step, in an attempt to reduce energy burden on the overall process.

At the heart of the RO process, lies a semipermeable membrane. R\&D in the membrane field can yield us break-through in energy reductions. TFC membranes dominate the RO market today, with water permeability and salt rejection up to $3.5 \times 10^{-12} \mathrm{~m}^{3} / \mathrm{m}^{2}$-Pa-s and 99.6 respectively [412]. Further improvements in these values is empirically difficult [413]. Thus, scientists and researchers are developing new, advanced membranes for improved performances [414-417]. For example, a significant amount of energy has to be put in for maintaining the permeate flux when membrane fouling occurs. While membrane cleaning usually adds to added costs. Hence, several membrane materials have been put forward for improved biofouling resistance for maintaining the SEC of the process [418-421]. Developments on both lab- and industrial-scale and underway. On lab-scale, research is more focused on fabricating novel active layers, advanced nano-scale membranes [422], optimized membrane configurations, while industrial perspective is more focused on modification of existing membranes for improved water quality and playing with the number of stages, module selections and hybrid options.

It is anticipated that UPMs hold immense potential in lowering down the energy consumption through reduced hydraulic pressure requirements. However, it is suggested that a significant reduction in energy can only be achieved if the membrane area is lowered and membrane 
permeability is at least doubled than the current values [423]. New generation RO membranes can bring about reduction in feed pressures by increasing more fresh water production per membrane element and compact membrane packing [424]. Though most of the research on such membranes is directed towards carbon nanotubes (CNTs) [425] and aquaporin [426] membranes, several other novel membrane concepts based on ceramic materials have also been reported [427-429]. Table 21 compares the most prominent next generation RO membranes.

Table 21. Advanced membrane material comparisons. Adapted from [39].

\begin{tabular}{|c|c|c|c|c|}
\hline $\begin{array}{c}\text { Membrane } \\
\text { type }\end{array}$ & Principle & $\begin{array}{c}\text { Energy } \\
\text { consumption }\end{array}$ & Advantages & Drawbacks \\
\hline Nanocomposite & $\begin{array}{c}\text { Zeolite } \\
\text { nanoparticles } \\
\text { incorporated in } \\
\text { PA matrix for } \\
\text { enhanced water } \\
\text { permeability. }\end{array}$ & $\begin{array}{l}20 \% \text { lower } \\
\text { energy } \\
\text { consumption } \\
\text { than } \\
\text { conventional } \\
\text { SWRO. }\end{array}$ & $\begin{array}{l}\text { More than } \\
\text { double the flux } \\
\text { of currently } \\
\text { available SWRO } \\
\text { membranes. }\end{array}$ & $\begin{array}{c}\text { Chemical compatibility } \\
\text { and structural stability } \\
\text { is not known. } \\
\text { Rejection of specific } \\
\text { contaminants is not } \\
\text { known. } \\
\text { Long-term operational } \\
\text { data not available. }\end{array}$ \\
\hline Nanotube & $\begin{array}{l}\text { Transport of water } \\
\text { molecules through } \\
\text { structured carbon } \\
\text { and boron nitride } \\
\text { nanotubes. }\end{array}$ & $\begin{array}{c}\text { 30-50\% lower } \\
\text { energy } \\
\text { consumption } \\
\text { than } \\
\text { conventional } \\
\text { SWRO. }\end{array}$ & $\begin{array}{l}\text { Ten - fold } \\
\text { higher flux than } \\
\text { currently } \\
\text { available SWRO } \\
\text { membranes }\end{array}$ & $\begin{array}{l}\text { Only modeling results } \\
\text { available. } \\
\text { Rejection of specific } \\
\text { contaminants is not } \\
\text { known. }\end{array}$ \\
\hline Biomimetic & $\begin{array}{l}\text { Aquaporins used } \\
\text { to regulate } \\
\text { transport of water } \\
\text { molecules. }\end{array}$ & $\begin{array}{c}\text { Energy } \\
\text { consumption is } \\
\text { not known. }\end{array}$ & $\begin{array}{c}\text { Hundred times } \\
\text { permeable than } \\
\text { currently } \\
\text { available SWRO } \\
\text { membranes. }\end{array}$ & $\begin{array}{l}\text { Inability to withstand } \\
\text { high operating } \\
\text { pressures. } \\
\text { Rejection of specific } \\
\text { contaminants is not } \\
\text { known. } \\
\text { Long-term operational } \\
\text { data not available. }\end{array}$ \\
\hline
\end{tabular}


CNTs have been reported to consume much less energy than the conventional RO and FO membranes [430, 431]. Theoretical calculations show that aligned CNTs can produce fluxes which are 3-4 times higher than the present hydrodynamic theories [425, 432]. This is due to their smooth nanotube walls, and its energetic landscape [433, 434]. However, even if such challenging theoretical values are reached, membrane fouling will be exacerbated, and adequate salt rejection without CNT functionalization is still not applicable [435]. Nevertheless, because SWRO is already operating quite near its thermodynamic limit, energy savings from these novel membranes are ought to be quite small. A ten-fold increase in membrane performance may finally result in about 30-50\% energy savings. For these reasons, biofouling resistant membranes hold more potential for energy, environmental and ecological improvements. One possibility is to develop fouling release membranes that the foulants are washed away by hydrodynamic mixing as they approach the membrane surface [436].

Thin-film nanocomposite (TFN) membranes have shown superior performance to conventional TFC membranes. Compared to commercial SWRO membranes, TFN membranes are capable of producing 20 times more flux with the same surface area leading to around $20 \%$ reductions in energy consumption $[39,106,437]$. These membranes are usually fabricated by incorporating zeolite nanoparticles in the active PA layer [438, 439]. Zeolite, a well-ordered microporous aluminosilicate is a versatile material [440-443], which has gained immense interest in desalination membranes over the past years [444, 445]. For incorporating them into a PA layer, zeolite nanoparticles are dispersed in either of the monomer solutions before interfacial polymerization. Through improved fluxes with high, $99.7 \%$ rejections have been demonstrated, chemical stability of such nanoparticles within the active layer is a question which needs to be addressed by researchers before the product can be commercialized. In addition, the membrane has not shown 
promising results for boron rejection, which is concerning for increasing boron stringent limits. This is another area where researchers need to focus for possible improvements.

Highly selective water transport is possible through cell membranes, thus advancing membrane research in biomimetic membranes $[446,447]$. The extremely high rates of water transportation across the cell membranes is ought to the presence of aquaporins [447]. Aquaporins are natural water channel proteins which transport water rapidly across cell membranes while excluding solutes $[448,449]$. One way to form biomimetic membranes is by incorporating aquaporin within a synthetic analog to vesicular such as ABA triblock copolymer [450]. For example, Kumar et al. [426] investigated the permeability of polymeric vesicles containing Aquaporin $\mathrm{Z}$ which is a bacterial aquaporin extracted from Escherichia coli (E. coli). They found that water productivity in the aquaporin containing polymer was 800 times higher than that of pure polymer. Also, compared to commercial BW30 RO membranes, productivity of aquaporin containing vesicles was approximately 84 times higher. Although, these vesicles were not tested in RO, their high productivity makes them extremely attractive for desalination. A more convenient approach for the implementation of aquaporins in membranes is by incorporating these proteins in synthetically prepared polymeric membranes [447, 448]. Zhao et al. [451] prepared a PA coating film containing proteoliposomes incorporated with aquaporin $\mathrm{Z}$ by interfacial polymerization method. RO experiments with an applied pressure of 5 bar, showed that the permeability of biomimetic membrane $\left(4.0 \mathrm{~L} / \mathrm{m}^{2} \mathrm{~h}\right.$ bar) was an order of magnitude higher than the commercial SWRO membrane. These results indicate that biomimetic membrane prepared by interfacial polymerization have great potential in SWRO. Li et al. [452] used a similar fabrication procedure. However, in their study, the membrane was a hollow fiber. The flux of the modified membrane was found to be $200 \%$ higher than that of the commercial RO membrane. Biomimetic membranes, 
hold a high potential, almost up to $70 \%$ energy reductions, due to their UHP compared with the present commercial RO membranes. This is quite a promising research area for energy minimization, with studies acing in the direction of overcoming mechanical integrity challenges and developing defect-free membranes $[451,453]$. However, commercialization of biomimetic membranes is challenged by the lack of understanding of the interaction between the membrane and the protein, and the cost and complexity of scaling-up using the available methods for synthesizing biomimetic membranes [448]. Hence, further research should be directed towards understanding membrane chemistry, enhancing mechanical integrity and proposing new massscale production methods.

Besides investing in new membrane materials for energy minimizations, innovative desalination technologies and modification to current designs are required. Well-designed SWRO systems with minimum frictional losses can bring down the SEC to $1.56 \mathrm{~kW}-\mathrm{h} / \mathrm{m}^{2}$ [45]. A staged membrane design, which uses two high-pressure pumps and membrane modules in series, may bring the actual energy closer to the theoretical minimum [454]. Less energy is consumed through this design where smaller volumes of water are brought to higher pressures. Ideally, each stage may be operated at the same percent recovery; however, a more practical design is to operate the second stage at a higher, desired recovery. Under these conditions, SEC of $1.28 \mathrm{~kW}-\mathrm{h} / \mathrm{m}^{2}$ can be achieved at $50 \%$ recovery desalinating $35,000 \mathrm{ppm}$ of SW.

Lin and Elimelech [200] presented a detailed comparison on the energy efficiency and potential of various RO configurations; single-staged, multi-stage direct pass (DP) and a closed circuit (CC) configuration. In a multi-stage DP-RO process, the brine solution from a previous stage becomes the feed solution of the next one (Fig. 29). Osmotic pressure is thus increased progressively along the stages, requiring higher hydraulic pressures. As can be seen in Fig. 29a, the SEC of a multi- 
stage setup is considerably lower than a single-staged one, with significant reductions in energy with infinite stages. In a CC-RO process, the brine recirculates (Fig. 29b) in a closed circuit and remixes with the feed solution [455]. As can be seen form the SEC versus recovery graph, an infinite stage is not a practical option. However, a four or higher-stage process may deem to approach SEC of $\mathrm{CC} \infty(\mathrm{R})$ throughout the entire recovery percentage. Another noticeable feature is that the SEC in the $\mathrm{CC} \infty(\mathrm{R})$ is higher than the SEC of the DP $\infty(\mathrm{R})$. SWRO units usually operate at $50 \%$ recovery, and thus an eight-stage $\mathrm{CC}-\mathrm{RO}$ can potentially reduce the SEC by $\sim 22 \%$ (saving $0.5 \mathrm{~kW}-\mathrm{h} / \mathrm{m}^{3}$ ) in contrast to a single-staged one for a feed salinity of 35,000 ppm. Their [200] study showed that the CC-RO was theoretically more beneficial, and economically more practical, however, the process itself is still in its emerging phase, and requires further developments in terms of hydraulic pressure variations on membrane performance and limitations on high pressure pumps [456].

In a hybrid RO configuration having seven elements, ideally each membrane element should produce $14.3 \%$ of the total permeate flux. However, this is not true in conventional systems, where the flow distribution in each vessel is quite uneven, with the first vessel producing majority of the flow which gradually declines along the vessels owing to feed salinity and osmotic pressure differences. Because the first element produces majority of the flux, it uses up most of the available energy for desalination, not providing enough energy for the upcoming RO elements. Thus, the overall energy efficiency in conventional SWRO systems is not really optimized, with additional burden of membrane fouling in the first RO element due to retention of large quantities of solutes [106]. A much more energy efficient RO system would be possible if each vessel had an even feed flow. This may be achieved through a novel membrane configuration with three different membranes having different permeability within the same vessel. This approach was perfected by 
Dow Filmtec [457], and has been applied to several RO plants worldwide. Kim and [458] reported an optimized SWRO internally staged design (ISD) for improved energy efficiency and permeate quality. In an ISD configuration, high-rejection membranes are placed in the front, while high-flux ones are placed at the back [459]. This aimed in distributing the flux evenly in the RO elements, with the higher-flux membrane at the end requiring less pressure and thus lower SEC. The same group of researchers [460] assessed the feasibility of a novel single-pass RO configuration with a split partial single-pass (SSP) RO design. This design allowed the blending of the permeate with the RO feed. This blending resulted in feed dilution, whence producing high-quality permeate with a lower energy demand. A seven element RO module was used which showed superior results to a two-staged RO system. Their theoretical models showed a SEC of about 2.17 to $2.29 \mathrm{~kW}-\mathrm{h} / \mathrm{m}^{3}$ at a recovery rate of $40 \%$. However, their system was not experimentally investigated.

Chong et al. [461] reported an energy-efficient RO (EERO) process using a single-staged RO with a countercurrent membrane cascade with recycle (CMCR). The retentate from the first stage was taken as the feed for the CMCR which employed a countercurrent retentate and permeate flow. This configuration resulted in reduced membrane fouling, allowing higher recoveries than the single-stage RO system. A SEC of $2.323 \mathrm{~kW}-\mathrm{h} / \mathrm{m}^{3}$ was calculated for a three-stage EERO process having 50\% water recovery, while a SEC of $3.773 \mathrm{~kW}-\mathrm{h} / \mathrm{m}^{3}$ was reported for a four-stage EERO system with $75 \%$ overall water recovery. Nevertheless, energy savings through two or multiple stages and/or RO elements should be off-set by their capital cost, which explains the reason for not implementing several of these proposed designs, such as the multiple-stage DP-RO system. 
a)

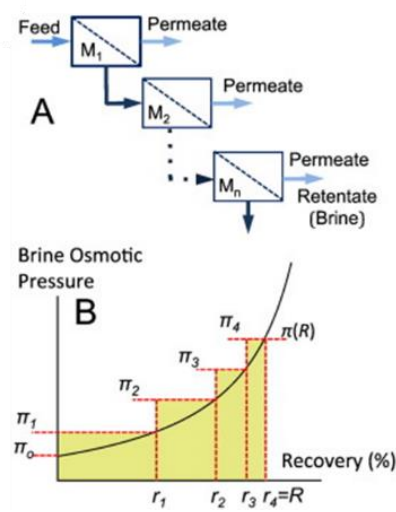

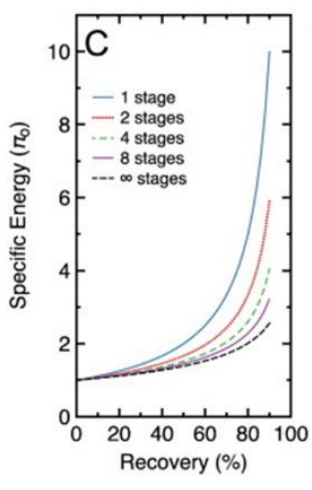

b)

A Closed Circuit

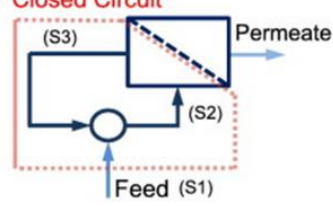

Brine Osmotic

Pressure

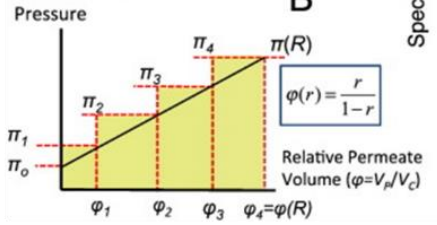

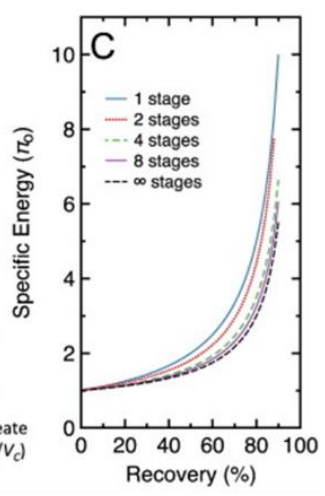

Fig. 29. (a) A: Schematic of a multi-stage DP-RO process, B: Brine osmotic pressure as a function of recovery rate. The yellow region signifies minimum SEC to achieve an R recovery rate, C: SEC of a DP$\mathrm{RO}$ as a function of recovery rate with different number of stages. (b) A: Schematic of a CC-RO process, $\mathrm{B}$ : normalized retentate osmotic pressure as a function of the relative permeate volume, $\varphi, \mathrm{C}$ : SEC of a CC-RO as a function of recovery rate with different number of stages [200]. Copyright (C 2015, Elsevier.

Besides SWRO, there are several emerging low-energy desalination technologies which hold potential to reach close to the theoretical minimum energy [119]. Ion concentration polarization is one such method in which ionic species are prevented from flowing into a fresh water reservoir through an ion depletion zone on passing a potential across a nano channel. This system is more applicable for remote locations as little feed pretreatment is necessary. For large-scale units, the SEC might exceed the current SWRO, hence rendering the technology unfeasible [462]. CDI was developed as an energy-efficient, cost-effective alternative to RO [463]. However, owing to the gap in research innovation for optimum electrode materials, stand-alone processes have not been commercialized yet $[464,465]$. In CDI, salt water flows through a capacitor module consisting of high-surface area electrodes. Upon applying an electric field, anions and cations are electrosorbed upon polarization of each electrode. SEC of $1.37-1.67 \mathrm{~kW}-\mathrm{h} / \mathrm{m}^{3}$ has been reported for BW desalination using CDI [466] while there is little information on SEC for high saline waters in the literature. 
Significant innovations have also been made in RE assisted desalination. For example, much interest is put into MD utilizing photothermal nanoparticles which can significantly reduce the thermal contribution to energy which accounts to almost 70\% of the total MD cost [204]. Interested readers are suggested to read reviews such as those by Peng Wang [467] on nanoenabled photothermal materials. These also include nanofluids which are nanoparticle suspensions, and can absorb solar energy for increased solar absorption efficiency [468, 469]. Though this research is in its early phase, there are already material prototypes such as metals, metal oxides, metal nitrides and carbon-based nanoparticles for potential nanofluids. Zhang et al. [470] used TiN nanofluid for improved solar energy efficiency in solar powered MD. An increase in TiN concentration from 0 to $100 \mathrm{ppm}$ showed a flux increase by a factor of 1.57 , concurrently increasing energy efficiency from $32.1 \%$ to $50.5 \%$. The increase in flux was bought about by an increased temperature difference between the feed and permeate side, thus increasing the driving force for MD. This concept is becoming popular, with many research groups focusing on nanoparticle-assisted solar vaporization recently [185].

Fig. 30 shows the future roadmap for both thermal and RO processes [7, 471], and how new, innovative desalination technologies are essential in closing the gap between current and near thermodynamic energy limit. In addition, innovations in desalination are ought to put less environmental burden, hence paving the way for a more sustainable desalination future. Highperformance membranes will easily take up 5-10 years to achieve the landmark, however, thermal processes are readily available, and have a faster prospect for achieving the sustainability zone if used in conjunction with other processes. Even with several new desalination technologies being sought to bring down the SEC, it is not expected that a significant reduction can be achieved 
anytime soon. Thus, it is quite foreseeable that RO will lead in membrane-based desalination technologies, hence escalating research in advanced RO membranes and efficient ERDs.
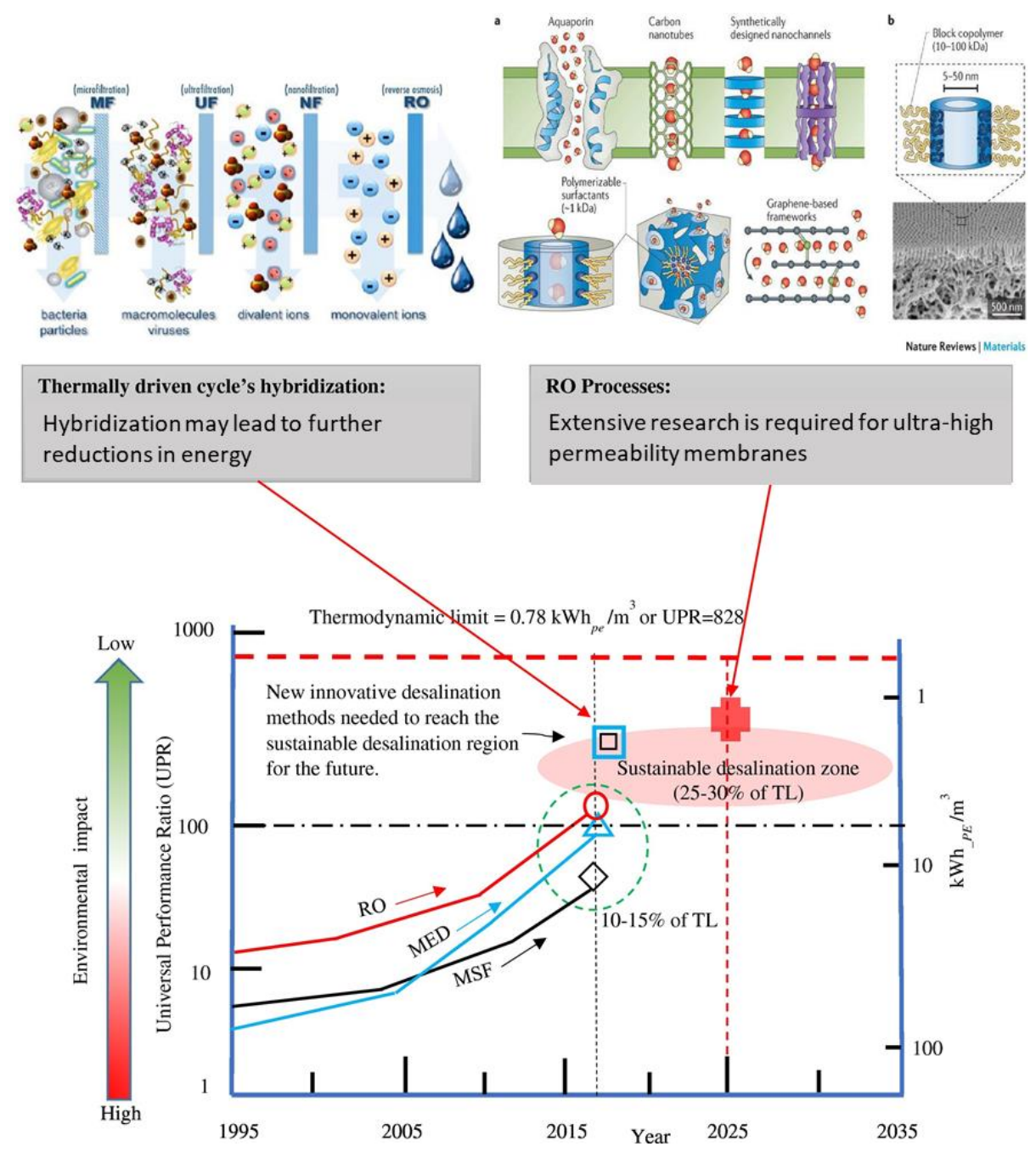

Fig. 30. Desalination technologies roadmap for future sustainability. $T L=$ thermodynamic limit $[7,471]$

\section{Conclusions and Future Recommendations}

Over the past decades, desalination technologies have witnessed significant improvements in design for energy and cost reductions. However, optimization of energy consumption by 
desalination is still an issue. The increasing demand for fresh water and depletion of fossil fuels call for innovative solutions to enhance the energy efficiency of desalination. Given that SEC of current thermal desalination and RO plants is still above the minimum practical energy required for desalination, further reduction in SEC is still possible and desirable. Understanding the sources of energy consumption in desalination technologies and factors that affect it are a key for developing solutions to reduce their energy requirements. Moreover, improving the energy efficiency of desalination processes can be realized by introducing hybrid systems which combine the advantages of the standalone processes. Advances in desalination technologies should also be directed towards providing fresh water in a sustainable manner which can be achieved by coupling desalination with renewable energy sources.

This paper provided a comprehensive review on energy requirements for various desalination technologies. Factors affecting SEC of desalination were reviewed and gaps in the literature were identified for possible directions for researchers to invest in the area of energy optimization. Major conclusions and future directions are highlighted below:

- Thermal desalination are mature technologies. Advances in process configuration and optimization for enhanced energy efficiency are usually studied using theoretical models. These models show minor reductions in SEC. Considering the irreversible losses in real processes, these advances may not significantly impact the SEC of thermal processes. However, regardless of their high energy requirements, thermal desalination technologies are still needed in some parts of the world due to their advantage of treating highly saline feeds.

- High pressure pumps are the major energy consumers in RO. It has been already established that increasing the size of the high pressure pumps reduces SEC. However, this 
might not be an adequate solution for energy reduction because it requires more space and makes system maintenance more challenging. Alternatively, energy reductions can be achieved by enhancing the efficiency of high pressure pumps and decreasing their irreversible work. Part of the energy losses in the high pressure pumps is due to irreversible work (entropy generation). Irreversible losses can be minimized by supplying energy to the RO process in a staged manner.

- Enhancing the energy efficiency of RO by improving membrane permeability is limited by thermodynamics. Most of the research is theoretical. There is a need for experiments and pilot scale tests to evaluate the effect of membrane permeability. Fouling and concentration polarization are not accounted for in simulations or short-term experiments even though they are critical parameters which can significantly affect membrane performance. Development of ultra-high permeability membranes might open the doors for reduced energy consumption in $\mathrm{RO}$ as well as improved fouling mitigation. While coating conventional membranes to reduce fouling significantly reduces their flux, coating ultrahigh permeability membranes will result in high permeability membranes with long durability.

- Following the implementation of high efficiency energy recovery devices, the SEC of RO is now approaching the minimum practical energy needed for desalination. The most efficient energy recovery devices which is currently used in commercial RO plants is PX with a reported efficiency of $98 \%$. Therefore, advancement in equipment efficiency for energy reduction is very limited.

- The current SEC of emerging technologies such as membrane distillation is much higher than the minimum thermodynamic energy limit. Nevertheless, due to the reduction in 
conductive heat flux, the SEC of the process decreases with improved membrane performance. In addition, feed preheating at a high temperature further increases the permeate yield, leading to savings in energy.

- membrane distillation energy requirement is determined by many factors, of which the most important is the membrane efficiency, namely its thermal efficiency and other deciding factors. Other factors include membrane distillation configuration and energy recovery. The process has the ability to meet the target threshold if it uses waste heat for its thermal evaporation which constitutes more than $100 \mathrm{~kW}-\mathrm{h} / \mathrm{m}^{3}$.

- The energy requirements for forward osmosis are controversial with various studies reporting different analysis and conclusions. However, forward osmosis does hold immense potential for desalination when compared to several existing desalination technologies. Nevertheless, forward osmosis membranes are prone to fouling, calling for an urgent need to invest in this area of research for developing fouling resistant and high permeability membranes. This might be possible by incorporating functional nanoparticles [11] in the existing forward osmosis polymeric membranes, similar to what is being done to RO, UF, MF and other types of membranes [444, 472, 473]. In addition, to obtain similar SEC as RO, a higher membrane area is required, thus putting a dire need to focus on this research perspective.

- Advances in membrane manufacturing and implementation of efficient high pressure pumps and energy recovery devices led to significant decrease in SEC of RO. Further reduction in SEC can be achieved using hybrid systems. FO-RO hybrid configuration where low salinity wastewater is used to dilute the SW feed, is the most promising hybrid configuration for energy efficient desalination. To ensure economic feasibility and realize 
commercialization of hybrid FO-RO, future research should focus on designing high flux FO membranes. However, the need for a large amount of wastewater to achieve reasonable water recovery remains a challenge.

- Energy recovery from SWRO brine using pressure retarded osmosis is somehow similar to forward osmosis where low salinity wastewater or river water is required to dilute the brine. Results from theoretical models confirm the potential of hybrid RO-pressure retarded osmosis to reduce the SEC by 50\% compared to standalone SWRO [163, 267]. However, the recent analysis of energy feasibility by Park et al. [249] indicated that practically, the maximum amount of energy extracted in by pressure retarded osmosis is only $0.14 \mathrm{~kW}$ $\mathrm{h} / \mathrm{m}^{3}$. Although, this value is not high, there is still potential for energy recovery by PRO. Developing high performance membranes designed specifically for pressure retarded osmosis to reduce fouling and concentration polarization may increase the energy savings by RO- pressure retarded osmosis.

- Increasing the top brine temperature to enhance the performance of thermal desalination processes is limited by scaling. Using antiscalants to control scaling in thermal processes is associated with complexities related to dosing which if not done systematically might lead to adverse results. Therefore, pretreatments of SW by NF or forward osmosis before being fed to the thermal process offer potential alternatives to antiscalants. Removing the ions responsible for scale formation by FO or NF will allow us to operate MSF and MED at higher top brine temperature to enhance the process efficiency. Future work should be focused on evaluating the process economics and estimating the SEC of the overall hybrid system. 
- Recent studies showed that the performance of conventional MED can be potentially enhanced by attaching an adsorption desalination cycle to the last effect in MED. These hybrid systems yield a water production rate that is almost $50 \%$ higher than standalone MED. However, MED-adsorption desalination hybrids are still far from commercialization as the economic feasibility is still in question and pilot-scale tests are limited. MSF-MED hybrid systems do not seem to be attractive for energy reduction due to their complexity and inflexible operation

- The future of SW desalination might lie in renewable energy sources. However, at present only a small percentage of desalinated water comes from renewable energy operated plants, with a clear lack of data on energy consumption. Several research areas need attention. Many of the renewable energy powered units such as PV-RO are limited to small scales and have varying SEC values ranging from $1.1-16 \mathrm{~kW}-\mathrm{h} / \mathrm{m}^{3}$. The variability in solar energy source is unavoidable, and thus efficient storage means and batteries are required to tackle this problem. For remote locations, instead of RO, the use of PV is more attractive for electrodialysis where BW is readily available throughout a year. In addition, studies are required which deal with the PV-RO combination, addressing the energy requirements of each of its components, rather than dealing with them separately.

- The non-intermittent nature of geothermal energy makes it an attractive and valuable resource. To further explore this energy source for desalination, there is a need to accelerate the development of low-enthalpy geothermal desalination plants, perform detailed economic and energy modeling for future developments, and combine the geothermal source with the several well-established desalination technologies on a commercial scale. 
Most of the studies are theoretical, and more experimental findings are necessary to evaluate system feasibility in real time operation.

- Thin film nanocomposite hold potential for ultra-high permeable RO membranes for reduced energy consumptions. Though high rejections, $99.7 \%$ and improved fluxes have been demonstrated in zeolite-based Thin film nanocomposite membranes, the chemical stability of such nanoparticles within the active layer remains low, which poses hindrance for its commercialization. Research in this direction is underway, however, another future route is to either use zeotypes [474] or hybrid nanoparticle and nanowire combinations [475-479] for improved chemical stability and rejections against other contaminants such as boron. Substantial pilot-scale studies are also needed for Thin film nanocomposite membranes to progress them towards commercialization.

\section{Abbreviations}

3DGN Three-dimensional graphene network

$\mathrm{A}_{\mathrm{c}} \quad$ solar collector areas

AD Adsorption desalination

ADC Affordable desalination collaboration

AGMD Air gap membrane distillation

BP Booster pump

BR Brine recirculation

BW Brackish water

CC Closed circuit 
CDI Capacitive deionization

CMCR Countercurrent membrane cascade with recycle

CNTs Carbon nanotubes

CSP Concentrated solar power

DCMD Direct contact membrane distillation

DP Direct pass

DWEER Dual work exchanger energy recovery

E. coli Escherichia coli

ED Electrodialysis

$\mathrm{E}_{\mathrm{d}} \quad$ Exergy destruction

EERO Energy efficient reverse osmosis

ERD Energy recovery device

FO Forward osmosis

GHG Greenhouse gases

GO Graphene oxide

GOR Gain output ratio

GWI Global Water Intelligence

HPP High pressure pump

IDA International Desalination Association

IEM Ion exchange membrane

ISD Internally staged design

LCOW Lower levelized cost of water

LDPE Low density polyethylene

LFR Linear Fresnel reflector

LPP Low pressure pump

MD Membrane distillation

MED Multi-effect distillation

MENA Middle East and North Africa

MSF Multi stage flash

MVC Mechanical vapor compression

NF Nanofiltration

O\&M Operation and maintenance

ORC Organic Rankine cycle

OT Once through 


\begin{tabular}{|c|c|}
\hline PA & Polyamide \\
\hline PAFO & Pressure assisted forward osmosis \\
\hline PDS & Parabolic dish systems \\
\hline $\mathrm{PE}$ & Polyethylene \\
\hline PP & Polypropylene \\
\hline PRO & Pressure retarded osmosis \\
\hline PTC & Parabolic trough collector \\
\hline PTFE & Polytetrafluoroethylene \\
\hline PV & Photovoltaic \\
\hline PVDF & Polyvinylidene fluoride \\
\hline PX & Pressure exchanger \\
\hline $\mathrm{RE}$ & Renewable energy \\
\hline RO & Reverse osmosis \\
\hline RSI & Ryznar Scale Index \\
\hline SEC & Specific energy consumption \\
\hline SGE & Salinity gradient energy \\
\hline SGMD & Sweeping gas membrane distillation \\
\hline SPT & Solar power tower \\
\hline SSP & Split partial single-pass \\
\hline SW & Seawater \\
\hline TBT & Top brine temperature \\
\hline TDS & Total dissolved solids \\
\hline $\mathrm{TF}_{\mathrm{a}}$ & Average feed temperature \\
\hline TFC & Thin film composite \\
\hline TFN & Thin-film nanocomposite \\
\hline TTD & Total temperature difference \\
\hline TVC & Thermal vapor compression \\
\hline UF & Ultrafiltration \\
\hline UPM & Ultra permeable membrane \\
\hline $\mathrm{VC}$ & Vapor compression \\
\hline VFD & Variable frequency drive \\
\hline VMD & Vacuum membrane distillation \\
\hline $\mathrm{V}_{\mathrm{st}}$ & Storage tank volume \\
\hline
\end{tabular}




\section{Symbols}

a Activity coefficient, a constant, a coefficient

$\pi \quad$ Osmotic pressure

$\mu \quad$ Chemical potential

$\mathrm{X} \quad$ A variable; $\mathrm{X}_{\mathrm{i}}$ fraction of species $\mathrm{i}$ in a mixture

$\mathrm{W} \quad$ Work per unit mass, $w_{t h}$ theoretical work

E Exergy rate

V Volume

P Pressure

\section{References}

[1] N. Ghaffour, T.M. Missimer, G.L. Amy, Technical review and evaluation of the economics of water desalination: Current and future challenges for better water supply sustainability, Desalination, 309 (2013) 197-207.

[2] Global Water Intelligence, The International Desalination Association, IDA Desalination Yearbook 2017-2018, Media Analytics Ltd., United Kingdom, 2017.

[3] Global Water Intelligence, The International Desalination Association, IDA Water Security Handbook 2019-2020, Media Analytics Ltd., United Kingdom, 2019.

[4] M. Nair, D.J.D. Kumar, W. Treatment, Water desalination and challenges: The Middle East perspective: a review, 51 (2013) 2030-2040.

[5] J. Schallenberg-Rodríguez, J.M. Veza, A. Blanco-Marigorta, Energy efficiency and desalination in the Canary Islands, Renewable and Sustainable Energy Reviews, 40 (2014) 741-748.

[6] GWI DesalData, Desalination and Reuse Market Update, in, United Kingdom, 2020.

[7] M.W. Shahzad, M. Burhan, L. Ang, K.C. Ng, Energy-water-environment nexus underpinning future desalination sustainability, Desalination, 413 (2017) 52-64.

[8] UN-Water, UN-Water Policy Brief: Water Quality, in, 2014.

[9] A. Al-Karaghouli, L.L. Kazmerski, Energy consumption and water production cost of conventional and renewable-energy-powered desalination processes, Renewable and Sustainable Energy Reviews, 24 (2013) 343356.

[10] UN-Water, The United Nations World Water Development Report, The United Nations Educational, Scientific and Cultural Organization, France, 2014.

[11] S.F. Anis, R. Hashaikeh, N. Hilal, Functional materials in desalination: A review, Desalination, 468 (2019) 114077.

[12] B.P. Walsh, S.N. Murray, D.T.J. O'Sullivan, The water energy nexus, an ISO50001 water case study and the need for a water value system, Water Resources and Industry, 10 (2015) 15-28.

[13] World Business Council on Sustainable Development, Water, Energy, and Climate Change: A Contribution from the Business Community, Atar Roto Presse SA, Switzerland, 2009. 
[14] D. Zarzo, D. Prats, Desalination and energy consumption. What can we expect in the near future?, Desalination, 427 (2018) 1-9.

[15] M.A. Abdelkareem, M. El Haj Assad, E.T. Sayed, B. Soudan, Recent progress in the use of renewable energy sources to power water desalination plants, Desalination, 435 (2018) 97-113.

[16] V.G. Gude, Geothermal source potential for water desalination - Current status and future perspective, Renewable and Sustainable Energy Reviews, 57 (2016) 1038-1065.

[17] B.D. Negewo, Renewable energy desalination: an emerging solution to close the water gap in the Middle East and North Africa, World Bank Publications, 2012.

[18] V.G. Gude, N. Nirmalakhandan, S.J.E. Deng, Desalination using solar energy: Towards sustainability, 36 (2011) 78-85.

[19] T. Mezher, H. Fath, Z. Abbas, A. Khaled, Techno-economic assessment and environmental impacts of desalination technologies, Desalination, 266 (2011) 263-273.

[20] S.F. Anis, R. Hashaikeh, N. Hilal, Reverse osmosis pretreatment technologies and future trends: A comprehensive review, Desalination, 452 (2019) 159-195.

[21] S. Miller, H. Shemer, R. Semiat, Energy and environmental issues in desalination, Desalination, 366 (2015) 2-8.

[22] K.C. Ng, K. Thu, S.J. Oh, L. Ang, M.W. Shahzad, A.B. Ismail, Recent developments in thermally-driven seawater desalination: Energy efficiency improvement by hybridization of the MED and AD cycles, Desalination, 356 (2015) 255-270.

[23] O.A. Hamed, Thermal Desalination: Performance and Challenges, in: V.S. Saji, A.A. Meroufel, A.A. Sorour (Eds.) Corrosion and Fouling Control in Desalination Industry, Springer International Publishing, Cham, 2020, pp. 29-47.

[24] A. Shrivastava, S. Rosenberg, M. Peery, Energy efficiency breakdown of reverse osmosis and its implications on future innovation roadmap for desalination, Desalination, 368 (2015) 181-192.

[25] J.M. Gordon, T.C. Hui, Thermodynamic perspective for the specific energy consumption of seawater desalination, Desalination, 386 (2016) 13-18.

[26] R.L. McGinnis, M. Elimelech, Energy requirements of ammonia-carbon dioxide forward osmosis desalination, Desalination, 207 (2007) 370-382.

[27] R. Dashtpour, S.N. Al-Zubaidy, Energy efficient reverse osmosis desalination process, International Journal of Environmental Science and Development, 3 (2012) 339.

[28] A.M. Delgado-Torres, L. García-Rodríguez, Status of solar thermal-driven reverse osmosis desalination, Desalination, 216 (2007) 242-251.

[29] T.H. Chong, S.-L. Loo, A.G. Fane, W.B. Krantz, Energy-efficient reverse osmosis desalination: effect of retentate recycle and pump and energy recovery device efficiencies, Desalination, 366 (2015) 15-31.

[30] R.K. McGovern, On the potential of forward osmosis to energetically outperform reverse osmosis desalination, Journal of Membrane Science, 469 (2014) 245-250.

[31] F.E. Ahmed, R. Hashaikeh, N. Hilal, Solar powered desalination - Technology, energy and future outlook, Desalination, 453 (2019) 54-76.

[32] H. Sharon, K. Reddy, A review of solar energy driven desalination technologies, Renewable and Sustainable Energy Reviews, 41 (2015) 1080-1118.

[33] C. Charcosset, A review of membrane processes and renewable energies for desalination, Desalination, 245 (2009) 214-231.

[34] L. Garcia-Rodriguez, Seawater desalination driven by renewable energies: a review, Desalination, 143 (2002) 103-113. 
[35] M. Chandrashekara, A. Yadav, Water desalination system using solar heat: A review, Renewable and Sustainable Energy Reviews, 67 (2017) 1308-1330.

[36] M.A. Eltawil, Z. Zhengming, L. Yuan, A review of renewable energy technologies integrated with desalination systems, Renewable and sustainable energy reviews, 13 (2009) 2245-2262.

[37] N. Ghaffour, J. Bundschuh, H. Mahmoudi, M.F. Goosen, Renewable energy-driven desalination technologies: A comprehensive review on challenges and potential applications of integrated systems, Desalination, 356 (2015) 94 114.

[38] A. Alkaisi, R. Mossad, A. Sharifian-Barforoush, A review of the water desalination systems integrated with renewable energy, Energy Procedia, 110 (2017) 268-274.

[39] A. Subramani, M. Badruzzaman, J. Oppenheimer, J.G. Jacangelo, Energy minimization strategies and renewable energy utilization for desalination: A review, Water Research, 45 (2011) 1907-1920.

[40] H. Shemer, R. Semiat, Sustainable RO desalination-Energy demand and environmental impact, Desalination, 424 (2017) 10-16.

[41] C. Fritzmann, J. Löwenberg, T. Wintgens, T. Melin, State-of-the-art of reverse osmosis desalination, Desalination, 216 (2007) 1-76.

[42] K. Spiegler, Y. El-Sayed, The energetics of desalination processes, Desalination, 134 (2001) 109-128.

[43] R. Stoughton, M. Lietzke, Calculation of Some Thermodynamic Properties of Sea Salt Solutions at Elevated Temperatures from Data on NaCl Solutions, Journal of Chemical and Engineering data, 10 (1965) 254-260.

[44] E. Jones, M. Qadir, M.T. van Vliet, V. Smakhtin, S.-m. Kang, The state of desalination and brine production: A global outlook, Science of the Total Environment, 657 (2019) 1343-1356.

[45] M. Elimelech, W.A. Phillip, The future of seawater desalination: energy, technology, and the environment, science, 333 (2011) 712-717.

[46] M. Wilf, C. Bartels, Optimization of seawater RO systems design, Desalination, 173 (2005) 1-12.

[47] T. Manth, M. Gabor, E. Oklejas, Minimizing RO energy consumption under variable conditions of operation, Desalination, 157 (2003) 9-21.

[48] V.G. Gude, Energy consumption and recovery in reverse osmosis, Desalination and water treatment, 36 (2011) 239-260.

[49] M.W. Shahzad, K. Thu, K.C. Ng, C. WonGee, Recent development in thermally activated desalination methods: achieving an energy efficiency less than 2.5 kWhelec/m3, Desalination and Water Treatment, 57 (2016) $7396-7405$.

[50] A.M. Helal, A.M. El-Nashar, E. Al-Katheeri, S. Al-Malek, Optimal design of hybrid RO/MSF desalination plants Part I: Modeling and algorithms, Desalination, 154 (2003) 43-66.

[51] O.A. Hamed, Overview of hybrid desalination systems - current status and future prospects, Desalination, 186 (2005) 207-214.

[52] A.M. Hassan, M.A.K. Al-Sofi, A.S. Al-Amoudi, A.T.M. Jamaluddin, A.M. Farooque, A. Rowaili, A.G.I. Dalvi, N.M. Kither, G.M. Mustafa, I.A.R. Al-Tisan, A new approach to membrane and thermal seawater desalination processes using nanofiltration membranes (Part 1), Desalination, 118 (1998) 35-51.

[53] L. Awerbuch, C. Sommariva, MSF distillate driven desalination process and apparatus, in, PCT/GB2005/003329, 2006.

[54] A.E. Al-Rawajfeh, S. Ihm, H. Varshney, A.N. Mabrouk, Scale formation model for high top brine temperature multi-stage flash (MSF) desalination plants, Desalination, 350 (2014) 53-60.

[55] N. Voutchkov, Desalination Engineering: Planning and Design, McGraw-Hill Education, 2012. 
[56] F. Alvarado-Revilla, Desalination Markets 2016: Global Perspective and Opportunities for Growth, Media Analytics Limited, 2015.

[57] A.D. Khawaji, I.K. Kutubkhanah, J.-M. Wie, Advances in seawater desalination technologies, Desalination, 221 (2008) 47-69.

[58] G. Tusel, R. Rautenbach, J.J.D. Widua, Seawater desalination plant "Sirte" —an example for an advanced MSF design, 96 (1994) 379-396.

[59] A.N.A. Mabrouk, Technoeconomic analysis of once through long tube MSF process for high capacity desalination plants, Desalination, 317 (2013) 84-94.

[60] C. Hanshik, H. Jeong, K.-W. Jeong, S.-H. Choi, Improved productivity of the MSF (multi-stage flashing) desalination plant by increasing the TBT (top brine temperature), Energy, 107 (2016) 683-692.

[61] I. Alatiqi, H. Ettouney, H. El-Dessouky, Process control in water desalination industry: an overview, Desalination, 126 (1999) 15-32.

[62] O.A. Hamed, M.A.K. Al-Sofi, M. Imam, G.M. Mustafa, K. Ba Mardouf, H. Al-Washmi, Thermal performance of multi-stage flash distillation plants in Saudi Arabia, Desalination, 128 (2000) 281-292.

[63] Y. Ghalavand, M.S. Hatamipour, A. Rahimi, A review on energy consumption of desalination processes, Desalination and Water Treatment, 54 (2015) 1526-1541.

[64] M.M. Alhazmy, Economic and thermal feasibility of multi stage flash desalination plant with brine-feed mixing and cooling, Energy, 76 (2014) 1029-1035.

[65] H.T. El-Dessouky, H.M. Ettouney, Y.J.C.E.J. Al-Roumi, Multi-stage flash desalination: present and future outlook, 73 (1999) 173-190.

[66] M.A.-K. Al-Sofi, Fouling phenomena in multi stage flash (MSF) distillers, Desalination, 126 (1999) 61-76.

[67] E.A.M. Hawaidi, I.M. Mujtaba, Simulation and optimization of MSF desalination process for fixed freshwater demand: Impact of brine heater fouling, Chemical Engineering Journal, 165 (2010) 545-553.

[68] S.-H. Choi, On the brine re-utilization of a multi-stage flashing (MSF) desalination plant, Desalination, 398 (2016) 64-76.

[69] M. Al-Hamahmy, H.E.S. Fath, K. Khanafer, Techno-economical simulation and study of a novel MSF desalination process, Desalination, 386 (2016) 1-12.

[70] A. Bazargan, A Multidisciplinary Introduction to Desalination, River Publishers, 2018.

[71] A. Bejan, G. Tsatsaronis, M.J. Moran, Thermal design and optimization, John Wiley, 1996.

[72] T.J. Kotas, The exergy method of thermal plant analysis, Krieger Pub., 1995.

[73] I. Dincer, M.A. Rosen, Exergy: Energy, Environment and Sustainable Development, Elsevier Science, 2012.

[74] M.H. Sharqawy, J.H. Lienhard V, S.M. Zubair, On exergy calculations of seawater with applications in desalination systems, International Journal of Thermal Sciences, 50 (2011) 187-196.

[75] M.A. Al-Weshahi, A. Anderson, G. Tian, Exergy efficiency enhancement of MSF desalination by heat recovery from hot distillate water stages, Applied Thermal Engineering, 53 (2013) 226-233.

[76] M. Al-Shammiri, M. Safar, Multi-effect distillation plants: state of the art, Desalination, 126 (1999) 45-59.

[77] L. Awerbuch, C. Sommariva, MSF distillate driven desalination process and apparatus, Patent No, in, PCT/GB2005/003329.

[78] H. El-Dessouky, I. Alatiqi, S. Bingulac, H. Ettouney, Steady-state analysis of the multiple effect evaporation desalination process, Chemical engineering \& Technology, 21 (1998) 437-451. 
[79] G. Raluy, L. Serra, J.J.E. Uche, Life cycle assessment of MSF, MED and RO desalination technologies, 31 (2006) 2361-2372.

[80] B.R. Hughes, F. Rezazadeh, H.N. Chaudhry, Economic viability of incorporating multi-effect distillation with district cooling systems in the United Arab Emirates, Sustainable Cities and Society, 7 (2013) 37-43.

[81] V.G. Gude, Energy storage for desalination processes powered by renewable energy and waste heat sources, Applied Energy, 137 (2015) 877-898.

[82] M.A. Darwish, H.K. Abdulrahim, Feed water arrangements in a multi-effect desalting system, Desalination, 228 (2008) 30-54.

[83] I.S. Al-Mutaz, I. Wazeer, Comparative performance evaluation of conventional multi-effect evaporation desalination processes, Applied Thermal Engineering, 73 (2014) 1194-1203.

[84] K. Yao, Y. Qin, Y. Yuan, L. Liu, F. He, Y. Wu, A continuous-effect membrane distillation process based on hollow fiber AGMD module with internal latent-heat recovery, AIChE Journal, 59 (2013) 1278-1297.

[85] O.J.D. Morin, Design and operating comparison of MSF and MED systems, 93 (1993) 69-109.

[86] B. Milow, E.J.D. Zarza, Advanced MED solar desalination plants. Configurations, costs, future-seven years of experience at the Plataforma Solar de Almeria (Spain), 108 (1997) 51-58.

[87] D. Saldivia, C. Rosales, R. Barraza, L.J.R.e. Cornejo, Computational analysis for a multi-effect distillation (MED) plant driven by solar energy in Chile, 132 (2019) 206-220.

[88] A. Ophir, A. Gendel, Steam driven large multi effect MVC (SD MVC) desalination process for lower energy consumption and desalination costs, Desalination, 205 (2007) 224-230.

[89] D.-Y. Choi, C.-F. Jin, Y.-H. Song, S.-H. Choi, H.-S. Chung, P.-H. Kim, A study on the MED-TVC operating performance characteristics of using the thermo-compressor, Journal of the Korean Society of Marine Engineering 32 (2008) 1185-1191.

[90] I.S. Al-Mutaz, I.J.D. Wazeer, W. Treatment, Current status and future directions of MED-TVC desalination technology, 55 (2015) 1-9.

[91] C. Sommariva, Desalination and advanced water treatment: Economics and financing, Balaban Desalination Publications Hopkinton, MA, 2010.

[92] G. Fiorenza, V. Sharma, G.J.E.c. Braccio, management, Techno-economic evaluation of a solar powered water desalination plant, 44 (2003) 2217-2240.

[93] B. Mayor, Growth patterns in mature desalination technologies and analogies with the energy field, Desalination, 457 (2019) 75-84.

[94] V.G. Gude, N. Nirmalakhandan, S. Deng, Renewable and sustainable approaches for desalination, Renewable and Sustainable Energy Reviews, 14 (2010) 2641-2654.

[95] M. Shatat, S.B. Riffat, Water desalination technologies utilizing conventional and renewable energy sources, International Journal of Low-Carbon Technologies, 9 (2014) 1-19.

[96] S.A. Kalogirou, Seawater desalination using renewable energy sources, Progress in energy and combustion science, 31 (2005) 242-281.

[97] R. Takagi, M. Vaselbehagh, H.J.J.o.m.s. Matsuyama, Theoretical study of the permselectivity of an anion exchange membrane in electrodialysis, 470 (2014) 486-493.

[98] L.F. Greenlee, D.F. Lawler, B.D. Freeman, B. Marrot, P.J.W.r. Moulin, Reverse osmosis desalination: water sources, technology, and today's challenges, 43 (2009) 2317-2348.

[99] M. Qasim, M. Badrelzaman, N.N. Darwish, N.A. Darwish, N. Hilal, Reverse osmosis desalination: A state-of-theart review, Desalination, 459 (2019) 59-104. 
[100] M. Faigon, Success behind advanced SWRO desalination plant, Filtration + Separation, 53 (2016) 29-31.

[101] A.J. Schunke, G.A. Hernandez Herrera, L. Padhye, T.-A. Berry, Energy Recovery in SWRO Desalination: Current Status and New Possibilities, Frontiers in Sustainable Cities, 2 (2020) 9.

[102] Global Water Intelligence, The International Desalination Association, IDA Water Security Handbook 20172018, Media Analytics Ltd., United Kingdom, 2018.

[103] N. Ghaffour, S. Lattemann, T. Missimer, K.C. Ng, S. Sinha, G.J.A.E. Amy, Renewable energy-driven innovative energy-efficient desalination technologies, 136 (2014) 1155-1165.

[104] N.R. Council, Desalination: a national perspective, National Academies Press, 2008.

[105] R.J.E.s. Semiat, technology, Energy issues in desalination processes, 42 (2008) 8193-8201.

[106] N. Voutchkov, Energy use for membrane seawater desalination - current status and trends, Desalination, 431 (2018) 2-14.

[107] W.L. Ang, A.W. Mohammad, N. Hilal, C.P. Leo, A review on the applicability of integrated/hybrid membrane processes in water treatment and desalination plants, Desalination, 363 (2015) 2-18.

[108] A. Brehant, V. Bonnelye, M.J.W.S. Perez, T.W. Supply, Assessment of ultrafiltration as a pretreatment of reverse osmosis membranes for surface seawater desalination, 3 (2003) 437-445.

[109] A.G. Fane, A grand challenge for membrane desalination: More water, less carbon, Desalination, 426 (2018) 155-163.

[110] R. Huehmer, F. Wang, Energy in desalination: comparison of energy requirements for developing desalination techniques, in: AWWA Membrane Technology Conference and Exposition, Memphis, Tennessee, USA, 2009.

[111] J. MacHarg, T.F. Seacord, B.J.D. Sessions, w. reuse, ADC baseline tests reveal trends in membrane performance, 18 (2008) 30-39.

[112] A.J. Karabelas, C.P. Koutsou, M. Kostoglou, D.C. Sioutopoulos, Analysis of specific energy consumption in reverse osmosis desalination processes, Desalination, 431 (2018) 15-21.

[113] M.J.D. Wilf, Design consequences of recent improvements in membrane performance, 113 (1997) $157-163$.

[114] A. Zhu, P.D. Christofides, Y.J.I. Cohen, E.C. Research, Effect of thermodynamic restriction on energy cost optimization of RO membrane water desalination, 48 (2009) 6010-6021.

[115] L. Song, J. Hu, S. Ong, W. Ng, M. Elimelech, M.J.D. Wilf, Emergence of thermodynamic restriction and its implications for full-scale reverse osmosis processes, 155 (2003) 213-228.

[116] O. Buros, The ABCs of desalting, International Desalination Association, Topsfield, Massachusetts, USA, 2000.

[117] C.B. Smith, K.E. Parmenter, Energy Management Principles: Applications, Benefits, Savings, Elsevier Science, 2015.

[118] A. de la Torre, Efficiency optimization in SWRO plant: high efficiency \& low maintenance pumps, Desalination, 221 (2008) 151-157.

[119] G. Amy, N. Ghaffour, Z. Li, L. Francis, R.V. Linares, T. Missimer, S. Lattemann, Membrane-based seawater desalination: Present and future prospects, Desalination, 401 (2017) 16-21.

[120] D. Cohen-Tanugi, R.K. McGovern, S.H. Dave, J.H. Lienhard, J.C.J.E. Grossman, E. Science, Quantifying the potential of ultra-permeable membranes for water desalination, 7 (2014) 1134-1141.

[121] M. Wilf, Effect of new generation of low pressure, high salt rejection membranes on power consumption of RO systems, in: Proceedings of AWWA Membrane Technology Conference, 1997, pp. 663-679. 
[122] R. Franks, C.R. Bartels, K. Andes, M. Patel, T. Young, Implementing energy saving RO technology in large scale wastewater treatment plants, in: Proceedings of the International Desalination and Water Reuse Conference, Las Palmas, Spain, 2007.

[123] A. Zhu, P.D. Christofides, Y.J.J.o.M.S. Cohen, On RO membrane and energy costs and associated incentives for future enhancements of membrane permeability, 344 (2009) 1-5.

[124] M.N. Abu Seman, M. Khayet, N. Hilal, Development of antifouling properties and performance of nanofiltration membranes modified by interfacial polymerisation, Desalination, 273 (2011) 36-47.

[125] K. Jeong, M. Park, S.J. Ki, J.H.J.J.o.M.S. Kim, A systematic optimization of Internally Staged Design (ISD) for a full-scale reverse osmosis process, 540 (2017) 285-296.

[126] K.P. Lee, T.C. Arnot, D.J.J.o.M.S. Mattia, A review of reverse osmosis membrane materials for desalinationDevelopment to date and future potential, 370 (2011) 1-22.

[127] A.C. Sagle, E.M. Van Wagner, H. Ju, B.D. McCloskey, B.D. Freeman, M.M.J.J.o.M.S. Sharma, PEG-coated reverse osmosis membranes: desalination properties and fouling resistance, 340 (2009) 92-108.

[128] Y. Okamoto, J.H. Lienhard, How RO membrane permeability and other performance factors affect process cost and energy use: A review, Desalination, 470 (2019) 114064.

[129] B. Peñate, L. García-Rodríguez Lourdes, Energy optimisation of existing SWRO (seawater reverse osmosis) plants with ERT (energy recovery turbines): Technical and thermoeconomic assessment, Energy, 36 (2011) 613626.

[130] E. Kadaj, R. Bosleman, Energy Recovery Devices in Membrane Desalination Processes, Renewable Energy Powered Desalination Handbook, (2018) 415-444.

[131] S. Arenas Urrea, F. Díaz Reyes, B. Peñate Suárez, J.A. de la Fuente Bencomo, Technical review, evaluation and efficiency of energy recovery devices installed in the Canary Islands desalination plants, Desalination, 450 (2019) 54-63.

[132] A.M. Farooque, A.T.M. Jamaluddin, A.R. Al-Reweli, P.A.M. Jalaluddin, S.M. Al-Marwani, A.S.A. Al-Mobayed, A.H. Qasim, Comparative study of various energy recovery devices used in SWRO process, in: Saline Water Desalination Research Institute, Saline Water Conversion Corporation (SWCC), 2004.

[133] R.L. Stover, Seawater reverse osmosis with isobaric energy recovery devices, Desalination, 203 (2007) 168175.

[134] T.A. El-Sayed, A.A. Abdel Fatah, Performance of hydraulic turbocharger integrated with hydraulic energy management in SWRO desalination plants, Desalination, 379 (2016) 85-92.

[135] Y. Kim, M.G. Kang, S. Lee, S.G. Jeon, J.S. Choi, Reduction of energy consumption in seawater reverse osmosis desalination pilot plant by using energy recovery devices, Desalination and Water Treatment, 51 (2013) 766-771.

[136] B. Peñate, J.A. de la Fuente, M. Barreto, Operation of the RO Kinetic ${ }^{\circledast}$ energy recovery system: Description and real experiences, Desalination, 252 (2010) 179-185.

[137] B. Schneider, Selection, operation and control of a work exchanger energy recovery system based on the Singapore project, Desalination, 184 (2005) 197-210.

[138] R. Lemes, R. Falcon, R. Arocha, J. Curbelo, V. Platas, L. De Lorenzo, Different designs in energy savings of SWRO plant of las palmas III, Desalination and Water Treatment, 51 (2013) 749-758.

[139] J. Kim, K. Park, D.R. Yang, S. Hong, A comprehensive review of energy consumption of seawater reverse osmosis desalination plants, Applied Energy, 254 (2019) 113652.

[140] O.L. Villa Sallangos, Operating experience of the Dhekelia seawater desalination plant using an innovative energy recovery system, Desalination, 173 (2005) 91-102. 
[141] J.A. Redondo, Lanzarote IV, a new concept for two-pass SWRO at low O\&M cost using the new high-flow FILMTEC SW30-380, Desalination, 138 (2001) 231-236.

[142] S. Meyer-Steele, A. von Gottberg, J.L. Talavera, seawater reverse osmosis plants in the caribbean recover energy and brine and reduce costs, in, 2005.

[143] M. Petry, M.A. Sanz, C. Langlais, V. Bonnelye, J.P. Durand, D. Guevara, W.M. Nardes, C.H. Saemi, The El Coloso (Chile) reverse osmosis plant, Desalination, 203 (2007) 141-152.

[144] M.A. Sanz, R.L. Stover, S.A. Degrémont, Low energy consumption in the Perth seawater desalination plant, in: IDA World Congress-Maspalomas, Gran Canaria, Spain, IDA World Congress, Gran Canaria, 2007.

[145] A. Belatoui, H. Bouabessalam, O.R. Hacene, J.A. De-La-Ossa-Carretero, E. Martinez-Garcia, J.L. SanchezLizaso, Environmental effects of brine discharge from two desalination plants in Algeria (South Western Mediterranean), Desalination and Water Treatment, 76 (2017) 311-318.

[146] A. Efraty, Closed circuit desalination series no-6: Conventional RO compared with the conceptually different new closed circuit desalination technology, Desalination and Water Treatment, 41 (2012) 279-295.

[147] R. Singh, Membrane Technology and Engineering for Water Purification: Application, Systems Design and Operation: Second Edition, Membrane Technology and Engineering for Water Purification: Application, Systems Design and Operation: Second Edition, (2014).

[148] S.H. Chae, Y.M. Kim, H. Park, J. Seo, S.J. Lim, J.H. Kim, Modeling and Simulation Studies Analyzing the Pressure-Retarded Osmosis (PRO) and PRO-Hybridized Processes, Energies, 12 (2019) 243.

[149] Y. Qu, P.G. Campbell, L. Gu, J.M. Knipe, E. Dzenitis, J.G. Santiago, M. Stadermann, Energy consumption analysis of constant voltage and constant current operations in capacitive deionization, Desalination, 400 (2016) 18-24.

[150] Z. Jia, B. Wang, S. Song, Y. Fan, Blue energy: Current technologies for sustainable power generation from water salinity gradient, Renewable and Sustainable Energy Reviews, 31 (2014) 91-100.

[151] R. Zhao, P. Biesheuvel, A. Van der Wal, Energy consumption and constant current operation in membrane capacitive deionization, Energy \& Environmental Science, 5 (2012) 9520-9527.

[152] N.Y. Yip, M. Elimelech, Thermodynamic and energy efficiency analysis of power generation from natural salinity gradients by pressure retarded osmosis, Environmental science \& technology, 46 (2012) 5230-5239.

[153] F. Helfer, C. Lemckert, Y.G. Anissimov, Osmotic power with pressure retarded osmosis: theory, performance and trends-a review, Journal of Membrane Science, 453 (2014) 337-358.

[154] S. Loeb, F. Van Hessen, J. Levi, M. Ventura, The osmotic power plant, in: 11th Intersociety Energy Conversion Engineering Conference, 1976, pp. 51-57.

[155] N.Y. Yip, A. Tiraferri, W.A. Phillip, J.D. Schiffman, L.A. Hoover, Y.C. Kim, M. Elimelech, Thin-film composite pressure retarded osmosis membranes for sustainable power generation from salinity gradients, Environmental science \& technology, 45 (2011) 4360-4369.

[156] S. Chou, R. Wang, L. Shi, Q. She, C. Tang, A.G. Fane, Thin-film composite hollow fiber membranes for pressure retarded osmosis (PRO) process with high power density, Journal of membrane science, 389 (2012) 25-33.

[157] T.-S. Chung, L. Luo, C.F. Wan, Y. Cui, G. Amy, What is next for forward osmosis (FO) and pressure retarded osmosis (PRO), Separation and Purification Technology, 156 (2015) 856-860.

[158] N.Y. Yip, M. Elimelech, Comparison of energy efficiency and power density in pressure retarded osmosis and reverse electrodialysis, Environmental science \& technology, 48 (2014) 11002-11012.

[159] G.Z. Ramon, B.J. Feinberg, E.M. Hoek, Membrane-based production of salinity-gradient power, Energy \& environmental science, 4 (2011) 4423-4434. 
[160] M.H. Sharqawy, S.M. Zubair, Second law analysis of reverse osmosis desalination plants: An alternative design using pressure retarded osmosis, Energy, 36 (2011) 6617-6626.

[161] A. Altaee, G. Zaragoza, A. Sharif, Pressure retarded osmosis for power generation and seawater desalination: Performance analysis, Desalination, 344 (2014) 108-115.

[162] J. Kim, M. Park, S.A. Snyder, J.H. Kim, Reverse osmosis (RO) and pressure retarded osmosis (PRO) hybrid processes: Model-based scenario study, Desalination, 322 (2013) 121-130.

[163] J.L. Prante, J.A. Ruskowitz, A.E. Childress, A. Achilli, RO-PRO desalination: an integrated low-energy approach to seawater desalination, Applied Energy, 120 (2014) 104-114.

[164] A.P. Straub, A. Deshmukh, M. Elimelech, Pressure-retarded osmosis for power generation from salinity gradients: is it viable?, Energy \& Environmental Science, 9 (2016) 31-48.

[165] Z. Lei, B. Chen, Z. Ding, Special distillation processes, Elsevier, 2005.

[166] K.W. Lawson, D.R. Lloyd, Membrane distillation, Journal of membrane Science, 124 (1997) 1-25.

[167] S. Lin, N.Y. Yip, M. Elimelech, Direct contact membrane distillation with heat recovery: Thermodynamic insights from module scale modeling, Journal of Membrane Science, 453 (2014) 498-515.

[168] A. Deshmukh, C. Boo, V. Karanikola, S. Lin, A.P. Straub, T. Tong, D.M. Warsinger, M. Elimelech, Membrane distillation at the water-energy nexus: limits, opportunities, and challenges, Energy \& Environmental Science, 11 (2018) 1177-1196.

[169] J. Swaminathan, H.W. Chung, D.M. Warsinger, F.A. AlMarzooqi, H.A. Arafat, Energy efficiency of permeate gap and novel conductive gap membrane distillation, Journal of Membrane Science, 502 (2016) 171-178.

[170] D. Brogioli, F. La Mantia, N.Y. Yip, Thermodynamic analysis and energy efficiency of thermal desalination processes, Desalination, 428 (2018) 29-39.

[171] M.H. Sharqawy, J.H. Lienhard, S.M. Zubair, Thermophysical properties of seawater: a review of existing correlations and data, Desalination and water Treatment, 16 (2010) 354-380.

[172] E. Guillén-Burrieza, J. Blanco, G. Zaragoza, D.-C. Alarcón, P. Palenzuela, M. Ibarra, W. Gernjak, Experimental analysis of an air gap membrane distillation solar desalination pilot system, Journal of Membrane Science, 379 (2011) 386-396.

[173] A. Criscuoli, E. Drioli, Energetic and exergetic analysis of an integrated membrane desalination system, Desalination, 124 (1999) 243-249.

[174] J. Koschikowski, M. Wieghaus, M. Rommel, Solar thermal-driven desalination plants based on membrane distillation, Desalination, 156 (2003) 295-304.

[175] M. Khayet, C. Cojocaru, Air gap membrane distillation: Desalination, modeling and optimization, Desalination, 287 (2012) 138-145.

[176] Z. Ding, L. Liu, Z. Li, R. Ma, Z. Yang, Experimental study of ammonia removal from water by membrane distillation (MD): The comparison of three configurations, Journal of membrane Science, 286 (2006) 93-103.

[177] E.K. Summers, H.A. Arafat, Energy efficiency comparison of single-stage membrane distillation (MD) desalination cycles in different configurations, Desalination, 290 (2012) 54-66.

[178] A. Deshmukh, M. Elimelech, Understanding the impact of membrane properties and transport phenomena on the energetic performance of membrane distillation desalination, Journal of Membrane Science, 539 (2017) 458-474.

[179] J. Swaminathan, H.W. Chung, D.M. Warsinger, Simple method for balancing direct contact membrane distillation, Desalination, 383 (2016) 53-59. 
[180] W. Jantaporn, A. Ali, P. Aimar, Specific energy requirement of direct contact membrane distillation, Chemical Engineering Research and Design, 128 (2017) 15-26.

[181] A. Ali, F. Macedonio, E. Drioli, S. Aljlil, O.A. Alharbi, Experimental and theoretical evaluation of temperature polarization phenomenon in direct contact membrane distillation, Chemical Engineering Research and Design, 91 (2013) 1966-1977.

[182] H. Geng, Q. He, H. Wu, P. Li, C. Zhang, H. Chang, Experimental study of hollow fiber AGMD modules with energy recovery for high saline water desalination, Desalination, 344 (2014) 55-63.

[183] J. Vanneste, J.A. Bush, K.L. Hickenbottom, C.A. Marks, D. Jassby, C.S. Turchi, T.Y. Cath, Novel thermal efficiency-based model for determination of thermal conductivity of membrane distillation membranes, Journal of Membrane Science, 548 (2018) 298-308.

[184] Y. Zhang, Y. Peng, S. Ji, Z. Li, P. Chen, Review of thermal efficiency and heat recycling in membrane distillation processes, Desalination, 367 (2015) 223-239.

[185] J. Zhang, S. Gray, Predicting the influence of operating conditions on DCMD flux and thermal efficiency for incompressible and compressible membrane systems, Desalination, 323 (2013) 142-149.

[186] E.K. Summers, Experimental study of thermal performance in air gap membrane distillation systems, including the direct solar heating of membranes, Desalination, 330 (2013) 100-111.

[187] H. Geng, H. Wu, P. Li, Q. He, Study on a new air-gap membrane distillation module for desalination, Desalination, 334 (2014) 29-38.

[188] G. Meindersma, C. Guijt, A. De Haan, Desalination and water recycling by air gap membrane distillation, Desalination, 187 (2006) 291-301.

[189] J. Swaminathan, H.W. Chung, D.M. Warsinger, Energy efficiency of membrane distillation up to high salinity: Evaluating critical system size and optimal membrane thickness, Applied energy, 211 (2018) 715-734.

[190] M.I. Ali, E.K. Summers, H.A. Arafat, J.H.L. V, Effects of membrane properties on water production cost in small scale membrane distillation systems, Desalination, 306 (2012) 60-71.

[191] G. Zakrzewska-Trznadel, M. Harasimowicz, A.G. Chmielewski, Concentration of radioactive components in liquid low-level radioactive waste by membrane distillation, Journal of Membrane Science, 163 (1999) 257-264.

[192] G. Guan, X. Yang, R. Wang, R. Field, A.G. Fane, Evaluation of hollow fiber-based direct contact and vacuum membrane distillation systems using aspen process simulation, Journal of Membrane Science, 464 (2014) 127-139.

[193] N. Dow, S. Gray, J.-d. Li, J. Zhang, E. Ostarcevic, A. Liubinas, P. Atherton, G. Roeszler, A. Gibbs, M. Duke, Pilot trial of membrane distillation driven by low grade waste heat: Membrane fouling and energy assessment, Desalination, 391 (2016) 30-42.

[194] H.C. Duong, P. Cooper, B. Nelemans, T.Y. Cath, L.D. Nghiem, Evaluating energy consumption of air gap membrane distillation for seawater desalination at pilot scale level, Separation and Purification Technology, 166 (2016) 55-62.

[195] X. Wang, L. Zhang, H. Yang, H. Chen, Feasibility research of potable water production via solar-heated hollow fiber membrane distillation system, Desalination, 247 (2009) 403-411.

[196] F. Banat, N. Jwaied, M. Rommel, J. Koschikowski, M. Wieghaus, Performance evaluation of the "large SMADES" autonomous desalination solar-driven membrane distillation plant in Aqaba, Jordan, Desalination, 217 (2007) 17-28.

[197] S. Al-Obaidani, E. Curcio, F. Macedonio, G. Di Profio, H. Al-Hinai, E. Drioli, Potential of membrane distillation in seawater desalination: thermal efficiency, sensitivity study and cost estimation, Journal of Membrane Science, 323 (2008) 85-98. 
[198] I.C. Karagiannis, P.G. Soldatos, Water desalination cost literature: review and assessment, Desalination, 223 (2008) 448-456.

[199] K. Tarnacki, M. Meneses, T. Melin, J. Van Medevoort, A. Jansen, Environmental assessment of desalination processes: Reverse osmosis and Memstill ${ }^{\circledR}$, Desalination, 296 (2012) 69-80.

[200] S. Lin, M. Elimelech, Staged reverse osmosis operation: Configurations, energy efficiency, and application potential, Desalination, 366 (2015) 9-14.

[201] G. Chen, X. Yang, Y. Lu, R. Wang, A.G. Fane, Heat transfer intensification and scaling mitigation in bubblingenhanced membrane distillation for brine concentration, Journal of membrane science, 470 (2014) 60-69.

[202] A.S. Rattner, S. Garimella, Energy harvesting, reuse and upgrade to reduce primary energy usage in the USA, Energy, 36 (2011) 6172-6183.

[203] U.K. Kesieme, N. Milne, H. Aral, C.Y. Cheng, M. Duke, Economic analysis of desalination technologies in the context of carbon pricing, and opportunities for membrane distillation, Desalination, 323 (2013) 66-74.

[204] N. Thomas, M.O. Mavukkandy, S. Loutatidou, H.A. Arafat, Membrane distillation research \& implementation: Lessons from the past five decades, Separation and Purification Technology, 189 (2017) 108-127.

[205] F. Banat, N. Jwaied, Economic evaluation of desalination by small-scale autonomous solar-powered membrane distillation units, Desalination, 220 (2008) 566-573.

[206] M.R. Qtaishat, F. Banat, Desalination by solar powered membrane distillation systems, Desalination, 308 (2013) 186-197.

[207] M. Khayet, Solar desalination by membrane distillation: Dispersion in energy consumption analysis and water production costs (a review), Desalination, 308 (2013) 89-101.

[208] L. Carlsson, The new generation in sea water desalination SU membrane distillation system, Desalination, 45 (1983) 221-222.

[209] A. Criscuoli, E. Drioli, Energetic and exergetic analysis of an integrated membrane desalination system, Desalination, 124 (1999) 243-249.

[210] C. Cabassud, D. Wirth, Membrane distillation for water desalination: how to chose an appropriate membrane?, Desalination, 157 (2003) 307-314.

[211] R.G. Raluy, R. Schwantes, V.J. Subiela, B. Peñate, G. Melián, J.R. Betancort, Operational experience of a solar membrane distillation demonstration plant in Pozo Izquierdo-Gran Canaria Island (Spain), Desalination, 290 (2012) $1-13$.

[212] X. Wang, L. Zhang, H. Yang, H. Chen, Feasibility research of potable water production via solar-heated hollow fiber membrane distillation system, Desalination, 247 (2009) 403-411.

[213] A. Kullab, A. Martin, Membrane distillation and applications for water purification in thermal cogeneration plants, Separation and Purification Technology, 76 (2011) 231-237.

[214] J.-G. Lee, W.-S. Kim, Numerical modeling of the vacuum membrane distillation process, Desalination, 331 (2013) 46-55.

[215] O.R. Lokare, S. Tavakkoli, V. Khanna, R.D. Vidic, Importance of feed recirculation for the overall energy consumption in membrane distillation systems, Desalination, 428 (2018) 250-254.

[216] M.R. Elmarghany, A.H. El-Shazly, M.S. Salem, M.N. Sabry, N. Nady, Thermal analysis evaluation of direct contact membrane distillation system, Case Studies in Thermal Engineering, 13 (2019) 100377.

[217] T. Tong, M. Elimelech, The global rise of zero liquid discharge for wastewater management: drivers, technologies, and future directions, Environmental science \& technology, 50 (2016) 6846-6855. 
[218] M. Qasim, N.A. Darwish, S. Sarp, N. Hilal, Water desalination by forward (direct) osmosis phenomenon: A comprehensive review, Desalination, 374 (2015) 47-69.

[219] D.J. Johnson, W.A. Suwaileh, A.W. Mohammed, N. Hilal, Osmotic's potential: An overview of draw solutes for forward osmosis, Desalination, 434 (2018) 100-120.

[220] W.A. Phillip, J.S. Yong, M. Elimelech, Reverse draw solute permeation in forward osmosis: modeling and experiments, Environmental science \& technology, 44 (2010) 5170-5176.

[221] S. Zhao, L. Zou, C.Y. Tang, D. Mulcahy, Recent developments in forward osmosis: opportunities and challenges, Journal of membrane science, 396 (2012) 1-21.

[222] R.K. McGovern, J.H. Lienhard V, On the potential of forward osmosis to energetically outperform reverse osmosis desalination, Journal of Membrane Science, 469 (2014) 245-250.

[223] L.A. Hoover, W.A. Phillip, A. Tiraferri, N.Y. Yip, M. Elimelech, Forward with Osmosis: Emerging Applications for Greater Sustainability, Environmental Science \& Technology, 45 (2011) 9824-9830.

[224] J.O. Kessler, C.D. Moody, Drinking water from sea water by forward osmosis, Desalination, 18 (1976) 297 306.

[225] S. Phuntsho, H.K. Shon, S. Hong, S. Lee, S. Vigneswaran, A novel low energy fertilizer driven forward osmosis desalination for direct fertigation: Evaluating the performance of fertilizer draw solutions, Journal of Membrane Science, 375 (2011) 172-181.

[226] K.H. Mistry, J.H. Lienhard, Generalized least energy of separation for desalination and other chemical separation processes, Entropy, 15 (2013) 2046-2080.

[227] S. Lee, C. Boo, M. Elimelech, S. Hong, Comparison of fouling behavior in forward osmosis (FO) and reverse osmosis (RO), Journal of Membrane Science, 365 (2010) 34-39.

[228] N.M. Mazlan, D. Peshev, A.G. Livingston, Energy consumption for desalination - A comparison of forward osmosis with reverse osmosis, and the potential for perfect membranes, Desalination, 377 (2016) $138-151$.

[229] V. Yangali-Quintanilla, Z. Li, R. Valladares, Q. Li, G. Amy, Indirect desalination of Red Sea water with forward osmosis and low pressure reverse osmosis for water reuse, Desalination, 280 (2011) 160-166.

[230] C.Y. Tang, Q. She, W.C. Lay, R. Wang, R. Field, A.G. Fane, Modeling double-skinned FO membranes, Desalination, 283 (2011) 178-186.

[231] J. Wei, C. Qiu, C.Y. Tang, R. Wang, A.G. Fane, Synthesis and characterization of flat-sheet thin film composite forward osmosis membranes, Journal of membrane science, 372 (2011) 292-302.

[232] W. Xu, Q. Chen, Q. Ge, Recent advances in forward osmosis (FO) membrane: Chemical modifications on membranes for FO processes, Desalination, 419 (2017) 101-116.

[233] P.H. Duong, J. Zuo, T.-S. Chung, Highly crosslinked layer-by-layer polyelectrolyte FO membranes: Understanding effects of salt concentration and deposition time on FO performance, Journal of membrane science, 427 (2013) 411-421.

[234] L. Shen, X. Zhang, J. Zuo, Y. Wang, Performance enhancement of TFC FO membranes with polyethyleneimine modification and post-treatment, Journal of Membrane Science, 534 (2017) 46-58.

[235] A. Achilli, T.Y. Cath, A.E. Childress, Selection of inorganic-based draw solutions for forward osmosis applications, Journal of membrane science, 364 (2010) 233-241.

[236] S. Phuntsho, H.K. Shon, S. Hong, S. Lee, S. Vigneswaran, A novel low energy fertilizer driven forward osmosis desalination for direct fertigation: evaluating the performance of fertilizer draw solutions, Journal of Membrane Science, 375 (2011) 172-181.

[237] K.S. Bowden, A. Achilli, A.E. Childress, Organic ionic salt draw solutions for osmotic membrane bioreactors, Bioresource technology, 122 (2012) 207-216. 
[238] C. Tan, H. Ng, A novel hybrid forward osmosis-nanofiltration (FO-NF) process for seawater desalination: Draw solution selection and system configuration, Desalination and water treatment, 13 (2010) 356-361.

[239] Q. Ge, J. Su, G.L. Amy, T.-S. Chung, Exploration of polyelectrolytes as draw solutes in forward osmosis processes, Water research, 46 (2012) 1318-1326.

[240] M.M. Ling, T.-S. Chung, Desalination process using super hydrophilic nanoparticles via forward osmosis integrated with ultrafiltration regeneration, Desalination, 278 (2011) 194-202.

[241] D.L. Shaffer, J.R. Werber, H. Jaramillo, S. Lin, M. Elimelech, Forward osmosis: Where are we now?, Desalination, 356 (2015) 271-284.

[242] S.F. Anis, A. Khalil, G. Singaravel, R. Hashaikeh, A review on the fabrication of zeolite and mesoporous inorganic nanofibers formation for catalytic applications, Microporous and Mesoporous Materials, 236 (2016) 176192.

[243] B. Zhuman, Saepurahman, S.F. Anis, R. Hashaikeh, Obtaining high crystalline ball milled H-Y zeolite particles with carbon nanostructures as a damping material, Microporous and Mesoporous Materials, 273 (2019) 19-25.

[244] R. Mondragón Cazorla, J.E. Juliá Bolívar, A. Barba Juan, J.C. Jarque Fonfría, Determination of the packing fraction of silica naoparticles from the rheological and viscoelastic measurements of nanofluids, (2012).

[245] H. Hong, F.D. Marquis, Carbon naoparticle-containing hydrophilic nanofluid, in, Google Patents, 2007.

[246] M. Shibuya, M. Miyauchi, Site-Selective Deposition of Metal Nanoparticles on Aligned WO3 Nanotrees for Super-Hydrophilic Thin Films, Advanced Materials, 21 (2009) 1373-1376.

[247] B.T. Anto, S. Sivaramakrishnan, L.L. Chua, P.K. Ho, Hydrophilic Sparse Ionic Monolayer-Protected Metal Nanoparticles: Highly Concentrated Nano-Au and Nano-Ag "Inks" that can be Sintered to Near-Bulk Conductivity at $150^{\circ} \mathrm{C}$, Advanced Functional Materials, 20 (2010) 296-303.

[248] M. Elimelech, W.A.J.s. Phillip, The future of seawater desalination: energy, technology, and the environment, 333 (2011) 712-717.

[249] K. Park, J. Kim, D.R. Yang, S. Hong, Towards a low-energy seawater reverse osmosis desalination plant: A review and theoretical analysis for future directions, Journal of Membrane Science, 595 (2020) 117607.

[250] Y.-N. Wang, K. Goh, X. Li, L. Setiawan, R.J.D. Wang, Membranes and processes for forward osmosis-based desalination: Recent advances and future prospects, 434 (2018) 81-99.

[251] J. Seo, Y.M. Kim, S.H. Chae, S.J. Lim, H. Park, J.H. Kim, An optimization strategy for a forward osmosis-reverse osmosis hybrid process for wastewater reuse and seawater desalination: A modeling study, Desalination, 463 (2019) 40-49.

[252] B.G. Choi, M. Zhan, K. Shin, S. Lee, S. Hong, Pilot-scale evaluation of FO-RO osmotic dilution process for treating wastewater from coal-fired power plant integrated with seawater desalination, Journal of Membrane Science, 540 (2017) 78-87.

[253] Y. Choi, H. Cho, Y. Shin, Y. Jang, S.J.M. Lee, Economic evaluation of a hybrid desalination system combining forward and reverse osmosis, 6 (2016) 3.

[254] G. Blandin, A.R.D. Verliefde, C.Y. Tang, P. Le-Clech, Opportunities to reach economic sustainability in forward osmosis-reverse osmosis hybrids for seawater desalination, Desalination, 363 (2015) 26-36.

[255] T.Y. Cath, N.T. Hancock, C.D. Lundin, C. Hoppe-Jones, J.E.J.J.o.m.s. Drewes, A multi-barrier osmotic dilution process for simultaneous desalination and purification of impaired water, 362 (2010) 417-426.

[256] S.J.W.H.O.G. Geneva, Switzerland, Guidelines for drinking-water quality, (2011).

[257] R.S. Ayers, D.W. Westcot, Water quality for agriculture, Food and Agriculture Organization of the United Nations Rome, 1985. 
[258] D.L. Shaffer, N.Y. Yip, J. Gilron, M. Elimelech, Seawater desalination for agriculture by integrated forward and reverse osmosis: Improved product water quality for potentially less energy, Journal of Membrane Science, 415416 (2012) 1-8.

[259] A. Zhu, P.D. Christofides, Y. Cohen, Minimization of energy consumption for a two-pass membrane desalination: Effect of energy recovery, membrane rejection and retentate recycling, Journal of Membrane Science, 339 (2009) 126-137.

[260] S. Lee, J. Choi, Y.-G. Park, H. Shon, C.H. Ahn, S.-H. Kim, Hybrid desalination processes for beneficial use of reverse osmosis brine: Current status and future prospects, Desalination, 454 (2019) 104-111.

[261] O. Schaetzle, C.J. Buisman, Salinity gradient energy: current state and new trends, in, Elsevier, 2015.

[262] J.L. Prante, J.A. Ruskowitz, A.E. Childress, A.J.A.E. Achilli, RO-PRO desalination: an integrated low-energy approach to seawater desalination, 120 (2014) 104-114.

[263] S.I. Sandler, Chemical, biochemical, and engineering thermodynamics, John Wiley \& Sons, 2017.

[264] S. Sarp, Y. In-Ho, Y.G. Park, Membrane based desalination apparatus with osmotic energy recovery and membrane based desalination method with osmotic energy recovery, in, Google Patents, 2016.

[265] K. Saito, M. Irie, S. Zaitsu, H. Sakai, H. Hayashi, A.J.D. Tanioka, W. Treatment, Power generation with salinity gradient by pressure retarded osmosis using concentrated brine from SWRO system and treated sewage as pure water, 41 (2012) 114-121.

[266] S. Loeb, Energy production at the Dead Sea by pressure-retarded osmosis: challenge or chimera?, Desalination, 120 (1998) 247-262.

[267] C.F. Wan, T.-S. Chung, Energy recovery by pressure retarded osmosis (PRO) in SWRO-PRO integrated processes, Applied Energy, 162 (2016) 687-698.

[268] H. Sakai, T. Ueyama, M. Irie, K. Matsuyama, A. Tanioka, K. Saito, A.J.D. Kumano, Energy recovery by PRO in sea water desalination plant, 389 (2016) 52-57.

[269] M. Kurihara, H.J.W. Takeuchi, SWRO-PRO system in "Mega-ton Water System" for energy reduction and low environmental impact, 10 (2018) 48.

[270] S. Zhang, P. Sukitpaneenit, T.-S.J.C.E.J. Chung, Design of robust hollow fiber membranes with high power density for osmotic energy production, 241 (2014) 457-465.

[271] S.H. Chae, J.H. Kim, Chapter Four - Integration of PRO into Desalination Processes, in: K. Touati, F. Tadeo, S.H. Chae, J.H. Kim, O. Alvarez-Silva (Eds.) Pressure Retarded Osmosis, Academic Press, 2017, pp. 129-151.

[272] A. Altaee, A. Sharif, Pressure retarded osmosis: advancement in the process applications for power generation and desalination, Desalination, 356 (2015) 31-46.

[273] A.P. Straub, S. Lin, M. Elimelech, Module-scale analysis of pressure retarded osmosis: performance limitations and implications for full-scale operation, 48 (2014) 12435-12444.

[274] D. Attarde, M. Jain, P.K. Singh, S.K. Gupta, Energy-efficient seawater desalination and wastewater treatment using osmotically driven membrane processes, Desalination, 413 (2017) 86-100.

[275] V.S. Sim, Q. She, T.H. Chong, C.Y. Tang, A.G. Fane, W.B.J.M. Krantz, Strategic co-location in a hybrid process involving desalination and pressure retarded osmosis (PRO), 3 (2013) 98-125.

[276] D.I. Kim, J. Kim, H.K. Shon, S. Hong, Pressure retarded osmosis (PRO) for integrating seawater desalination and wastewater reclamation: Energy consumption and fouling, Journal of Membrane Science, 483 (2015) 34-41.

[277] A.M. Helal, M.J.D. Odeh, The once-through MSF design. Feasibility for future large capacity desalination plants, 166 (2004) 25-39. 
[278] B. Van der Bruggen, C. Vandecasteele, Distillation vs. membrane filtration: overview of process evolutions in seawater desalination, Desalination, 143 (2002) 207-218.

[279] A. Farooque, A. Rowaili, A. Dalvi, N. Kither, G. Mustafa, I.J.D. Al-Tisan, A new approach to membrane and thermal seawater desalination processes using nanofiltration membranes (Part 1), 118 (1998) 3551Helfferich.

[280] A. Hassan, Fully integrated NF-thermal seawater desalination process and equipment, in, Google Patents, 2006.

[281] M.A.K. Al-Sofi, A.M. Hassan, G.M. Mustafa, A.G.I. Dalvi, M.N.M. Kither, Nanofiltration as a means of achieving higher TBT of $\geq 120^{\circ} \mathrm{C}$ in MSF, Desalination, 118 (1998) 123-129.

[282] A. Schaefer, A.G. Fane, T.D. Waite, Nanofiltration: Principles and Applications, Elsevier Science, 2005.

[283] A.M. Hassan, Process for desalination of saline water, especially water, having increased product yield and quality, in, Google Patents, 2003.

[284] O.A. Hamed, A.M. Hassan, K. Al-Shail, K. Bamardouf, S. Al-Sulami, A. Hamza, M.A. Farooque, A. Al-Rubain, Operational performance of an integrated NF/MSF desalination pilot plant, in: Proc. of IDA World Congress on Desalination and Water Reuse, Paradise Island, Sept.-28-October, 2003.

[285] A. Altaee, G. Zaragoza, A conceptual design of low fouling and high recovery FO-MSF desalination plant, Desalination, 343 (2014) 2-7.

[286] A. Altaee, A. Mabrouk, K. Bourouni, P. Palenzuela, Forward osmosis pretreatment of seawater to thermal desalination: High temperature FO-MSF/MED hybrid system, Desalination, 339 (2014) 18-25.

[287] A. Altaee, A. Mabrouk, K. Bourouni, A novel Forward osmosis membrane pretreatment of seawater for thermal desalination processes, Desalination, 326 (2013) 19-29.

[288] K. Thu, Y.-D. Kim, G. Amy, W.G. Chun, K.C. Ng, A hybrid multi-effect distillation and adsorption cycle, Applied Energy, 104 (2013) 810-821.

[289] X. Wang, K.C. Ng, Experimental investigation of an adsorption desalination plant using low-temperature waste heat, Applied Thermal Engineering, 25 (2005) 2780-2789.

[290] M.W. Shahzad, M. Burhan, L. Ang, K.C. Ng, Adsorption desalination-Principles, process design, and its hybrids for future sustainable desalination, in: V.G. Gude (Ed.) Emerging Technologies for Sustainable Desalination Handbook, Butterworth-Heinemann, 2018, pp. 3-34.

[291] K. Thu, Y.-D. Kim, G. Amy, W.G. Chun, K.C. Ng, A synergetic hybridization of adsorption cycle with the multieffect distillation (MED), Applied Thermal Engineering, 62 (2014) 245-255.

[292] M.W. Shahzad, K.C. Ng, K. Thu, B.B. Saha, W.G. Chun, Multi effect desalination and adsorption desalination (MEDAD): A hybrid desalination method, Applied Thermal Engineering, 72 (2014) 289-297.

[293] T. Kyaw, Y.D. Kim, M.W. Shahzad, J. Saththasivam, K. Choon, Performance investigation of an advanced multi-effect adsorption desalination cycle, in: 7th Asian Conference on Refrigeration and Air Conditioning, ACRA 2014, 2014.

[294] K.C. Ng, K. Thu, M.W. Shahzad, W. Chun, Progress of adsorption cycle and its hybrids with conventional multi-effect desalination processes, IDA Journal of Desalination and Water Reuse, 6 (2014) 44-56.

[295] A.N. Mabrouk, H.E.S. Fath, Technoeconomic study of a novel integrated thermal MSF-MED desalination technology, Desalination, 371 (2015) 115-125.

[296] H.E.-B.S. Fath, Combined Multi Stage Flash-multi Effect Distillation System with Brine Reheat, in, 1998.

[297] A.S. Nafey, H.E.S. Fath, A.A. Mabrouk, Thermo-economic investigation of multi effect evaporation (MEE) and hybrid multi effect evaporation-multi stage flash (MEE-MSF) systems, Desalination, 201 (2006) 241-254.

[298] L. Awerbuch, S. May, R. Soo-Hoo, V.J.D. Van Der Mast, Hybrid desalting systems, 76 (1989) 189-197. 
[299] F. Mahbub, M.N.A. Hawlader, A.S. Mujumdar, Combined water and power plant (CWPP) - a novel desalination technology, Desalination and Water Treatment, 5 (2009) 172-177.

[300] R. Borsani, S. Rebagliati, Fundamentals and costing of MSF desalination plants and comparison with other technologies, Desalination, 182 (2005) 29-37.

[301] C. Sommariva, H. Hogg, K. Callister, Cost reduction and design lifetime increase in thermal desalination plants: thermodynamic and corrosion resistance combined analysis for heat exchange tubes material selection, Desalination, 158 (2003) 17-21.

[302] M.A. Darwish, N.M. Al-Najem, Energy consumptions and costs of different desalting systems, Desalination, 64 (1987) 83-96.

[303] S. Lattemann, T. Höpner, Environmental impact and impact assessment of seawater desalination, Desalination, 220 (2008) 1-15.

[304] B. Bourland, P. Gamble, Saudi Arabia's coming oil and fiscal challenge, Jadwa Investment, Julio, (2011).

[305] S. Gallagher, R. Tiron, E. Whelan, E. Gleeson, F. Dias, R. McGrath, The nearshore wind and wave energy potential of Ireland: a high resolution assessment of availability and accessibility, Renewable Energy, 88 (2016) 494-516.

[306] G. Boyle, Renewable energy, Open University., 2004.

[307] E. Barbier, Nature and technology of geothermal energy: a review, Renewable and sustainable energy reviews, 1 (1997) 1-69.

[308] J.A. Turner, A realizable renewable energy future, Science, 285 (1999) 687-689.

[309] J.A. Smith, J.F. Dwyer, Avian interactions with renewable energy infrastructure: An update, The Condor: Ornithological Applications, 118 (2016) 411-423.

[310] J. Ding, A. Somani, A long-term investment planning model for mixed energy infrastructure integrated with renewable energy, in: 2010 IEEE green technologies conference, IEEE, 2010, pp. 1-10.

[311] W. Lacher, D. Kumetat, The security of energy infrastructure and supply in North Africa: Hydrocarbons and renewable energies in comparative perspective, Energy policy, 39 (2011) 4466-4478.

[312] S. Sen, S. Ganguly, Opportunities, barriers and issues with renewable energy development-A discussion, Renewable and Sustainable Energy Reviews, 69 (2017) 1170-1181.

[313] A. Prakash, M. Potoski, The voluntary environmentalists: Green clubs, ISO 14001, and voluntary environmental regulations, Cambridge University Press, 2006.

[314] W.-T. Tsai, An investigation of Taiwan's education regulations and policies for pursuing environmental sustainability, International Journal of Educational Development, 32 (2012) 359-365.

[315] S. Liyin, Y. Hong, A. Griffith, Improving environmental performance by means of empowerment of contractors, Management of environmental quality: an international journal, (2006).

[316] R.E. Dunlap, A.M. McCright, Organized climate change denial, The Oxford handbook of climate change and society, 1 (2011) 144-160.

[317] F.D.A.S.M. Azevedo, Renewable energy powered desalination systems: technologies and market analysis, in, 2014.

[318] M. Shatat, M. Worall, S. Riffat, Opportunities for solar water desalination worldwide: Review, Sustainable Cities and Society, 9 (2013) 67-80.

[319] T.M. Letcher, 1 - Why Solar Energy?, in: T.M. Letcher, V.M. Fthenakis (Eds.) A Comprehensive Guide to Solar Energy Systems, Academic Press, 2018, pp. 3-16.

[320] IRENA, The power to change: solar and wind cost reduction potential to 2025., (2016). 
[321] A. Wahed, M. Bieri, T.K. Kui, T. Reindl, Levelized Cost of Solar Thermal System for Process Heating Applications in the Tropics, in: A. Sayigh (Ed.) Transition Towards 100\% Renewable Energy: Selected Papers from the World Renewable Energy Congress WREC 2017, Springer International Publishing, Cham, 2018, pp. 441-450.

[322] D. Dsilva Winfred Rufuss, S. Iniyan, L. Suganthi, P.A. Davies, Solar stills: A comprehensive review of designs, performance and material advances, Renewable and Sustainable Energy Reviews, 63 (2016) 464-496.

[323] K. Kim, S. Yu, C. An, S.-W. Kim, J.-H. Jang, Mesoporous Three-Dimensional Graphene Networks for Highly Efficient Solar Desalination under 1 sun Illumination, ACS Applied Materials \& Interfaces, 10 (2018) 15602-15608.

[324] M. Shang, N. Li, S. Zhang, T. Zhao, C. Zhang, C. Liu, H. Li, Z. Wang, Full-Spectrum Solar-to-Heat Conversion Membrane with Interfacial Plasmonic Heating Ability for High-Efficiency Desalination of Seawater, ACS Applied Energy Materials, 1 (2018) 56-61.

[325] C. Finnerty, L. Zhang, D.L. Sedlak, K.L. Nelson, B. Mi, Synthetic Graphene Oxide Leaf for Solar Desalination with Zero Liquid Discharge, Environmental Science \& Technology, 51 (2017) 11701-11709.

[326] X. Yin, Y. Zhang, Q. Guo, X. Cai, J. Xiao, Z. Ding, J. Yang, Macroporous Double-Network Hydrogel for HighEfficiency Solar Steam Generation Under 1 sun Illumination, ACS Applied Materials \& Interfaces, 10 (2018) 1099811007.

[327] Z. Liu, Z. Yang, X. Huang, C. Xuan, J. Xie, H. Fu, Q. Wu, J. Zhang, X. Zhou, Y. Liu, High-absorption recyclable photothermal membranes used in a bionic system for high-efficiency solar desalination via enhanced localized heating, Journal of Materials Chemistry A, 5 (2017) 20044-20052.

[328] G. Zhu, J. Xu, W. Zhao, F. Huang, Constructing Black Titania with Unique Nanocage Structure for Solar Desalination, ACS Applied Materials \& Interfaces, 8 (2016) 31716-31721.

[329] M.T. Islam, N. Huda, A.B. Abdullah, R. Saidur, A comprehensive review of state-of-the-art concentrating solar power (CSP) technologies: Current status and research trends, Renewable and Sustainable Energy Reviews, 91 (2018) 987-1018.

[330] D.A. Baharoon, H.A. Rahman, W.Z.W. Omar, S.O. Fadhl, Historical development of concentrating solar power technologies to generate clean electricity efficiently - A review, Renewable and Sustainable Energy Reviews, 41 (2015) 996-1027.

[331] S.J. Wagner, E.S. Rubin, Economic implications of thermal energy storage for concentrated solar thermal power, Renewable Energy, 61 (2014) 81-95.

[332] S.J. DeCanio, A. Fremstad, Economic feasibility of the path to zero net carbon emissions, Energy Policy, 39 (2011) 1144-1153.

[333] H.L. Zhang, J. Baeyens, J. Degrève, G. Cacères, Concentrated solar power plants: Review and design methodology, Renewable and Sustainable Energy Reviews, 22 (2013) 466-481.

[334] W. Association, Seawater desalination power consumption (White Paper), (2011).

[335] W. Gocht, A. Sommerfeld, R. Rautenbach, T. Melin, L. Eilers, A. Neskakis, D. Herold, V. Horstmann, M. Kabariti, A. Muhaidat, Decentralized desalination of brackish water by a directly coupled reverse-osmosisphotovoltaic-system - a pilot plant study in Jordan, Renewable Energy, 14 (1998) 287-292.

[336] W.W. Boesch, World's first solar powered reverse osmosis desalination plant, Desalination, 41 (1982) 233237.

[337] Z. Al Suleimani, V.R. Nair, Desalination by solar-powered reverse osmosis in a remote area of the Sultanate of Oman, Applied Energy, 65 (2000) 367-380.

[338] M. Khayet, M. Essalhi, C. Armenta-Déu, C. Cojocaru, N. Hilal, Optimization of solar-powered reverse osmosis desalination pilot plant using response surface methodology, Desalination, 261 (2010) 284-292. 
[339] S.M. Shalaby, Reverse osmosis desalination powered by photovoltaic and solar Rankine cycle power systems: A review, Renewable and Sustainable Energy Reviews, 73 (2017) 789-797.

[340] M.C. Garg, Chapter 4 - Renewable Energy-Powered Membrane Technology: Cost Analysis and Energy Consumption, in: A. Basile, A. Cassano, A. Figoli (Eds.) Current Trends and Future Developments on (Bio-) Membranes, Elsevier, 2019, pp. 85-110.

[341] H.D. Raval, S. Maiti, A novel photovoltaic powered reverse osmosis with improved productivity of reverse osmosis and photovoltaic panel, Journal of Membrane Science and Research, 1 (2015) 113-117.

[342] H.D. Raval, S. Maiti, Ultra-low energy reverse osmosis with thermal energy recovery from photovoltaic panel cooling and TFC RO membrane modification, Desalination and Water Treatment, 57 (2016) 4303-4312.

[343] E. Skoplaki, J.A. Palyvos, On the temperature dependence of photovoltaic module electrical performance: $A$ review of efficiency/power correlations, Solar Energy, 83 (2009) 614-624.

[344] M. Monnot, G.D.M. Carvajal, S. Laborie, C. Cabassud, R. Lebrun, Integrated approach in eco-design strategy for small RO desalination plants powered by photovoltaic energy, Desalination, 435 (2018) 246-258.

[345] D. Herold, A. Neskakis, A small PV-driven reverse osmosis desalination plant on the island of Gran Canaria, Desalination, 137 (2001) 285-292.

[346] B. Peñate, L. García-Rodríguez, Current trends and future prospects in the design of seawater reverse osmosis desalination technology, Desalination, 284 (2012) 1-8.

[347] F. Vélez, Selecting working fluids in an organic Rankine cycle for power generation from low temperature heat sources, DYNA, 81 (2014) 173-180.

[348] D. Manolakos, G. Papadakis, E.S. Mohamed, S. Kyritsis, K. Bouzianas, Design of an autonomous lowtemperature solar Rankine cycle system for reverse osmosis desalination, Desalination, 183 (2005) 73-80.

[349] A.S. Nafey, M.A. Sharaf, L. García-Rodríguez, Thermo-economic analysis of a combined solar organic Rankine cycle-reverse osmosis desalination process with different energy recovery configurations, Desalination, 261 (2010) 138-147.

[350] A.S. Nafey, M.A. Sharaf, Combined solar organic Rankine cycle with reverse osmosis desalination process: Energy, exergy, and cost evaluations, Renewable Energy, 35 (2010) 2571-2580.

[351] J.E. Lundstrom, Water desalting by solar powered electrodialysis, Desalination, 31 (1979) 469-488.

[352] M.R. Adiga, S. Adhikary, P. Narayanan, W. Harkare, S. Gomkale, K. Govindan, Performance analysis of photovoltaic electrodialysis desalination plant at Tanote in Thar desert, Desalination, 67 (1987) 59-66.

[353] N. Ishimaru, Solar photovoltaic desalination of brackish water in remote areas by electrodialysis, Desalination, 98 (1994) 485-493.

[354] F. Banat, N. Jwaied, M. Rommel, J. Koschikowski, M. Wieghaus, Desalination by a "compact SMADES" autonomous solarpowered membrane distillation unit, Desalination, 217 (2007) 29-37.

[355] J. Koschikowski, M. Wieghaus, M. Rommel, V.S. Ortin, B.P. Suarez, J.R. Betancort Rodríguez, Experimental investigations on solar driven stand-alone membrane distillation systems for remote areas, Desalination, 248 (2009) 125-131.

[356] G. Zaragoza, A. Ruiz-Aguirre, E. Guillén-Burrieza, Efficiency in the use of solar thermal energy of small membrane desalination systems for decentralized water production, Applied Energy, 130 (2014) 491-499.

[357] E. Curcio, E. Drioli, Membrane distillation and related operations-a review, Separation and Purification Reviews, 34 (2005) 35-86.

[358] Y.-D. Kim, K. Thu, N. Ghaffour, K.C. Ng, Performance investigation of a solar-assisted direct contact membrane distillation system, Journal of Membrane Science, 427 (2013) 345-364. 
[359] Y.-D. Kim, K. Thu, H.K. Bhatia, C.S. Bhatia, K.C. Ng, Thermal analysis and performance optimization of a solar hot water plant with economic evaluation, Solar energy, 86 (2012) 1378-1395.

[360] F. Banat, N. Jwaied, M. Rommel, J. Koschikowski, M. Wieghaus, Performance evaluation of the "large SMADES" autonomous desalination solar-driven membrane distillation plant in Aqaba, Jordan, Desalination, 217 (2007) 17-28.

[361] S.E. Moore, S.D. Mirchandani, V. Karanikola, T.M. Nenoff, R.G. Arnold, A.E. Sáez, Process modeling for economic optimization of a solar driven sweeping gas membrane distillation desalination system, Desalination, 437 (2018) 108-120.

[362] A. Cipollina, M. Di Sparti, A. Tamburini, G. Micale, Development of a membrane distillation module for solar energy seawater desalination, Chemical engineering research and design, 90 (2012) 2101-2121.

[363] M.F.A. Goosen, H. Mahmoudi, N. Ghaffour, Today's and Future Challenges in Applications of Renewable Energy Technologies for Desalination, Critical Reviews in Environmental Science and Technology, 44 (2014) 929999.

[364] N. Ghaffour, V.K. Reddy, M. Abu-Arabi, Technology development and application of solar energy in desalination: MEDRC contribution, Renewable and Sustainable Energy Reviews, 15 (2011) 4410-4415.

[365] B. Bouchekima, A small solar desalination plant for the production of drinking water in remote arid areas of southern Algeria, Desalination, 159 (2003) 197-204.

[366] D. Zejli, R. Benchrifa, A. Bennouna, K. Zazi, Economic analysis of wind-powered desalination in the south of Morocco, Desalination, 165 (2004) 219-230.

[367] D.A. Dehmas, N. Kherba, F.B. Hacene, N.K. Merzouk, M. Merzouk, H. Mahmoudi, M.F.A. Goosen, On the use of wind energy to power reverse osmosis desalination plant: A case study from Ténès (Algeria), Renewable and Sustainable Energy Reviews, 15 (2011) 956-963.

[368] A. Ali, R.A. Tufa, F. Macedonio, E. Curcio, E. Drioli, Membrane technology in renewable-energy-driven desalination, Renewable and Sustainable Energy Reviews, 81 (2018) 1-21.

[369] J. Koschikowski, B. Heijman, Renewable energy drives desalination processes in remote or arid regions, Membrane Technology, 2008 (2008) 8-9.

[370] C. Thumthae, T. Chitsomboon, Optimal angle of attack for untwisted blade wind turbine, Renewable energy, 34 (2009) 1279-1284.

[371] D.A. Dehmas, N. Kherba, F.B. Hacene, N.K. Merzouk, M. Merzouk, H. Mahmoudi, M.F. Goosen, On the use of wind energy to power reverse osmosis desalination plant: A case study from Ténès (Algeria), Renewable and Sustainable Energy Reviews, 15 (2011) 956-963.

[372] T. Ackermann, L. Söder, An overview of wind energy-status 2002, Renewable and sustainable energy reviews, 6 (2002) 67-127.

[373] M.S. Miranda, D. Infield, A wind-powered seawater reverse-osmosis system without batteries, Desalination, 153 (2003) 9-16.

[374] S.A. Kershman, J. Rheinländer, T. Neumann, O. Goebel, Hybrid wind/PV and conventional power for desalination in Libya-GECOL's facility for medium and small scale research at Ras Ejder, Desalination, 183 (2005) 1-12.

[375] I. de la Nuez Pestana, F.J.G. Latorre, C.A. Espinoza, A.G. Gotor, Optimization of RO desalination systems powered by renewable energies. Part I: Wind energy, Desalination, 160 (2004) 293-299.

[376] J. Carta, J. Gonzalez, V. Subiela, The SDAWES project: an ambitious R\&D prototype for wind-powered desalination, Desalination, 161 (2004) 33-48. 
[377] A. Peral, A.C. Gomez, J. Trujillo, IDM-Project: results of one year of operation, in: Seminar on New Technologies for the Use of Renewable Energies in Water Desalination, Athens, 1991, pp. $26 \mathrm{e} 28$.

[378] M. Forstmeier, F. Mannerheim, F. D'Amato, M. Shah, Y. Liu, M. Baldea, A. Stella, Feasibility study on windpowered desalination, Desalination, 203 (2007) 463-470.

[379] A. Al Malki, M. Al Amri, H. Al Jabri, Experimental study of using renewable energy in the rural areas of Oman, Renewable Energy, 14 (1998) 319-324.

[380] D. Weiner, D. Fisher, E.J. Moses, B. Katz, G. Meron, Operation experience of a solar-and wind-powered desalination demonstration plant, Desalination, 137 (2001) 7-13.

[381] G. Petersen, S. Fries, J. Mohn, A. Müller, Wind and solar powered reverse osmosis desalination units-design, start up, operating experience, Desalination, 39 (1981) 125-135.

[382] I. Houcine, F. Benjemaa, M.-H. Chahbani, M. Maalej, Renewable energy sources for water desalting in Tunisia, Desalination, 125 (1999) 123-132.

[383] S.A. Kershman, J. Rheinländer, H. Gabler, Seawater reverse osmosis powered from renewable energy sources-hybrid wind/photovoltaic/grid power supply for small-scale desalination in Libya, Desalination, 153 (2003) 17-23.

[384] E.S. Mohamed, G. Papadakis, Design, simulation and economic analysis of a stand-alone reverse osmosis desalination unit powered by wind turbines and photovoltaics, Desalination, 164 (2004) 87-97.

[385] E.S. Mohamed, G. Papadakis, E. Mathioulakis, V. Belessiotis, An experimental comparative study of the technical and economic performance of a small reverse osmosis desalination system equipped with an hydraulic energy recovery unit, Desalination, 194 (2006) 239-250.

[386] A.M. Gilau, M.J. Small, Designing cost-effective seawater reverse osmosis system under optimal energy options, Renewable energy, 33 (2008) 617-630.

[387] A. Abusharkh, A. Giwa, S. Hasan, Wind and geothermal energy in desalination: a short review on progress and sustainable commercial processes, Industrial Engineering and Management, 4 (2015) 2169-0316.1000175.

[388] L. Awerbuch, T. Lindemuth, S. May, A. Rogers, Geothermal energy recovery process, Desalination, 19 (1976) 325-336.

[389] K. Bourouni, M. Chaibi, Application of geothermal energy for brackish water desalination in the south of Tunisia, Ground Water, 2185 (2005) 225.

[390] V.G. Gude, Geothermal source potential for water desalination-Current status and future perspective, Renewable and Sustainable Energy Reviews, 57 (2016) 1038-1065.

[391] E. Barbier, Geothermal energy technology and current status: an overview, Renewable and sustainable energy reviews, 6 (2002) 3-65.

[392] K. Karytsas, V. Alexandrou, I. Boukis, The Kimolos geothermal desalination project, in: Proceedings, 2002, pp. 5-7.

[393] M. Papapetrou, C. Biercamp, M. Wieghaus, Roadmap for the Development of Desalination Powered by Renewable Energy: Promotion for Renewable Energy for Water Production through Desalination, Fraunhofer Verlag, 2010.

[394] N. Drouiche, N. Ghaffour, M.W. Naceur, H. Mahmoudi, T. Ouslimane, Reasons for the fast growing seawater desalination capacity in Algeria, Water resources management, 25 (2011) 2743-2754.

[395] A. Hepbasli, Z. Alsuhaibani, A key review on present status and future directions of solar energy studies and applications in Saudi Arabia, Renewable and Sustainable Energy Reviews, 15 (2011) 5021-5050.

[396] C.J. Koroneos, A.L. Polyzakis, D.C. Rovas, Combine Desalination-Cooling plant in Nisyros Island utilizing geothermal energy, desalination, 4 (2007) 5. 
[397] M. Rodríguez-Gironés, J. Perez, J. Veza, A systematic approach to desalination powered by solar, wind and geothermal energy sources, in: Proceedings of the Mediterranean conference on renewable energy sources for water production, European Commission, EURORED Network, CRES, EDS Santorini, Greece, 1996, pp. 20-25.

[398] C. Karytsas, D. Mendrinos, G. Radoglou, The current geothermal exploration and development of the geothermal field of Milos Island in Greece, GHC Bulletin, June, (2004).

[399] R. Sarbatly, C.-K. Chiam, Evaluation of geothermal energy in desalination by vacuum membrane distillation, Applied Energy, 112 (2013) 737-746.

[400] S. Loutatidou, H.A. Arafat, Techno-economic analysis of MED and RO desalination powered by low-enthalpy geothermal energy, Desalination, 365 (2015) 277-292.

[401] T.M. Missimer, Y.-D. Kim, R. Rachman, K.C. Ng, Sustainable renewable energy seawater desalination using combined-cycle solar and geothermal heat sources, Desalination and Water Treatment, 51 (2013) 1161-1170.

[402] D. Voivontas, K. Misirlis, E. Manoli, G. Arampatzis, D. Assimacopoulos, A tool for the design of desalination plants powered by renewable energies, Desalination, 133 (2001) 175-198.

[403] S. Kalogirou, Survey of solar desalination systems and system selection, energy, 22 (1997) 69-81.

[404] A. Poullikkas, A comparative overview of large-scale battery systems for electricity storage, Renewable and Sustainable Energy Reviews, 27 (2013) 778-788.

[405] T.M.I. Mahlia, T.J. Saktisahdan, A. Jannifar, M.H. Hasan, H.S.C. Matseelar, A review of available methods and development on energy storage; technology update, Renewable and Sustainable Energy Reviews, 33 (2014) 532545.

[406] T. Kousksou, P. Bruel, A. Jamil, T. El Rhafiki, Y. Zeraouli, Energy storage: Applications and challenges, Solar Energy Materials and Solar Cells, 120 (2014) 59-80.

[407] M. Goosen, H. Mahmoudi, N. Ghaffour, Water desalination using geothermal energy, Energies, 3 (2010) 1423-1442.

[408] M. Goosen, H. Mahmoudi, N. Ghaffour, S.S. Sablani, Application of renewable energies for water desalination, Desalination, trends and technologies, (2011) 89-118.

[409] K. Li, H. Bian, C. Liu, D. Zhang, Y. Yang, Comparison of geothermal with solar and wind power generation systems, Renewable and Sustainable Energy Reviews, 42 (2015) 1464-1474.

[410] V.J. Subiela, B. Peñate, Autonomous desalination and cooperation. The experience in Morocco within the ADIRA Project, in: Water Security in the Mediterranean Region, Springer, 2011, pp. 319-337.

[411] M. Moser, F. Trieb, T. Fichter, J. Kern, Renewable desalination: a methodology for cost comparison, Desalination and Water Treatment, 51 (2013) 1171-1189.

[412] M. Busch, W. Mickols, Reducing energy consumption in seawater desalination, Desalination, 165 (2004) 299312.

[413] D.R. Paul, Reformulation of the solution-diffusion theory of reverse osmosis, Journal of membrane science, 241 (2004) 371-386.

[414] S.F. Anis, B.S. Lalia, R. Hashaikeh, Controlling swelling behavior of poly (vinyl) alcohol via networked cellulose and its application as a reverse osmosis membrane, Desalination, 336 (2014) 138-145.

[415] S.G. Kim, D.H. Hyeon, J.H. Chun, B.-H. Chun, S.H. Kim, Novel thin nanocomposite RO membranes for chlorine resistance, Desalination and Water Treatment, 51 (2013) 6338-6345.

[416] B.J.A. Tarboush, D. Rana, T. Matsuura, H. Arafat, R. Narbaitz, Preparation of thin-film-composite polyamide membranes for desalination using novel hydrophilic surface modifying macromolecules, Journal of Membrane Science, 325 (2008) 166-175. 
[417] G. Chen, S. Li, X. Zhang, S. Zhang, Novel thin-film composite membranes with improved water flux from sulfonated cardo poly (arylene ether sulfone) bearing pendant amino groups, Journal of Membrane Science, 310 (2008) 102-109.

[418] M. Herzberg, M. Elimelech, Biofouling of reverse osmosis membranes: role of biofilm-enhanced osmotic pressure, Journal of Membrane Science, 295 (2007) 11-20.

[419] S. Coker, P. Sehn, Four years field experience with fouling resistant reverse osmosis membranes, Desalination, 132 (2000) 211-215.

[420] M. Ginic-Markovic, T.G. Barclay, K.T. Constantopoulos, E. Markovic, S.R. Clarke, J.G. Matisons, Biofouling resistance of polysulfobetaine coated reverse osmosis membranes, Desalination, 369 (2015) 37-45.

[421] W.-F. Chan, E. Marand, S.M. Martin, Novel zwitterion functionalized carbon nanotube nanocomposite membranes for improved RO performance and surface anti-biofouling resistance, Journal of membrane science, 509 (2016) 125-137.

[422] M. Buonomenna, Nano-enhanced reverse osmosis membranes, Desalination, 314 (2013) 73-88.

[423] A. Zhu, P.D. Christofides, Y. Cohen, On RO membrane and energy costs and associated incentives for future enhancements of membrane permeability, Journal of Membrane Science, 344 (2009) 1-5.

[424] N. Voutchkov, Seawater Desalination Technology, Water Conditioning \& Purification, (2007).

[425] J.K. Holt, H.G. Park, Y. Wang, M. Stadermann, A.B. Artyukhin, C.P. Grigoropoulos, A. Noy, O. Bakajin, Fast mass transport through sub-2-nanometer carbon nanotubes, Science, 312 (2006) 1034-1037.

[426] M. Kumar, M. Grzelakowski, J. Zilles, M. Clark, W. Meier, Highly permeable polymeric membranes based on the incorporation of the functional water channel protein Aquaporin Z, Proceedings of the National Academy of Sciences, 104 (2007) 20719-20724.

[427] J. Gu, C. Ren, X. Zong, C. Chen, L. Winnubst, Preparation of alumina membranes comprising a thin separation layer and a support with straight open pores for water desalination, Ceramics international, 42 (2016) 1242712434.

[428] S. Tao, Y.-D. Xu, J.-Q. Gu, H. Abadikhah, J.-W. Wang, X. Xu, Preparation of high-efficiency ceramic planar membrane and its application for water desalination, Journal of Advanced Ceramics, 7 (2018) 117-123.

[429] M. Safarpour, A. Khataee, V. Vatanpour, Thin film nanocomposite reverse osmosis membrane modified by reduced graphene oxide/TiO2 with improved desalination performance, Journal of Membrane Science, 489 (2015) 43-54.

[430] T.M. Truskett, The subtleties of water in small spaces, Proceedings of the National Academy of Sciences, 100 (2003) 10139-10140.

[431] Y.-x. Jia, H.-I. Li, M. Wang, L.-y. Wu, Y.-d. Hu, Carbon nanotube: possible candidate for forward osmosis, Separation and Purification Technology, 75 (2010) 55-60.

[432] M. Majumder, N. Chopra, R. Andrews, B. Hinds, Erratum: Nanoscale hydrodynamics: Enhanced flow in carbon nanotubes, Nature, 438 (2005) 930-930.

[433] B. Corry, Designing carbon nanotube membranes for efficient water desalination, The Journal of Physical Chemistry B, 112 (2008) 1427-1434.

[434] K. Falk, F. Sedlmeier, L. Joly, R.R. Netz, L. Bocquet, Molecular origin of fast water transport in carbon nanotube membranes: superlubricity versus curvature dependent friction, Nano letters, 10 (2010) 4067-4073.

[435] M.M. Pendergast, E.M. Hoek, A review of water treatment membrane nanotechnologies, Energy \& Environmental Science 4(2011) 1946-1971.

[436] J.A. Callow, M.E. Callow, Trends in the development of environmentally friendly fouling-resistant marine coatings, Nature communications, 2 (2011) 1-10. 
[437] A. Wahab Mohammad, N. Hilal, M. Nizam Abu Seman, A study on producing composite nanofiltration membranes with optimized properties, Desalination, 158 (2003) 73-78.

[438] B.-H. Jeong, E.M. Hoek, Y. Yan, A. Subramani, X. Huang, G. Hurwitz, A.K. Ghosh, A. Jawor, Interfacial polymerization of thin film nanocomposites: a new concept for reverse osmosis membranes, Journal of membrane science, 294 (2007) 1-7.

[439] E.M. Hoek, M.T.M. Pendergast, A.K. Ghosh, Nanotechnology-based membranes for water purification, in: Nanotechnology applications for clean water, Elsevier, 2014, pp. 133-154.

[440] S.F. Anis, R. Hashaikeh, Electrospun zeolite-Y fibers: Fabrication and morphology analysis, Microporous and Mesoporous Materials, 233 (2016) 78-86.

[441] S.F. Anis, G. Singaravel, R. Hashaikeh, Electropsun Ni-W/zeolite composite fibers for $n$-heptane hydrocracking and hydroisomerization, Materials Chemistry and Physics, 200 (2017) 146-154.

[442] T. Kaminski, S.F. Anis, M.M. Husein, R. Hashaikeh, Hydrocracking of Athabasca VR Using NiO-WO3 ZeoliteBased Catalysts, Energy \& Fuels, (2018).

[443] S.F. Anis, G. Singaravel, R. Hashaikeh, Hierarchical nano zeolite-Y hydrocracking composite fibers with highly efficient hydrocracking capability, RSC Advances, 8 (2018) 16703-16715.

[444] S.F. Anis, R. Hashaikeh, N. Hilal, Flux and salt rejection enhancement of polyvinyl(alcohol) reverse osmosis membranes using nano-zeolite, Desalination, 470 (2019) 114104.

[445] J. Duan, Y. Pan, F. Pacheco, E. Litwiller, Z. Lai, I. Pinnau, High-performance polyamide thin-filmnanocomposite reverse osmosis membranes containing hydrophobic zeolitic imidazolate framework-8, Journal of membrane science, 476 (2015) 303-310.

[446] W.R. Bowen, Biomimetic separations-learning from the early development of biological membranes, Desalination, 199 (2006) 225-227.

[447] M. Kumar, M.M. Payne, S.K. Poust, J.L. Zilles, Polymer-based biomimetic membranes for desalination, in: Biomimetic membranes for sensor and separation applications, Springer, 2011, pp. 43-62.

[448] Y.-x. Shen, P.O. Saboe, I.T. Sines, M. Erbakan, M. Kumar, Biomimetic membranes: A review, Journal of Membrane Science, 454 (2014) 359-381.

[449] H. Sui, B.-G. Han, J.K. Lee, P. Walian, B.K. Jap, Structural basis of water-specific transport through the AQP1 water channel, Nature, 414 (2001) 872-878.

[450] D. Ho, B. Chu, J.J. Schmidt, E.K. Brooks, C.D. Montemagno, Hybrid protein-polymer biomimetic membranes, 3 (2004) 256-263.

[451] Y. Zhao, C. Qiu, X. Li, A. Vararattanavech, W. Shen, J. Torres, C. Hélix-Nielsen, R. Wang, X. Hu, A.G. Fane, C.Y. Tang, Synthesis of robust and high-performance aquaporin-based biomimetic membranes by interfacial polymerization-membrane preparation and RO performance characterization, Journal of Membrane Science, 423424 (2012) 422-428.

[452] X. Li, S. Chou, R. Wang, L. Shi, W. Fang, G. Chaitra, C.Y. Tang, J. Torres, X. Hu, A.G. Fane, Nature gives the best solution for desalination: Aquaporin-based hollow fiber composite membrane with superior performance, Journal of Membrane Science, 494 (2015) 68-77.

[453] S. Qi, R. Wang, G.K.M. Chaitra, J. Torres, X. Hu, A.G. Fane, Aquaporin-based biomimetic reverse osmosis membranes: Stability and long term performance, Journal of Membrane Science, 508 (2016) 94-103.

[454] A. Zhu, P.D. Christofides, Y. Cohen, Effect of thermodynamic restriction on energy cost optimization of RO membrane water desalination, Industrial \& Engineering Chemistry Research, 48 (2009) 6010-6021.

[455] D.M. Warsinger, E.W. Tow, K.G. Nayar, L.A. Maswadeh, J.H. Lienhard V, Energy efficiency of batch and semibatch (CCRO) reverse osmosis desalination, Water Research, 106 (2016) 272-282. 
[456] G.P. Thiel, R.K. McGovern, S.M. Zubair, Thermodynamic equipartition for increased second law efficiency, Applied energy, 118 (2014) 292-299.

[457] W. Mickols, M. Busch, Y. Maeda, J. Tonner, A novel design approach for seawater plants, in: Proceedings of the International Desalination Association World Congress, Singapore, 2005, pp. 40-45.

[458] J. Kim, S. Hong, Optimizing seawater reverse osmosis with internally staged design to improve product water quality and energy efficiency, Journal of membrane science, 568 (2018) 76-86.

[459] H. Arafat, Desalination Sustainability: A Technical, Socioeconomic, and Environmental Approach, Elsevier, 2017.

[460] J. Kim, S. Hong, A novel single-pass reverse osmosis configuration for high-purity water production and low energy consumption in seawater desalination, Desalination, 429 (2018) 142-154.

[461] T.H. Chong, S.-L. Loo, W.B. Krantz, Energy-efficient reverse osmosis desalination process, Journal of Membrane Science, 473 (2015) 177-188.

[462] S.J. Kim, S.H. Ko, K.H. Kang, J. Han, Direct seawater desalination by ion concentration polarization, Nature nanotechnology, 5 (2010) 297-301.

[463] T. Welgemoed, Capacitive Deionization Technology: Development and Evaluation of an Industrial Prototype, (2005).

[464] J.C. Farmer, T.D. Tran, J.H. Richardson, D. Fix, S. May, S. Thomson, The application of carbon aerogel electrodes to desalination \{ampersand\} waste treatment, in, Lawrence Livermore National Lab., CA (United States), 1997.

[465] J.-B. Lee, K.-K. Park, S.-W. Yoon, P.-Y. Park, K.-I. Park, C.-W. Lee, Desalination performance of a carbon-based composite electrode, Desalination, 237 (2009) 155-161.

[466] T.J. Welgemoed, Capacitive deionization technologyTM development and evaluation of an industrial prototype system, in, University of Pretoria, 2006.

[467] P. Wang, Emerging investigator series: the rise of nano-enabled photothermal materials for water evaporation and clean water production by sunlight, Environmental Science: Nano, 5 (2018) 1078-1089.

[468] Q. He, S. Wang, S. Zeng, Z. Zheng, Experimental investigation on photothermal properties of nanofluids for direct absorption solar thermal energy systems, Energy Conversion and Management, 73 (2013) 150-157.

[469] Y. Xuan, H. Duan, Q. Li, Enhancement of solar energy absorption using a plasmonic nanofluid based on TiO 2/Ag composite nanoparticles, Rsc Advances, 4 (2014) 16206-16213.

[470] Y. Zhang, L. Liu, K. Li, D. Hou, J. Wang, Enhancement of energy utilization using nanofluid in solar powered membrane distillation, Chemosphere, 212 (2018) 554-562.

[471] J.R. Werber, C.O. Osuji, M. Elimelech, Materials for next-generation desalination and water purification membranes, Nature Reviews Materials, 1 (2016) 1-15.

[472] S.F. Anis, R. Hashaikeh, N. Hilal, Microfiltration membrane processes: A review of research trends over the past decade, Journal of Water Process Engineering, 32 (2019) 100941.

[473] S.F. Anis, B.S. Lalia, R. Hashaikeh, N. Hilal, Breaking through the selectivity-permeability tradeoff using nano zeolite-Y for micellar enhanced ultrafiltration dye rejection application, Separation and Purification Technology, 242 (2020) 116824.

[474] C. Feng, K. Khulbe, T. Matsuura, R. Farnood, A. Ismail, Recent progress in zeolite/zeotype membranes, Journal of Membrane Science and Research, 1 (2015) 49-72.

[475] S.F. Anis, B.S. Lalia, A.O. Mostafa, R. Hashaikeh, Electrospun nickel-tungsten oxide composite fibers as active electrocatalysts for hydrogen evolution reaction, Journal of Materials Science, 52 (2017) 7269-7281. 
[476] S.F. Anis, G. Singaravel, R. Hashaikeh, NiW/nano zeolite Y catalysts for $n$-heptane hydrocracking, Materials Chemistry and Physics, 212 (2018) 87-94.

[477] I.W. Azelee, P. Goh, W. Lau, A. Ismail, M. Rezaei-DashtArzhandi, K. Wong, M. Subramaniam, Enhanced desalination of polyamide thin film nanocomposite incorporated with acid treated multiwalled carbon nanotubetitania nanotube hybrid, Desalination, 409 (2017) 163-170.

[478] A. Al Mayyahi, Thin-film composite (TFC) membrane modified by hybrid ZnO-graphene nanoparticles (ZnO-Gr NPs) for water desalination, Journal of environmental chemical engineering, 6 (2018) 1109-1117.

[479] S.F. Anis, R. Hashaikeh, Electrochemical water splitting using nano-zeolite Y supported tungsten oxide electrocatalysts, Journal of Nanoparticle Research, 20 (2018) 47. 